\title{
Caracterización de las intrusiones de polvo en Canarias
}

\author{
Nota técnica 35 de AEMET
}

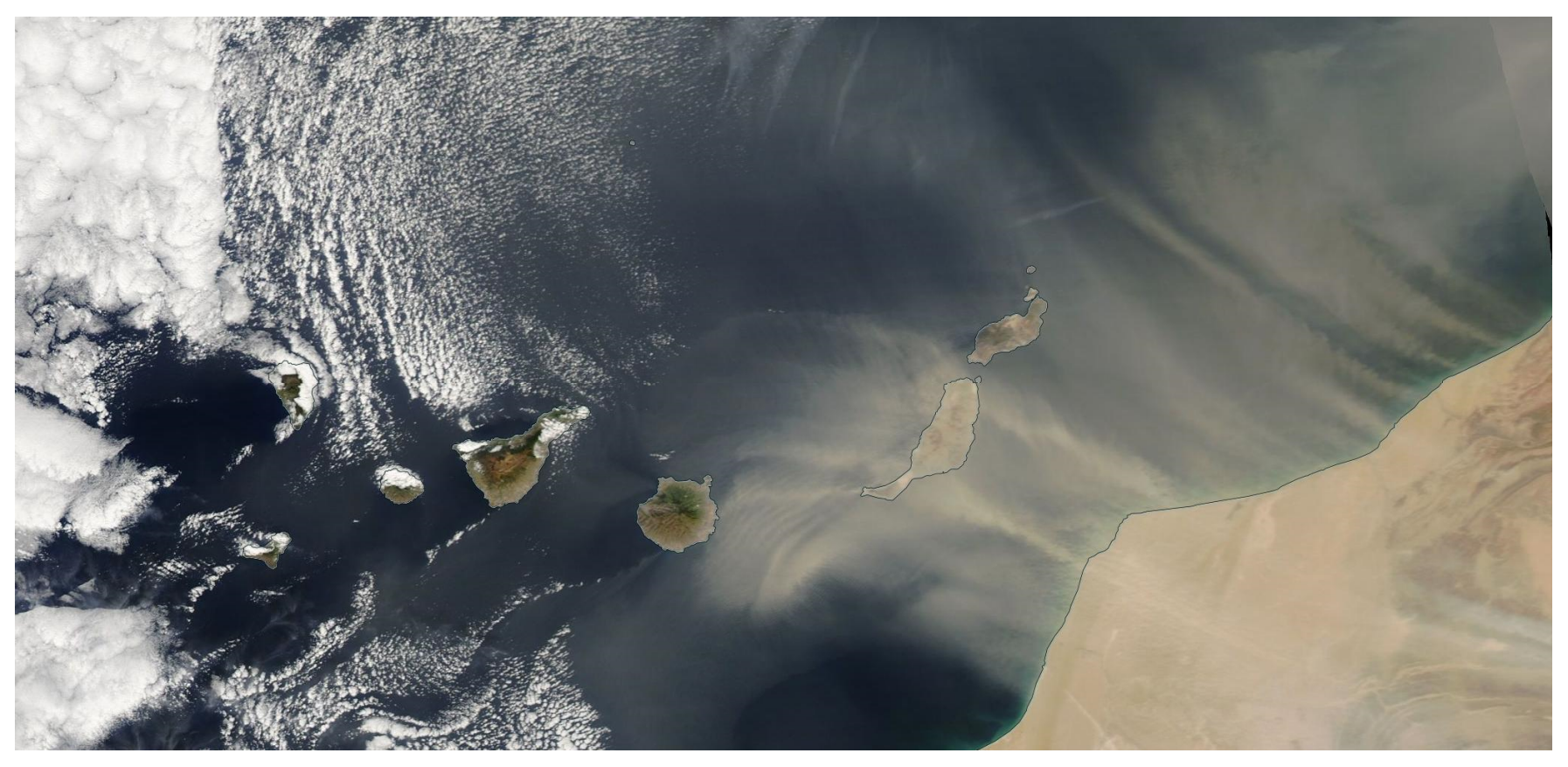

David Suárez Molina

Carlos Marrero de la Santa Cruz

Emilio Cuevas Agulló

Ernest Werner Hidalgo

Natalia Prats Porta

Sara Basart

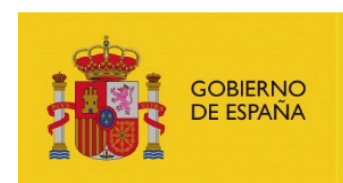

VICEPRESIDENCIA

CUARTA DEL GOBIERNO

MINISTERIO

PARA LATRANSICIÓN ECOLÓGICA Y EL RETO DEMOGRÁFICO

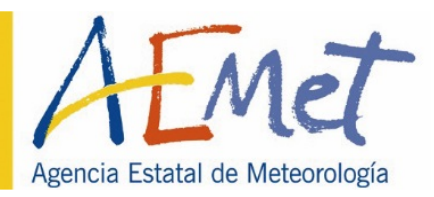





\title{
Caracterización de las intrusiones de polvo en Canarias
} (Nota técnica 35 de AEMET)

\author{
David Suárez Molina ${ }^{1}$ \\ Carlos Marrero de la Santa Cruz ${ }^{2}$ \\ Emilio Cuevas Agulló ${ }^{2}$ \\ Ernest Werner Hidalgo 3 \\ Natalia Prats Porta ${ }^{2}$ \\ Sara Basart ${ }^{4}$
}

1 Delegación Territorial de AEMET en Canarias

${ }^{2}$ Centro de Investigación Atmosférica de Izaña (AEMET)

3 Delegación Territorial de AEMET en Cataluña

${ }^{4}$ Barcelona Supercomputer Center - Centro Nacional de Supercomputación
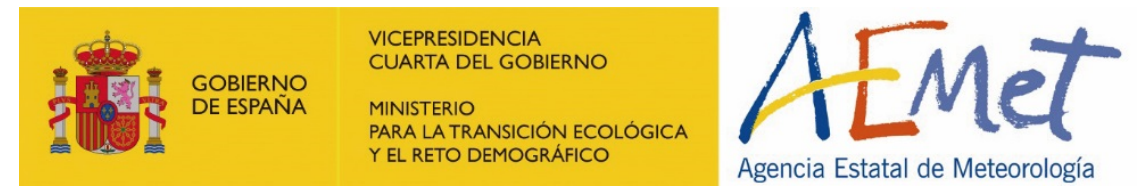
Aviso Legal: los contenidos de esta publicación podrán ser reutilizados, citando la fuente y la fecha, en su caso, de la última actualización

\section{Edita:}

(C) Ministerio para la Transición Ecológica y el Reto Demográfico Agencia Estatal de Meteorología

Madrid, 2021

Catálogo de Publicaciones de la Administración General del Estado: https://cpage.mpr.gob.es

NIPO: 666-20-026-4

https://doi.org/10.31978/666-20-026-4

Agencia Estatal de Meteorología (AEMET)

$\mathrm{C} /$ Leonardo Prieto Castro, 8

28040 Madrid

http://www.aemet.es/

1) @Aemet_Esp 


\section{ÍNDICE}

INTRODUCCIÓN

1. GENERALIDADES Y CONCEPTOS BÁSICOS SOBRE POLVO ATMOSFÉRICO 6

2. METODOLOGÍA 11

2.1 Introducción 11

2.2 Caracterización $\quad 12$

$\begin{array}{ll}2.3 \text { Herramientas } & 13\end{array}$

2.3.1 Red de Vigilancia de la Calidad del Aire del Gobierno de Canarias 13

$\begin{array}{ll}\text { 2.3.2 Retrotrayectorias } & 14\end{array}$

2.3.3 Índice NADFI (Intensidad del Dipolo del Norte de África) 16

2.3.4 Índice de africanidad (ARTI) 17

2.4 Metodología para la distinción de los tipos de escenario 18

2.4.1 Escenario en el que no hay intrusión de polvo africano 18

2.4.2 Escenario en el que sí hay intrusión de polvo africano 18

3. RESULTADOS 21

3.1 Episodios de Intrusión africanos. 21

3.1.1 Caracterización de la duración de los episodios. 21

3.1.2 Caracterización del efecto de las Intrusiones en la Calidad del Aire. 21

3.1.2.1 Estacionalidad de las intrusiones $\quad 22$

3.1.2.2 Efecto de las intrusiones por Islas $\quad 23$

3.2 Episodios sin intrusión africana $\quad 25$

3.3 Superaciones de umbrales por isla $\quad 26$

4. CASOS DE ESTUDIO

4.1 Episodios que afectan con mayor intensidad a las Islas más occidentales 27

4.1.1 Episodio del 4 al 6 de febrero de $2013 \quad 27$

4.1.2 Episodio del 25 al 28 de diciembre de 2015

4.2 Episodios que afectan con mayor intensidad a las Islas más orientales 38

4.2.1 Episodio del 26 al 28 de noviembre de 2013

4.2.2 Episodio del 4 al 6 de enero de 2013

4.3 Episodios que afectan de manera generalizada a todo el archipiélago 50

4.3.1 Episodio del 6 al 8 de marzo de $2015 \quad 50$

4.3.2 Episodio del 12 al 13 de agosto de 2015

5. CONCLUSIONES 61

6. CONSIDERACIONES PRÁCTICAS

6.1 Introducción $\quad 61$

6.2. Guía de apoyo para la predicción de calima 64

Agradecimientos $\quad 66$

REFERENCIAS BIBLIOGRÁFICAS $\quad 67$

Anexo $1 \quad 70$

$\begin{array}{ll}\text { Anexo } 2 & 79\end{array}$ 


\section{INTRODUCCIÓN}

Aerosol atmosférico es un término general utilizado para describir partículas sólidas secas suspendidas en la atmósfera que pueden presentar tamaños desde sub-micrométricos hasta varias decenas de micras. Las fuentes de aerosoles son muy variadas: por ejemplo, zonas áridas o semiáridas (que emiten polvo mineral), niebla salina, humo de incendios forestales y fuentes industriales, erupciones volcánicas, fuentes extraterrestres (es decir, polvo de meteoritos) y materiales orgánicos, como bacterias, polen de plantas, pelos de animales y células de la piel humana. Los aerosoles pueden viajar miles de kilómetros y tener graves impactos en la salud pública mundial, como bronquitis, asma, cáncer de pulmón y enfermedades circulatorias. Además, degradan la calidad del aire, pudiendo tener efectos negativos sobre el medio ambiente y algunas actividades económicas, en particular la aviación, por la disminución de visibilidad, y en la generación de energía solar. En particular, el polvo atmosférico, tiene algunos efectos positivos, que por su contenido de sales minerales y metales (sobre todo el hierro libre) puede tener un efecto fertilizador beneficioso en océanos y grandes selvas, como la del Amazonas. La proximidad de Canarias al continente africano convierte a las islas en un área de elevado interés, teniendo en cuenta la frecuencia de las intrusiones de polvo mineral desértico y el impacto que produce en la población, y por tanto es de suma relevancia la caracterización de las intrusiones de polvo desértico que afectan al archipiélago canario.

De conformidad con el artículo 8.a) del Real Decreto 186/2008, de 8 de febrero, por el que se aprueba el Estatuto de la Agencia Estatal de Meteorología, es competencia y función esencial de AEMET la elaboración, el suministro y la difusión de las informaciones meteorológicas y predicciones de interés general para los ciudadanos en todo el ámbito nacional, y la emisión de avisos y predicciones de fenómenos meteorológicos que puedan afectar a la seguridad de las personas y a los bienes materiales. Los fenómenos meteorológicos que puedan afectar a la seguridad de las personas y a los bienes materiales se denominan fenómenos meteorológicos adversos. Se considera fenómeno meteorológico adverso a todo evento atmosférico, capaz de producir, directa o indirectamente, daños a las personas o daños materiales de consideración. En sentido menos restringido, también puede considerarse como tal cualquier fenómeno, susceptible de alterar la actividad humana de forma significativa en un ámbito espacial determinado. Dentro de los fenómenos meteorológicos adversos se encuentra el fenómeno de "polvo en suspensión" [Meteoalerta, 2018]. Por tanto, la presencia de polvo en suspensión posibilita la emisión de un aviso, cuando se considere oportuno, asignando el nivel AMARILLO cuando se espere que la visibilidad se vea reducida por debajo de $3000 \mathrm{~m}$.

En el párrafo anterior queda patente que los avisos por polvo en suspensión, basados únicamente en la disminución de visibilidad, van dirigidos sobre todo a actividades aeronáuticas relacionadas con la operación de los aeropuertos. La visibilidad meteorológica [GonzálezLópez, 2005], se define como la distancia máxima a la que un objeto negro, de tamaño especificado, puede ser visto y reconocido contra el horizonte por un observador normal, sin que intervenga un procedimiento de iluminación.

La definición anterior hace referencia al término "observador normal", lo que implica un grado alto de subjetividad en la medida de visibilidad, que depende directamente de quien realice la observación. Como se ha mencionado, el principal sector afectado por eventos de visibilidad reducida por polvo en suspensión es el sector transportes (principalmente tráfico aeronáutico, marítimo y terrestre en menor medida). Sin embargo, como se expuso en el inicio de este apartado, las partículas de polvo generan, sobre todo, graves impactos en la salud pública 
mundial, así como en otras actividades económicas de relevancia. En este sentido, se habla de la concentración de material particulado (PM del inglés particulate matter), considerado en diferentes rangos de tamaños. A nivel internacional, y en el ámbito de calidad del aire, se recomienda, o es obligada por las diferentes legislaciones sobre el material particulado, la utilización de los parámetros PM10 y PM2.5 que indican la concentración (en $\mu \mathrm{g} / \mathrm{m}^{3}$ ) de partículas con un diámetro menor a 10 micras $\left(10^{-6} \mathrm{~m} ; \mu\right)$ y $2.5 \mu$ respectivamente.

Las partículas ultrafinas (partículas menores a $0.1 \mu \mathrm{m}$ de diámetro) han sido objeto de gran interés por parte de las comunidades científicas y de la salud, por su impacto en el clima y en la salud humana. La Organización Mundial de la Salud (OMS) establece valores de referencia mientras que la Unión Europea (UE) establece valores límites de calidad del aire. Los valores límites establecidos para PM10 por la OMS y EU son respectivamente 20 y $40 \mu \mathrm{g} / \mathrm{m}^{3} \mathrm{de}$ media anual. En cuanto al límite máximo establecido para la media diaria ambos coinciden en 50 $\mu \mathrm{g} / \mathrm{m}^{3}$.Numerosos estudios científicos han revelado el impacto derivado de la exposición a la contaminación atmosférica en la salud. Como ejemplo se cita el síndrome coronario agudo debido a la inflamación y coagulación endotelial, causado por la exposición de partículas [Domínguez-Rodríguez et al., 2017]. Además, existen estudios que analizan concretamente el impacto de la exposición al polvo del Sáhara. Los resultados obtenidos sugieren que la presencia de concentraciones elevadas de polvo sahariano (PM10: 50-200 $\mu \mathrm{g} / \mathrm{m}^{3}$ ) puede constituir un factor precipitante de ingreso por insuficiencia cardiaca aguda [DomínguezRodríguez et al., 2019].

Si se fusiona el grado de subjetividad que presenta el concepto de visibilidad, con el impacto que genera el polvo atmosférico en la salud de la población general, nace la necesidad de realizar un cambio de mentalidad y ampliación del enfoque de la predicción y observación de eventos de intrusiones de polvo desértico sobre las Islas Canarias, para que este pronóstico sea útil para los gestores de calidad del aire y responsables del ámbito sanitario. Este trabajo propone una nueva perspectiva para enfrentarse a la predicción y avisos de los episodios de intrusiones de polvo desértico, basándose en parámetros (PM10 y PM2.5) cuantitativos medibles, y verificables objetivamente. Estos parámetros, además de ser cuantitativos y objetivos, están legislados y vienen recogidos en el Índice Nacional de Calidad del Aire. El presente documento muestra los resultados de la caracterización de las intrusiones de polvo desértico en Canarias, y forma parte del proyecto "Desarrollo de un sistema de avisos de polvo atmosférico (PM10) para Canarias" enmarcado dentro del Plan Estratégico de AEMET 201921, cuyo objetivo principal es el establecimiento de un sistema de avisos de intrusiones de polvo desértico a partir de parámetros legislados de calidad del aire. Uno de los objetivos prioritarios de esta fase inicial del proyecto, es conocer los valores reales de PM10 presentes de forma habitual en las distintas zonas del archipiélago, para ser capaces de determinar si una intrusión de polvo desértico puede elevar la cantidad presente en la atmósfera de PM10 de forma que se superen los umbrales establecidos en la legislación vigente (i.e. $50 \mu \mathrm{g} / \mathrm{m}^{3}$ en promedio diario).

Esta nota técnica está dividida en cuatro capítulos. En el capítulo 1 se expondrán las generalidades, así como conceptos básicos sobre el polvo mineral atmosférico. En el capítulo 2 se desarrollará la metodología utilizada en este trabajo, en el que se describirán la red de observación, las series históricas de PM10 y se hará énfasis en explicar detalladamente el procedimiento para determinar si ha tenido lugar o no una intrusión de polvo desértico sobre el archipiélago canario. En el capítulo 3 se presentaran los resultados de la caracterización de las intrusiones de polvo desértico en Canarias. En este apartado se incluyen datos relevantes sobre la duración de los eventos, el efecto de las intrusiones en la calidad del aire, y además se caracteriza los valores PM10 de fondo (i.e. en situaciones sin contribución de polvo desértico) 
medidos en la red de calidad del aire del Gobierno de Canarias. En el capítulo 4 se expondrán varios casos de estudio, que muestran distintos tipos de eventos de intrusión de polvo en Canarias. Se analizaran casos que afectan de forma generalizada al archipiélago y adicionalmente se examinan episodios que generan un impacto asimétrico en las islas. El capítulo 5 recoge las conclusiones principales de este trabajo. Para finalizar el capítulo 6 denominado "Consideraciones prácticas" se incluye una guía básica que pretende servir de ayuda a la hora de enfrentarse a un posible evento de intrusión de polvo desértico. Además, se incluyen dos anexos. El anexo 1 contiene información adicional sobre las estaciones de la Red de Calidad del Aire del Gobierno de Canarias y el anexo 2 se relacionan los episodios de intrusión destacados y utilizados en los cálculos del capítulo 2.

\section{GENERALIDADES Y CONCEPTOS BÁSICOS SOBRE POLVO ATMOSFÉRICO}

Se conoce como material particulado atmosférico (también conocido como aerosol atmosférico), a todas aquellas partículas sólidas y/o líquidas (excepto partículas de agua) que puedan estar presentes en la atmósfera, ya sean de origen natural o antropogénico. Las intrusiones de masas de aire africano son las responsables de aumentar el nivel de material particulado mineral incluso en regiones que pueden estar alejadas de la fuente de este material. El polvo mineral del desierto es el segundo aerosol más importante en cuanto a contribución en masa al aerosol atmosférico global, después del aerosol marino [Huneeus et al., 2013]. Aunque existen otras zonas áridas del planeta que son fuentes de material particulado, son las fuentes del norte de África las que más material mineral aportan al total del material particulado existente en la atmósfera de nuestro planeta, con un rango de emisión entre 400 y $2200 \mathrm{Tg} / \mathrm{año}$ [Ginoux et al., 2001] [Ginoux et al., 2012] [Goudie and Middleton, 2001].

El polvo tiene un importante impacto en el clima [Foltz y Mcphaden, 2008] [Prospero y Lamb, 2003] [Tegen y Torres, 2005], en la calidad del aire [Prospero, 1999] [Prospero et al., 2014] y la salud [Prospero y Lamb, 2003] [Díaz et al., 2012] [Karanosiou et al., 2012]. La capa de aire sahariana (SAL del inglés Saharan Air Layer), que es como se conoce a la capa de aire procedente del Sahara normalmente cargada de polvo desértico procedentes del norte de África, y específicamente del Sáhara, el mayor desierto del mundo, alcanza regiones muy lejanas como el Caribe y América Central y del Norte.

En el caso de las islas Canarias es importante conocer los procesos que dan lugar al transporte natural de material particulado desde zonas áridas de África, que habitualmente causan episodios de alta concentración de polvo en suspensión (conocidos generalmente en las islas como calima) y que pueden presentar efectos en la salud de las personas, en la agricultura y en las condiciones de visibilidad [Alonso et al., 2007]. Los episodios de intrusiones de polvo desértico acaecidos en Canarias han sido documentados desde 1883, año del que data una muestra de "lluvia de tierra en la noche de 22 de febrero de 1883 en Tenerife". Sin embargo Darwin ya en 1832, a su llegada al puerto de Santa Cruz de Tenerife, describe una situación de intensa calima [Dorta, 2007]; otra referencia ampliamente descrita es la de febrero de 1898 y la presencia de grandes cantidades de polvo en suspensión que aparece reflejada también en multitud de textos antiguos. Este tipo de fenómenos atmosféricos son, por tanto, muy recurrentes en las islas (enero de 1983, febrero de 1994, marzo de 1995, etc.), aunque los 
eventos de mayor intensidad sólo se producen con una frecuencia de entre una y tres veces al año, constituyendo una amenaza más en el clima canario [Dorta, 2007].

Para la caracterización de las intrusiones de polvo desértico se pueden utilizar distintos parámetros. Por un lado, están los parámetros utilizados en calidad del aire (PM10 y PM2.5), y por otro lado, el espesor óptico de aerosoles (AOD del inglés Aerosol Optical Depth), que es utilizada para la cuantificación del contenido total de aerosoles en la columna atmosférica, tanto por sistemas de detección remota desde satélites o desde tierra, como por la comunidad que trabaja con modelos numéricos de predicción.

A continuación se definen algunos conceptos importantes relativos al aerosol atmosférico, así como técnicas de medida y redes de observación:

\section{Material particulado en superficie (PM10 y PM2.5)}

El material particulado (PM) es una mezcla compleja de componentes con características químicas y físicas diversas. Sus posibles efectos sobre la salud varían en función del tamaño y la composición. Pueden ser primarias o secundarias, es decir, formadas a partir de otros contaminantes primarios. Como se ha mencionado anteriormente, el término PM10 se refiere a partículas con un diámetro aerodinámico de hasta 10 micrómetros, mientras que el término PM2.5 se refiere a partículas con un diámetro aerodinámico de hasta 2.5 micrómetros. En general, la parte gruesa de las PM10 se compone en buena medida de partículas primarias emitidas directamente a la atmósfera tanto por fenómenos naturales ("spray marino", levantamiento de polvo en zonas áridas, o emisiones volcánicas) como por las actividades humanas (labores agrícolas o de construcción, resuspensión de polvo en carreteras no asfaltadas, actividades industriales, etc.). Las partículas finas o PM2.5, por el contrario, suelen estar compuestas principalmente por partículas secundarias formadas en la atmósfera a partir de un precursor gaseoso (NOx, SO2, $\mathrm{COV}, \mathrm{NH} 3$, etc.) mediante procesos químicos o por reacciones en fase líquida.

Las principales fuentes de emisión de partículas en España son las cementeras, grandes instalaciones de combustión, incineración y coincineración de residuos y el transporte (el lector puede obtener información adicional en https://www.miteco.gob.es/es/calidad-y-evaluacionambiental/temas/atmosfera-y-calidad-del-aire/emisiones/prob-amb/particulas.aspx). En las islas Canarias debido a la proximidad al continente africano una de las principales fuentes de material particulado son las intrusiones de polvo desértico, las denominadas calimas. Para poder determinar si la superación de los valores legislados es debida a la acción humana o si es natural, el Ministerio elabora un informe anual con las aportaciones de PM10 recogidas por la red de medición de fondo (EMEP/ CAMP), determinando qué días han ocurrido episodios de calima y que cantidad de partículas se deben a dicha intrusión, lo que permite el descuento de esas partículas de polvo desértico de los valores medidos por las estaciones.

La red española EMEP (European Monitoring and Evaluation Programme; https://emep.int/) /CAMP está dedicada a la contaminación de fondo a escala regional lejos de fuentes contaminantes y satisface los compromisos internacionales derivados de los programas EMEP y CAMP.

El Programa EMEP (Programa Concertado de Vigilancia y Evaluación del Transporte a Larga Distancia de los Contaminantes Atmosféricos en Europa) deriva del convenio de Ginebra sobre contaminación transfronteriza de 1977. Su fin es proporcionar a los países miembros información sobre la concentración y depósito de contaminantes atmosféricos, así como del 
transporte de los mismos a través de las fronteras nacionales. Sin embargo, Canarias no forma parte del ámbito geográfico europeo donde está establecida la red del programa EMEP.

- El Programa VAG (Vigilancia de la Atmósfera Global, 1989) se encuentra dentro del PIAMA (Programa de Investigación de la Atmósfera y el Medio Ambiente de la OMM -AREP). Constituido para comprender los cambios naturales y antropogénicos de la atmósfera, conocer las interacciones entre la atmósfera, el océano y la biosfera y para facilitar información científicamente fiable para el desarrollo de políticas medioambientales nacionales e internacionales. La importancia del programa VAG crece con el reconocimiento de los importantes vínculos entre la calidad del aire y el cambio climático. Solo existe en España una estación VAG de importancia global que es la de Izaña en Tenerife (http//izana.aemet.es). Algunas de las estaciones EMEP ubicadas en la Península son VAG regionales.

- El Programa CAMP (Programa Integral de Control Atmosférico), fruto del convenio Oslo-París de 1992 para la Protección del Medio Ambiente Marino del Atlántico Nordeste y tiene por objeto conocer los aportes atmosféricos terrestres a esta región atlántica y estudiar sus efectos sobre el medio marino.

La red representa la situación de la contaminación de fondo en España. En ellas se desarrolla un programa ordinario de mediciones con técnicas llamadas in-situ, dentro del cual se realizan observaciones periódicas de gases, aerosoles, gases + aerosoles y química de la precipitación. Las estaciones VAG gestionan programas de medida mucho más amplios, que incluyen los gases de efecto invernadero y la vigilancia de la capa de ozono, y se complementan con medidas más avanzadas utilizando técnicas de teledetección. El valor de este programa de medidas aumenta al considerar la continuidad de las mismas en el tiempo y su integración internacional. El programa de medidas EMEP se amplía en algunas estaciones para cumplir con los compromisos adquiridos dentro de otros acuerdos y colaboraciones existentes. Asimismo, se realizan de manera periódica campañas adicionales de mediciones reguladas por las leyes europeas relacionadas con la calidad del aire ambiente.

Con objeto de proteger la salud humana y el medio ambiente, la legislación establece una serie de valores límite, valores objetivo, umbrales de información y de alerta y niveles críticos de diferentes contaminantes (Directiva 2008/50/CE, de 21 de mayo de 2008 y la Directiva 2004/107/CE, de 15 de diciembre de 2004 o el Real Decreto 102/2011). La Comunidad Autónoma de Canarias tiene atribuidas las competencias relativas a la evaluación y gestión de la calidad del aire ambiente, así como la adopción de medidas ante situaciones desfavorables de calidad del aire. Para la realización de sus competencias, el Gobierno de Canarias cuenta con la Red de Estaciones Calidad del Aire, el Centro de Evaluación y Gestión de la Calidad del Aire (CEGCA), que gestiona en tiempo real la información en materia de calidad del aire, el sistema de información de calidad del aire, o los planes de calidad del aire.

(https://www.gobiernodecanarias.org/medioambiente/temas/calidad/centro-evaluaciongestion-calidad-aire/ )

\section{Concentración de aerosoles en columna:}

Para la radiación que se propaga a través de un medio, el coeficiente de extinción es la disminución fraccional de radiancia por unidad de longitud de camino óptico.

El volumen del coeficiente de extinción se define a través de la ley de Lambert-Beer como: 


$$
\frac{d L}{L}=-\gamma d s
$$

Donde $L$ es la radiancia monocromática a una longitud de onda dada, $\gamma$ es el volumen del coeficiente de extinción y $d s$ es el incremento de longitud de camino óptico. El coeficiente de extinción en masa es igual al coeficiente de extinción en volumen dividido por la densidad del medio. Por lo tanto, en unidades SI, el coeficiente de extinción de volumen tiene unidades de metros inversos y el coeficiente de extinción en masa tiene unidades de metros cuadrados por kilogramo. En general, la extinción de la energía radiante es causada por la absorción y la dispersión. El coeficiente de extinción es la suma del coeficiente de absorción y el coeficiente de dispersión, y generalmente depende de la longitud de onda y la temperatura.

\section{Espesor óptico de Aerosoles}

El espesor óptico de aerosoles (AOD, en sus siglas en inglés, Aerosol Optical Depth) es la variable principal recomendada para la medición continua de aerosol a largo plazo dentro del programa VAG [GAW Report, 162]. El AOD es una medida de la extinción del haz solar, debido a la presencia de partículas en una columna vertical de la atmósfera. En otras palabras, las partículas en la atmósfera (polvo, humo, contaminación) pueden bloquear la luz solar al absorber o dispersar la misma. El AOD nos dice cuánta luz solar directa se evita que llegue al suelo por estas partículas de aerosol. Es un número adimensional que está relacionado con la cantidad total de aerosoles en la columna vertical de la atmósfera sobre la ubicación de observación. La variación espectral del AOD (en varias longitudes de onda) nos permite determinar el exponente de Amströng que da cuenta del tamaño de las partículas y así inferir qué tipo de aerosoles o mezcla de aerosoles estaríamos midiendo en un lugar en particular. Los valores de AOD dependen de las condiciones atmosféricas, pero típicamente estos valores se encuentran entre el rango de $0.02-0.2$ para la radiación visible. Un valor de 0.01 corresponde con atmósfera extremadamente limpia y un valor alrededor de 0.4 corresponde a condiciones de atmósfera muy turbia. Este parámetro es el más importante en la medida, en ciertos ámbitos, de la observación de aerosoles porque es el que mejor miden los satélites y el que mejor simulan los modelos numéricos por lo que se utiliza para evaluar los valores de AOD de modelos y de sensores satelitales. En este estudio se utiliza de forma auxiliar en los casos de estudio ya que está orientado a las observaciones de aerosoles desde el punto de vista de calidad del aire con PM10.

\section{Redes de medidas remotas desde tierra}

La red VAG-PFR (del Centro Mundial de Radiación de Davos, Suiza; [Wherli, 2005]) empezó en 1999 como un proyecto piloto. El Grupo Asesor Científico del programa VAG para Aerosoles seleccionó 12 estaciones VAG como candidatas para el despliegue de 12 radiómetros de filtro de precisión (PFR del inglés Precision Filter Radiometers). Hay que poner en relieve, que en este proyecto piloto la estación de Izaña formó parte desde agosto de 2001. Actualmente operan 24 localizaciones adicionales (en Europa, Japón y la Antártida) en los programas de observación de AOD usando instrumentos PFR. En los Observatorios de Izaña y Mauna Loa hay permanentemente un instrumento de la referencia VAG-PFR.

El proyecto AERONET (AErosol RObotic NETwork; [Holben et al.1998]) es una agrupación de redes de teledetección de aerosoles desde tierra establecidas por, NASA, PHOTONS (PHOtométrie pour le Traitement Opérationnel de Normalisation Satellitaire; Univ. of Lille 1, CNES, and CNRS-INSU) y RIMA (Red Ibérica para la Medida de Aerosoles, Universidad de Valladolid y CIAI) en 1992 y está ampliamente expandido por redes y colaboradores de agencias nacionales, institutos, universidades, científicos individuales y socios, con más de 400 estaciones en todo el mundo. Es actualmente la red de referencia de medida de aerosoles en 
columna a nivel mundial. Durante más de 25 años, el proyecto ha proporcionado una base de datos a largo plazo y de dominio público, continua y de fácil acceso a las propiedades ópticas, microfísicas y radiativas de aerosol. Esta base de datos es utilizada para la investigación y caracterización de aerosoles, validación de recuperaciones satelitales y sinergia con otras bases de datos. La red impone la estandarización de instrumentos, calibración, procesamiento de datos y distribución de los mismos. En Canarias hay actualmente cuatro estaciones en operación situadas en Santa Cruz de Tenerife, Izaña, y Roque de los Muchachos (gestionadas por el CIAI) y en La Laguna (gestionada por la Universidad de La Laguna). Además el Observatorio de Izaña es centro de calibración de instrumentos de referencia de AERONET, junto a Mauna Loa (Hawái).A pesar de las marcadas diferencias técnicas entre ambas redes (AERONET, VAGPFR) y del número de instrumentos utilizados, sus datos de AOD a largo plazo son comparables y consistentes [Cuevas et al., 2019]. En condiciones de AOD mayor de 0.1 (presencia de polvo) VAG-PFR subestima ligeramente los valores.

\section{Medidas remotas desde satélite}

Los satélites toman medidas de las propiedades de los aerosoles de dos formas:

- Observaciones lidar: En 2006 NASA lanzó la misión CALIPSO (Clouds and Aerosol Lidar for Pathfinder Spaceborne Observations) que mide la distribución de aerosol en la vertical (i.e. extinción) en una porción de la atmósfera (https://www-calipso.larc.nasa.gov/a.gov/ ).

- Medidas en columna hechas desde sensores remotos pasivos: Los satélites suministran información global para vigilar la evolución diaria de los aerosoles y para comprender cómo éstos afectan al clima terrestre. Uno de los instrumentos satelitales para la medida del AOD más importantes, y que se utiliza con más frecuencia hoy día, es el MODIS (Moderate Resolution Imaging Spectrometer) a bordo de los satélites de la NASA Terra y Aqua (https://modis.gsfc.nasa.gov/ ). Existen además, otros instrumentos a bordo de satélites que permiten vigilar la evolución de aerosoles en la atmósfera:

-OMI (Ozone Monitoring Instrument) a bordo de Aura (https://aura.gsfc.nasa.gov/omi.html )

-VIIRS (The Visible Infrared Imaging Radiometer Suite) a bordo de Suomi NPP (National Polar-Orbiting Partnership, https://www.nasa.gov/mission_pages/NPP/main/index.html )

-SLSTR (Sea and Land Surface Temperature Instrument) a bordo de Sentinel-3 (https://sentinel.esa.int/web/sentinel/missions/sentinel-3).

Los instrumentos enumerados en el párrafo anterior tienen en común que viajan a bordo de satélites polares. Los satélites polares poseen una buena resolución espacial sin embargo, carecen de una buena resolución temporal. Para las labores de predicción y vigilancia a muy corto plazo, "nowcasting" es de utilidad hacer uso del producto RGB (Red, Green, Blue) de Polvo, basado en datos de los canales infrarrojos (IR8.7, IR10.8 e IR12.0) SEVIRI (Spinning Enhanced Visible and InfraRed Imager) del satélite Meteosat de segunda generación. Está diseñado para monitorear la evolución de las tormentas de polvo durante el día y la noche (https://navigator.eumetsat.int/product/EO:EUM:DAT:MSG:DUST ).

\section{Modelos de predicción numérica}

Para la predicción de eventos de intrusión de polvo la herramienta básica son los modelos numéricos de predicción de polvo. Para ello AEMET dispone de las predicciones diarias del Barcelona Dust Forecast Center (BDFC; https://dust.aemet.es/), Centro Meteorológico Regional Especializado en Predicción de Polvo Atmosférico (RSMC-ASDF) creado por la 
WMO en febrero de 2014 y gestionado conjuntamente por AEMET y el Barcelona Supercomputing Center (BSC-CNS).

El BDFC dispone de un modelo operativo de predicción de polvo, el NMMB-MONARCH que ofrece predicciones diarias de hasta 72 horas para el norte de África, Oriente Medio y Europa (https://dust.aemet.es/forecast/). Los parámetros que se predicen son los siguientes: espesor óptico de polvo (Dust AOD), concentración de polvo en superficie (Dust Surface Concentration), carga total de polvo (Dust Load), extinción en superficie (Dust Surface Extinction) y deposición seca y húmeda (Dust Dry and Wet Deposition).

AEMET y el BSC-CNS también gestionan conjuntamente el Centro Regional del Sistema de Alerta y Evaluación de Tormentas de Polvo y Arena para el Norte de África, Oriente Medio y Europa (SDS-WAS, https://sds-was.aemet.es/). Este centro fue creado en $2007 \mathrm{y}$ forma parte del proyecto SDS-WAS (Sand and Dust Storm Warning Advisory and Assessment System) de la OMM que tiene como objetivos principales la coordinación y mejora de la predicción de las tormentas de polvo y su monitorización a nivel mundial y así reducir los riesgos asociados al polvo mineral. En la página web del Centro Regional se pueden encontrar productos de predicción multimodelo y probabilísticos, basados en 12 modelos gestionados por agencias e instituciones meteorológicas internacionales (uno de ellos es Copernicus-CAMS del ECMWF), así como productos de observación para facilitar el seguimiento de las tormentas e intrusiones de polvo. Hay que tener presente que los pronósticos del SDS-WAS y del BDFC solo consideran el pronósticos de polvo mineral, mientras que los métodos de observación de parámetros como PM10 o AOD descritos anteriormente incluyen la contribución de todo tipo de aerosoles y no sólo la contribución debida al polvo.

\section{METODOLOGÍA}

\subsection{Introducción}

Trabajos previos han puesto de manifiesto la necesidad de la caracterización del polvo mineral atmosférico sobre el norte de África y Oriente Medio. En alguno de estos trabajos se ha evaluado la capacidad de los modelos de predicción numérica para reproducir el comportamiento de variables relacionadas con el polvo mineral atmosférico. Para ello, se han contrastado salidas de reanálisis de modelos de predicción numérica (concretamente el MACCII, reanálisis producido por el ECMWF) con distintos productos de satélite, datos in-situ y lidars [Cuevas et al., 2015]. En este estudio se concluyó que MACC-II reproduce bien la variabilidad del polvo registrada a lo largo de un transecto de tres estaciones en el Sahel, lo que refleja la variabilidad en la emisión de polvo por diferentes fuentes saharianas, y en su transporte, pero no reproduce correctamente eventos de polvo esporádicos y muy fuertes asociados con los sistemas convectivos de mesoescala durante la estación húmeda.

Otros estudios llevados a cabo en Canarias se han centrado en la obtención de series temporales de AOD en Izaña. En la publicación [Barreto et al., 2014] se reconstruye una serie temporal de 37 años de AOD en $\approx 770 \mathrm{~nm}$ a partir de medidas de irradiancia solar realizadas con el espectrómetro solar Mark-I situado en Izaña desde 1976. Esta serie se comparó con los datos obtenidos por el fotómetro Cimel de la red AERONET y el Radiómetro de VAG-PFR ubicados en el observatorio de Izaña. El análisis preliminar de tendencia de AOD en el periodo de 29 años comprendidos entre 1984-2012 con Mark I no revela tendencias significativas. Además 
de esta serie de 37 años de AOD, gracias al estudio de García et al. [2016] se dispone de una serie de 73 años de AOD en $500 \mathrm{~nm}$ para el observatorio de Izaña. Para la obtención de esta serie, se combinó AOD estimado mediante redes neuronales durante el periodo 1941-2001, con medidas directas de AOD obtenidas con el VAG-PFR entre 2003 y 2013.

Adicionalmente a los trabajos anteriores, que están centrados en la caracterización del polvo mineral atmosférico en el norte de África y Oriente Medio y en la obtención de series de AOD sobre Izaña, se han realizado publicaciones enfocadas en estimar parámetros cuantitativos (como el PM10) a partir de medidas de visibilidad. Se ha obtenido una ecuación empírica [Camino et al., 2015] que permite estimar la concentración de polvo (PM10) a partir de visibilidad horizontal obtenida en el Observatorio de Izaña y validada en tres estaciones de PM10 en el Sahel que poseen series largas de datos. Hay que tener en cuenta que desde el punto de vista de gestión de la calidad del aire interesa conocer la concentración de PM10 en un área determinada, y desde el punto de vista meteorológico clásico, interesa determinar la visibilidad horizontal.

\subsection{Caracterización}

El presente trabajo tiene como objetivo la caracterización de las intrusiones de polvo desértico en el archipiélago canario a partir de datos cuantitativos medidos in-situ. Se han establecido dos tipos de escenarios para realizar el estudio basado en los datos de PM10 de la Red de Vigilancia de la Calidad del Aire del Gobierno de Canarias (Sección 2.3). En el primero de estos escenarios, en el que hay una alta probabilidad de que no existe intrusión de polvo procedente de África, es considerado el escenario limpio o de fondo ("background"), mientras que el segundo escenario corresponde a intrusión de polvo. Para ello, se ha utilizado datos horarios de PM10 y PM2.5 comprendidos entre los años 2010 y 2017. Estos datos provienen de 51 estaciones de la red de Calidad del Aire del Gobierno de Canarias. Además, se ha utilizado retrotrayectorias FLEXTRA y se ha calculado índices de africanidad para el periodo 2010-2017 en 198 puntos de grid (el procedimiento de obtención de estos índices se detalla en la Sección 2.4).Una vez discriminados los escenarios, se analizarán los datos diarios promedio para todas las estaciones y se realizará un análisis con agrupaciones de estaciones por isla. El objetivo de este análisis es definir el comportamiento de las estaciones sin intrusión (background estadístico) y con intrusión (episodios).

Para el escenario de intrusión de polvo africano (episodios de intrusión), se calcularán valores típicos de duración, intensidad y magnitud de los episodios. Para ello se establecen umbrales de 50 y $100 \mu \mathrm{g} / \mathrm{m}^{3}$ y se tiene en cuenta la estacionalidad observada. Además se realizará una distribución por islas para contemplar el posible efecto de localización.

Para las series completas de datos (es decir, escenarios sin y con intrusión), se calcularán los estadísticos de superación por umbrales para conocer el porcentaje de eventos que corresponden a cada rango.

Por último, se realizará una distinción geográfica entre eventos con cierta intensidad, que permite distinguir episodios que afectan en mayor medida a la zona occidental, a la oriental o a la totalidad del archipiélago. 


\subsection{Herramientas}

\subsubsection{Red de Vigilancia de la Calidad del Aire del Gobierno de}

\section{Canarias}

Actualmente la Red de Vigilancia de la Calidad del Aire del Gobierno de Canarias está compuesta por tres redes de medición, de las cuales dos son privadas y están asociadas a fuentes de emisión, por lo que su principal cometido es el de garantizar el cumplimiento de los objetivos de la calidad del aire en el entorno de las instalaciones industriales, y la otra es de titularidad pública y pertenece a la Viceconsejería de Medio Ambiente. El número de estaciones que componen cada una de las redes (en la evaluación de 2017) se muestra en la Tabla 1:

\begin{tabular}{|c|c|}
\hline RED DE CALIDAD DEL AIRE & NÚMERO DE ESTACIONES \\
\hline UNELCO ENDESA & 30 \\
\hline CEPSA & 5 \\
\hline MEDIO AMBIENTE & 23 \\
\hline
\end{tabular}

Tabla 1: Red de Calidad del Aire del Gobierno de Canarias

Las tres redes de Calidad del Aire cuentan con los medios necesarios para asegurar una alta fiabilidad en los valores registrados. La Red de Vigilancia de la Calidad del Aire del Gobierno de Canarias está actualmente constituida por 58 estaciones (para la caracterización se han utilizado 51 estaciones), cuya cobertura temporal y espacial no es continua en el tiempo. Debido a esto, se ha elegido un periodo de estudio comprendido entre enero de 2010 y diciembre de 2017, en donde las islas de Lanzarote, Fuerteventura, Gran Canaria, Tenerife y La Palma poseen datos de la red. A partir de enero de 2012 se incorporó una estación en El Hierro, posteriormente, en noviembre de 2013, lo hizo la primera de las estaciones de La Gomera. Para llevar a cabo la caracterización del PM10, se ha utilizado datos del promedio diario compuestos al menos de 21 datos horarios.

La distribución de las estaciones de la Red de Calidad del Aire del Gobierno de Canarias utilizadas en este estudio se muestra en la siguiente Figura 1 y se detalla en el Anexo 1. 


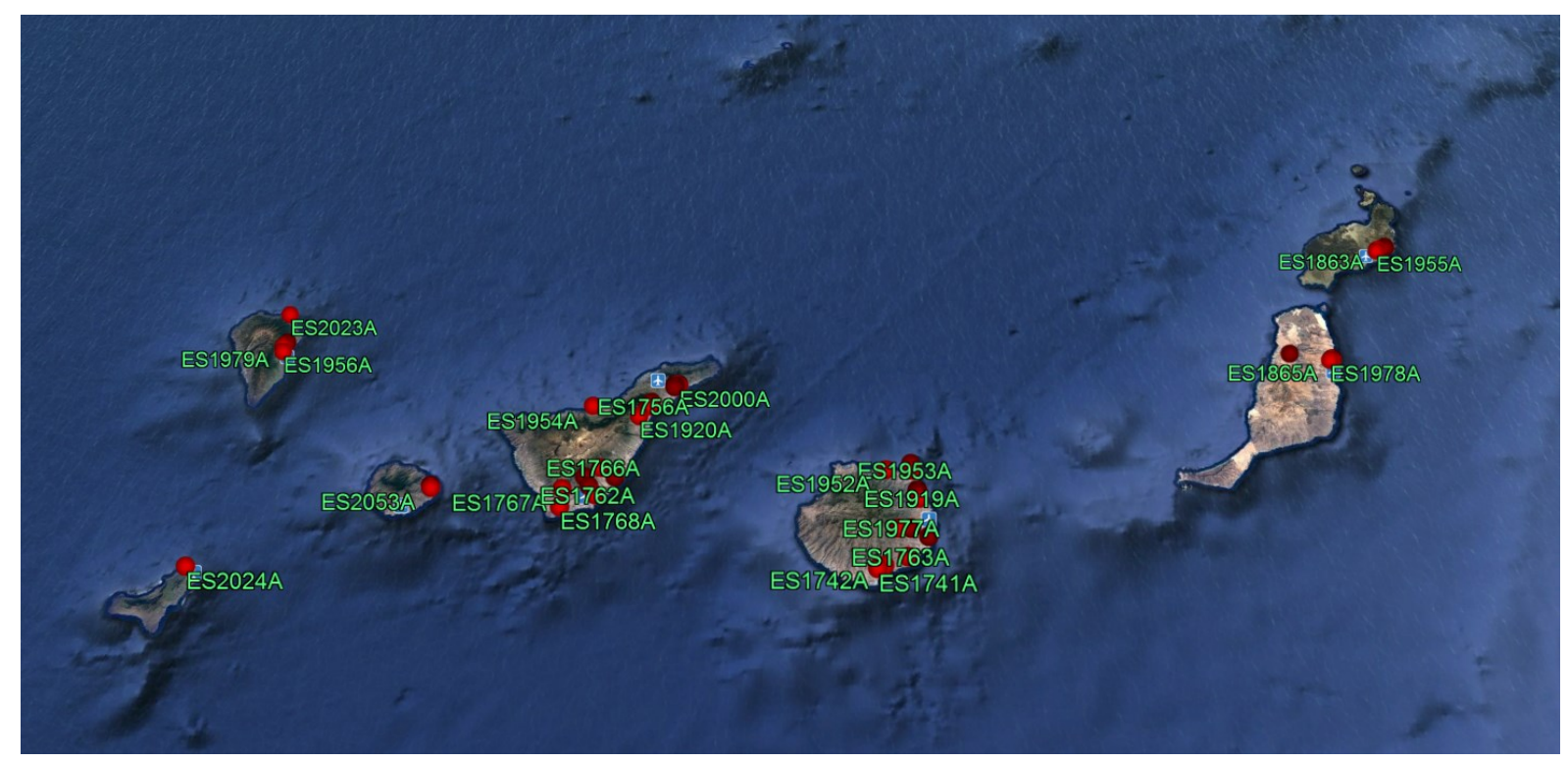

Figura 1. Localización de la estaciones de la Red de Calidad del Aire del Gobierno de Canarias.

\subsubsection{Retrotrayectorias}

El modelo de retrotrayectorias de masas de aire FLEXTRA [Stohl et. al., 1995; Stohl and Seibert, 1998] utiliza datos suministrados por el ECMWF provenientes del reanálisis global atmosférico ERA-Interim (información adicional acerca de ERA-Interim puede consultarse en https://www.ecmwf.int/en/elibrary/8174-era-interim-archive-version-20).

La resolución espacial de estos datos es de $1.25^{\circ}$ y poseen una resolución temporal de 6 horas. Las variables utilizadas provenientes del reanálisis del ECMWF son las siguientes:

- Componentes zonal y meridional del viento a 10 metros.

- Temperatura a 2 metros.

- Humedad relativa a 2 metros.

- Presión a nivel del mar.

- Precipitación total

- Evaporación.

Las trayectorias tridimensionales son calculadas usando el viento vertical también suministrado por el reanálisis meteorológico del ECMWF. Esta trayectoria tipo se piensa que es más precisa en la troposfera donde los procesos diabáticos (por ejemplo la condensación de vapor de agua) son importantes. La precisión de las trayectorias es normalmente del orden del $20 \%$ de la distancia de viaje [Stohl, 1998], aunque la incertidumbre en casos individuales puede ser mucho mayor. Una importante fuente de error de las retrotrayectorias de estaciones de superficie, es la turbulencia en la capa límite la cual no se puede tener en cuenta apropiadamente en las trayectorias simples. Por lo tanto, para cada sitio se calculan tres trayectorias que llegan a diferentes altitudes. Dependiendo de la situación meteorológica, su propagación puede sobreestimar o subestimar el área de la que proviene la masa de aire, pero da al menos una estimación aproximada de la ruta de la masa de aire. 
En el caso particular de este estudio, se han generado retrotrayectorias para el periodo comprendido entre 1 de enero de 2010 a 31 de diciembre de 2017. Como puntos de destino de estas trayectorias se ha creado una matriz de 198 puntos (Figura 2 y Figura 3), consistentes en 18 puntos de grid en la horizontal y 11 niveles en la vertical, que dan cobertura a todas las islas en la horizontal, y con nivel tope de $5000 \mathrm{~m}$. En la figura 4 se pueden ver algunos ejemplos de retrotrayectorias generadas.

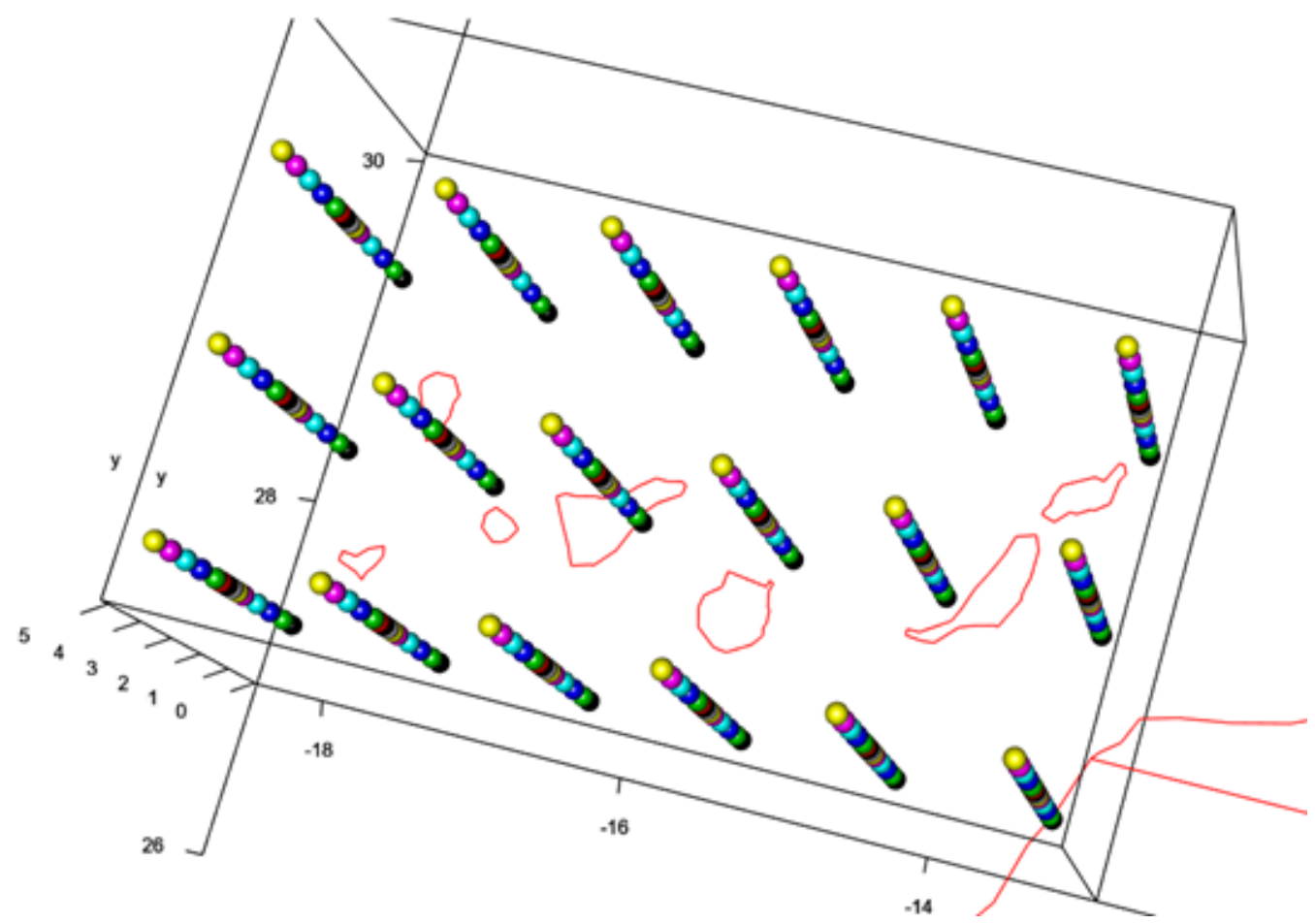

Figura 2. Matriz (18 puntos x 11 niveles) de destino de las retrotrayectorias.

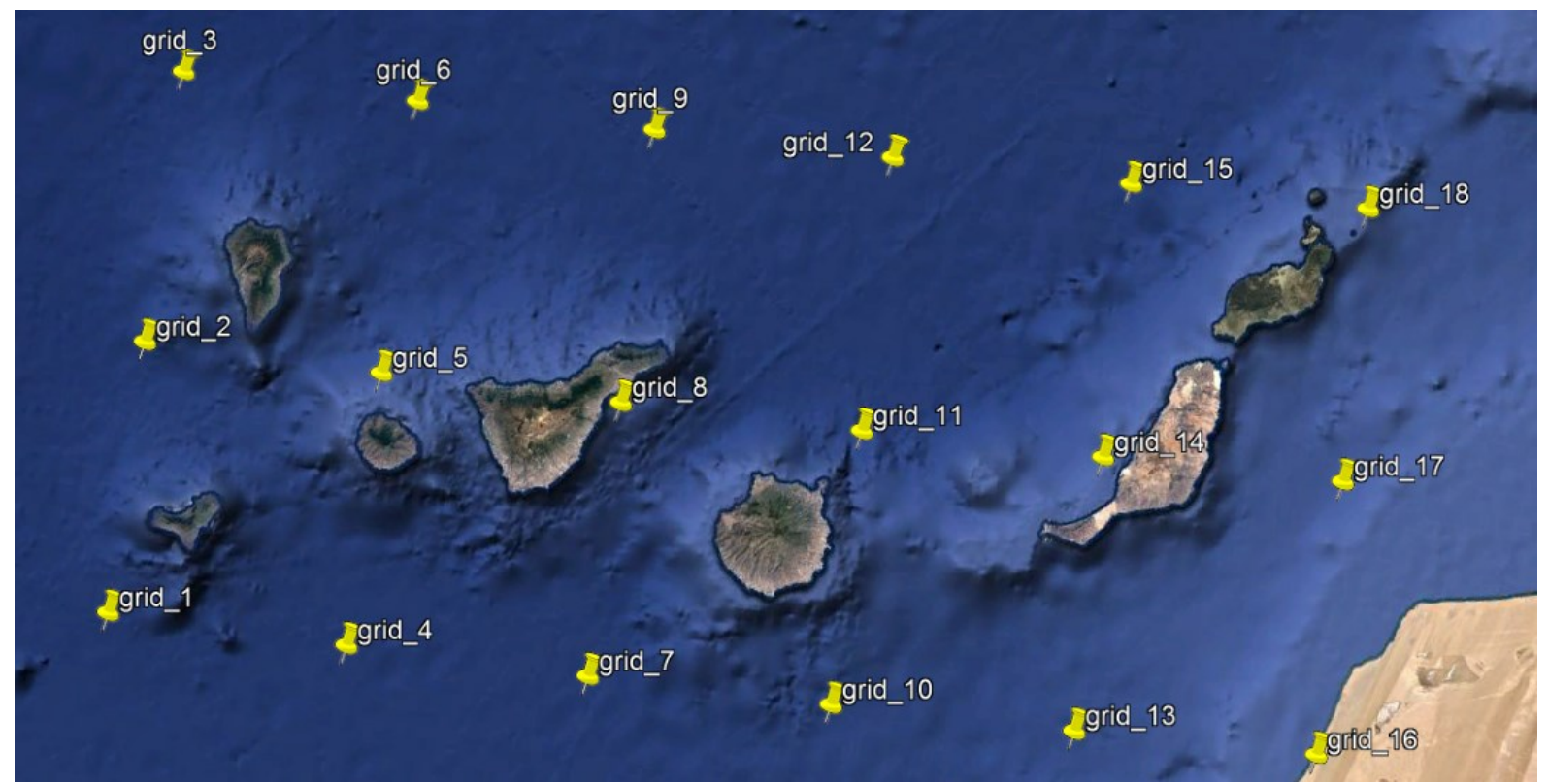

Figura 3. Denominación de los puntos de grid de destino de las retrotrayectorias. 


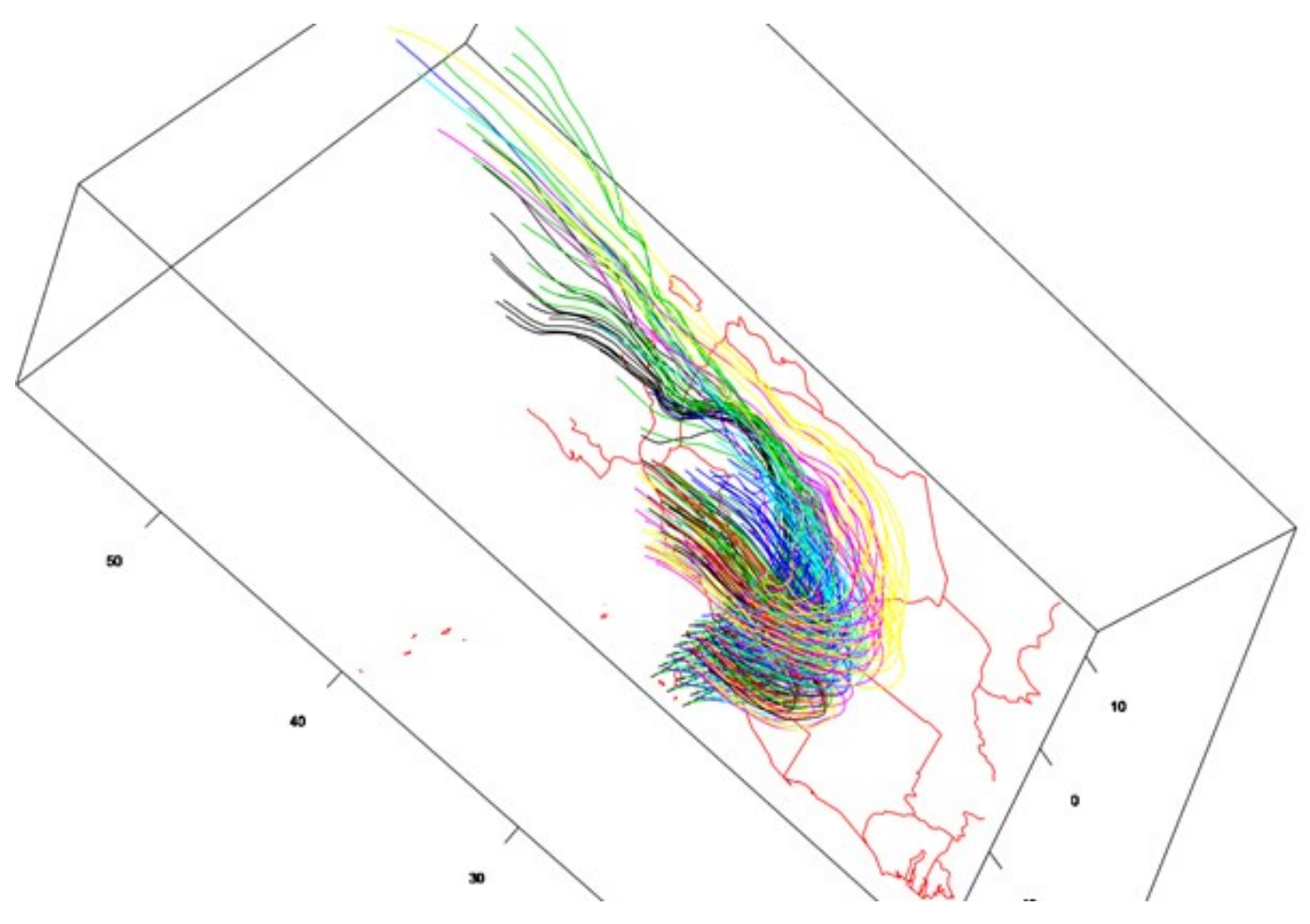

Figura 4. Ejemplo de retrotrayectorias con destino en la matriz diseñada.

\subsection{3 Índice NADFI (Intensidad del Dipolo del Norte de África)}

El índice NAFDI (Intensidad del Dipolo del Norte de África) da cuenta del dipolo (gradiente de geopotencial en $700 \mathrm{hPa}$, entre un punto al sur de Marruecos (alta) y sobre norte de Nigeria (baja) y permite establecer un simple modelo conceptual que relaciona la variabilidad en el transporte de polvo del Sáhara con la variabilidad a gran escala meteorológica en África noroccidental, sobre todo entre junio y septiembre. La medida de la variabilidad interanual de la intensidad del dipolo, y por tanto su relación con el gradiente del geopotencial, está relacionado con la intensidad del flujo geostrófico saliente del norte de África [Rodríguez et al 2015]. Además existe interacción entre las ondas de Rossby de latitudes medias (ondas planetarias) y el índice NAFDI, así como entre éste y el desplazamiento longitudinal de la baja térmica Sahariana (Saharan Heat Low -SLH-), de tal modo que el impacto de las ondas de Rossby en el norte de África hace variar el índice NAFDI y la SHL. Se han encontrado anomalías mensuales notables de cantidades generalizadas de AOD para cada fase de índice NAFDI sobre el corredor sahariano de polvo, indicando que el índice NAFDI presenta una variabilidad intraestacional y modula el transporte de polvo sobre la cuenca mediterránea y el Atlántico Norte [Cuevas et al 2017]. El índice NAFDI se define como sigue:

$$
\mathrm{NAFDI}=\frac{1}{10}\left(\left(\Phi_{\mathrm{Mo}}^{\mathrm{y}}-<\Phi>_{\mathrm{Mo}}\right)-\left(\Phi_{\mathrm{Ba}}^{\mathrm{y}}-<\Phi>_{\mathrm{Ba}}\right)\right)
$$


Donde

- $\Phi_{\mathrm{Mo}}^{\mathrm{y}}$ es la altura media de geopotencial en $700 \mathrm{hPa}$ promediada en la región central de Marruecos (30-32。 N, 5-7॰ W) en agosto del año "y".

$<\Phi>$ Mo es la altura media de geopotencial en $700 \mathrm{hPa}$ promediada en la región central de Marruecos (30-32॰ N, 5-7॰ W) para los meses de agosto desde 1948 a 2014.

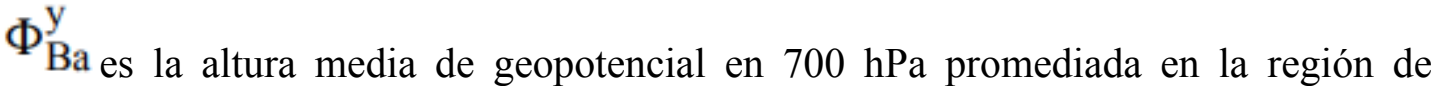
Bamako (10-13॰ N, 6-8॰ W) en agosto del año "y".

- $\quad<\Phi>\mathrm{Ba}$ es la altura media de geopotencial en $700 \mathrm{hPa}$ promediada en la región de Bamako (10-13॰ N, 6-8॰ W) para los meses de agosto desde 1948 a 2014.

- $\quad 1 / 10$ es un factor de escala.

Una vez expuesta la relación de los patrones sinópticos (el índice NAFDI) con la exportación de polvo en el Sáhara se pasa a detallar el índice de africanidad usado en este estudio.

\subsection{4 Índice de africanidad (el índice ARTI)}

El African Residence Time Index (el índice ARTI) representa la "africanidad" de la trayectoria, y se define como: el porcentaje de tiempo de los 5 días anteriores, que una masa de aire viaja sobre Africa antes de alcanzar el punto receptor (en este caso algún punto perteneciente a la matriz de 198 puntos definida anteriormente). Estadísticamente, un incremento en los valores del índice ARTI indica una alta frecuencia de masas de aire africana, lo que normalmente tiene asociado una alta concentración de polvo en comparación con las masas de aire oceánicas. Se ha delimitado el dominio geográfico sobre el continente africano (Figura 5) dentro del cual consideramos que la masa de aire se encuentra sobre África.

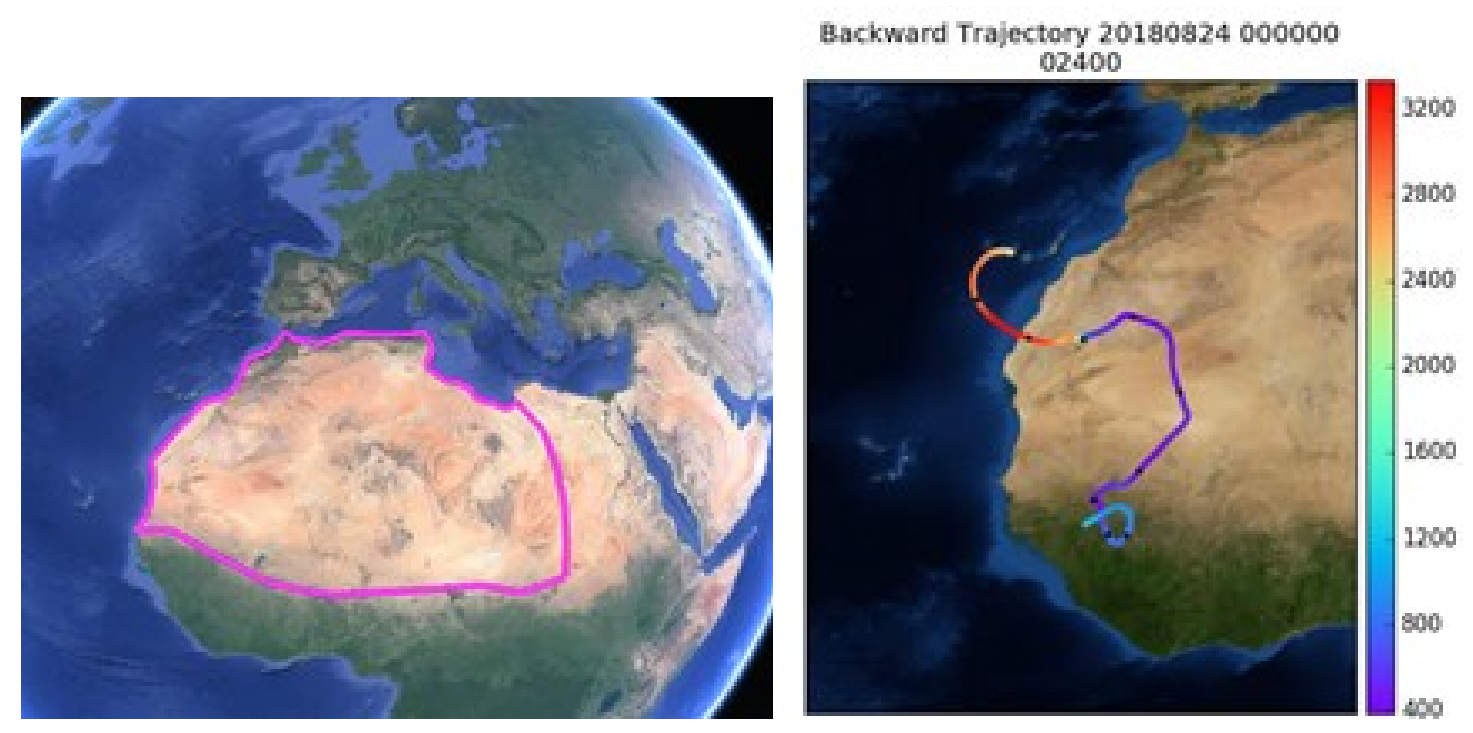

Figura 5. Izquierda: área delimitada sobre el continente africano para la definición de índice ARTI. Derecha: retrotrayectoria del ECMWF para el día 24 de agosto de 2018. 


\subsection{Metodología para la distinción de los tipos de escenario}

En este subapartado se describe detalladamente la metodología aplicada en la caracterización de intrusiones de polvo africano. Para ello, se han establecido dos tipos de escenarios para realizar el estudio de caracterización de los datos de PM10 de la Red de Vigilancia de la Calidad del Aire del Gobierno de Canarias. En el primero de estos escenarios, con alta probabilidad no hay intrusión de polvo procedente de África, corresponde a condiciones de fondo, mientras que el segundo escenario corresponde a situaciones de intrusión de polvo de África.

\subsubsection{Escenario en el que no hay intrusión de polvo africano}

Para seleccionar los días en los que con alta probabilidad no hay intrusión, se seleccionan los días en que se ha establecido que no hay masa de aire africana sobre las Islas Canarias. Para ello se han calculado las retrotrayectorias a 5 días usando los datos suministrados por el ECMWF provenientes del reanálisis global atmosférico ERA-Interim y el modelo de trayectorias FLEXTRA, así como el índice ARTI. Para establecer con alta probabilidad que no existe intrusión de polvo africano, se seleccionan los días cuyo valor máximo de índice ARTI sea nulo para los 198 puntos de la matriz, es decir, que ninguna de las trayectorias haya pasado por África en los 5 días anteriores.

En el periodo de estudio, en torno al $\mathbf{1 6 \%}$ del periodo corresponde al escenario en el que no hay intrusión de polvo africano. Con estos días seleccionados se caracteriza los datos de PM10 de las estaciones en este escenario (sección 3.2).

\subsubsection{Escenario en el que sí hay intrusión de polvo africano}

Para detectar los días en los que hay intrusión de polvo y evaluar tanto su intensidad como la duración de los episodios, se utilizan simultáneamente varios métodos que se describen a continuación:

- Se grafican series temporales de datos horarios de PM10 agrupados por isla (ver Figura 6). Esto permite conocer la extensión espacial de la intrusión y su magnitud. Los gráficos tienen una extensión temporal de 4 meses. 


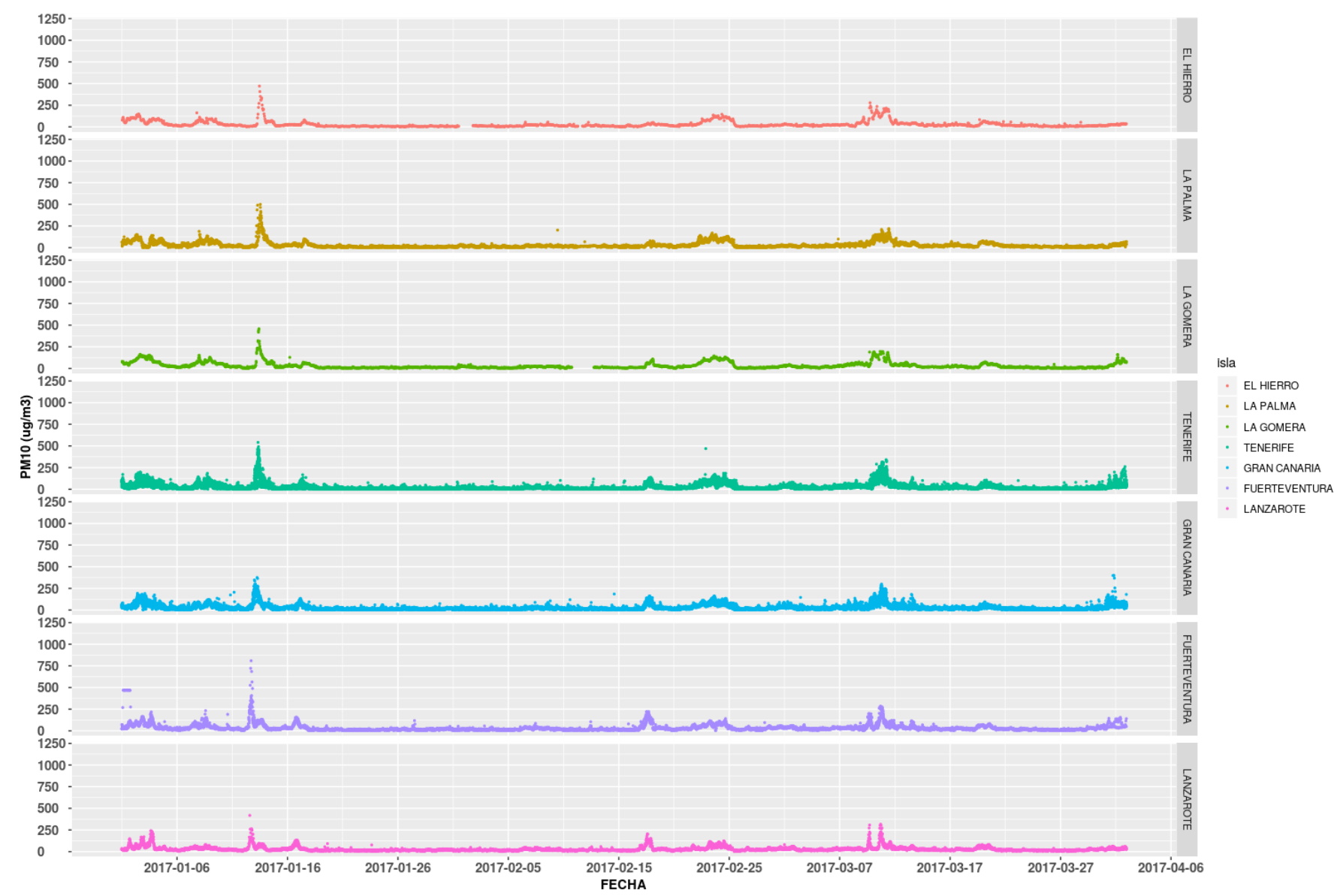

Figura 6.Serie temporal por islas de PM10 (datos horarios y con una extensión temporal de 4 meses).

- Con el objetivo de realizar una confirmación temporal a mayor resolución, se realizan gráficos (Figura 7), de PM10 frente al tiempo, del tipo boxplot, superponiendo todas las estaciones, coloreadas por isla. Los estadísticos obtenidos a través de los boxplot se contrastan con los estadísticos del índice ARTI diario (198 valores) correspondiente para una ventana de 3 meses.

- Además, se verifica visualmente que las masas de aire provienen de África con el enjambre de trayectorias y esto es confirmado con las imágenes de satélite Terra/MODIS (Figura 8).

Con estas condiciones se han identificado123 episodios en los 8 años de estudio (574 días, que corresponden a un $20 \%$ del total de días). 


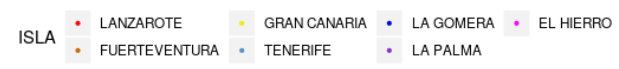
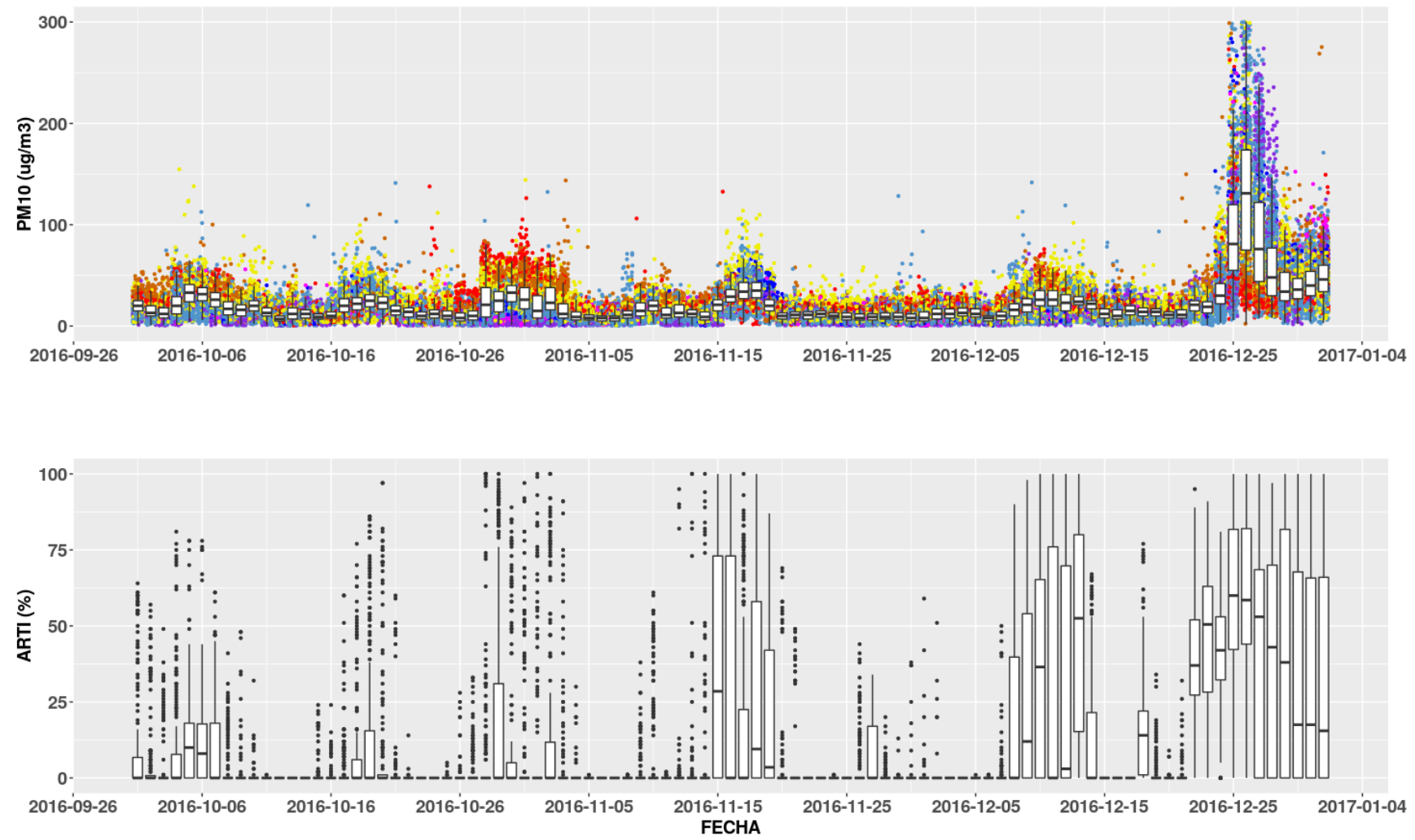

Figura 7.Serie temporal por islas de PM10 y boxplot de índice ARTI (Datos horarios y ventana temporal 3 meses).

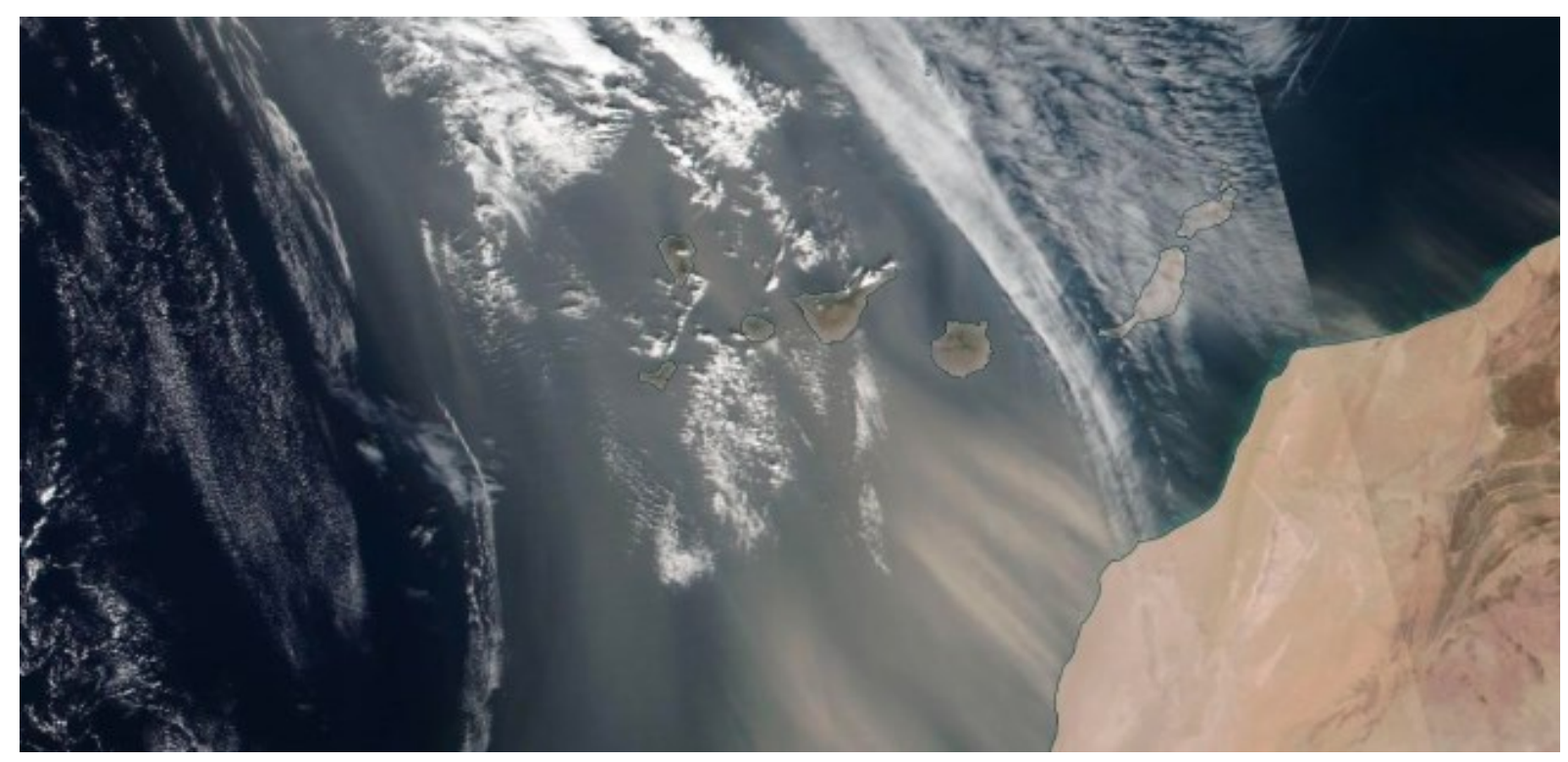

Figura 8. Imagen ejemplo de Satélite MODIS del 4 de febrero 2020. 


\section{RESULTADOS}

La caracterización de los episodios de intrusión sahariana permite entender el comportamiento de los diferentes tipos de intrusiones africanas, las magnitudes típicas que presentan y su estacionalidad. Además, la caracterización realizada en este documento permite conocer el valor de fondo ("background") de todas las estaciones y esto permitirá tenerlo en cuenta en fases futuras del proyecto, en el que el objetivo será el desarrollo de un sistema de predicción de PM10 de polvo mineral. La evaluación correspondiente deberá tener en cuenta el PM10 antrópico local en condiciones limpias para poder realizar una correcta comparación entre observación y predicción.

\subsection{Episodios de Intrusión africanos.}

\subsubsection{Caracterización de la duración de los episodios.}

En base a la técnica de detección de episodios que ha sido explicada en el apartado 2.4.2, se han contabilizado 123 días con intrusión sahariana acaecidos en el periodo 2010-2017. Estos episodios han afectado solo a algunas de las islas, o a todas.

En todo el periodo, la duración media de los episodios ha sido de 4.7 días, mientras que en los periodos octubre-noviembre y diciembre-marzo la duración promedia es de 3.7 días, y 6 días en los periodos de abril-mayo y junio-septiembre. La duración máxima ha sido de 8 días en el periodo octubre-noviembre en 2017, de 9 días para el periodo diciembre-marzo en 2013, de 8 días para abril-mayo en 2012 y 2011, y de 20 días en el periodo junio-septiembre en 2013.La tabla 2 muestra el resumen de la duración de los episodios:

\begin{tabular}{|c|c|}
\hline Periodo & $\begin{array}{c}\text { Duración media /Duración máxima y año de } \\
\text { ocurrencia (en } \mathrm{n}^{\circ} \text { de días) }\end{array}$ \\
\hline octubre-noviembre & $3.7 / 8(2017)$ \\
\hline diciembre-marzo & $3.7 / 9(2013)$ \\
\hline abril-mayo & $6 / 8(2011,2012)$ \\
\hline junio-septiembre & $6 / 20(2013)$ \\
\hline
\end{tabular}

Tabla 2. Resumen de la duración media y máxima de los episodios, así como el año de ocurrencia.

\subsubsection{Caracterización del efecto de las Intrusiones en la Calidad del Aire.}

Para caracterizar el efecto en la calidad del aire de las intrusiones se han usado dos umbrales de los incluidos en el "Índice Nacional de Calidad del Aire (ICA)". Por un lado, el umbral de 50 $\mu \mathrm{g} / \mathrm{m}^{3}$ en PM10, que se establece en la regulación de calidad del aire de la normativa europea como valor para contabilizar el número total de superaciones anuales permitidas (35). Por otro lado, el umbral de $100 \mu \mathrm{g} / \mathrm{m}^{3}$ de PM10 usado como siguiente límite en los umbrales del ICA. 
Analizados los datos diarios de todos los episodios y provenientes de todas las estaciones, se ha obtenido:

- $70 \%$ de valores PM10 $<=50 \mu \mathrm{g} / \mathrm{m}^{3}$

- $22 \%$ con valores $50 \mu \mathrm{g} / \mathrm{m}^{3}<$ PM10 $<=100 \mu \mathrm{g} / \mathrm{m}^{3}$ (U50-U100)

- $8 \%$ con valores PM10>100 $\mu \mathrm{g} / \mathrm{m}^{3}$ (U100).

La Figura 9 presenta el percentil 01, cuartiles y percentil 99 de los valores PM10 encontrados por Umbral.

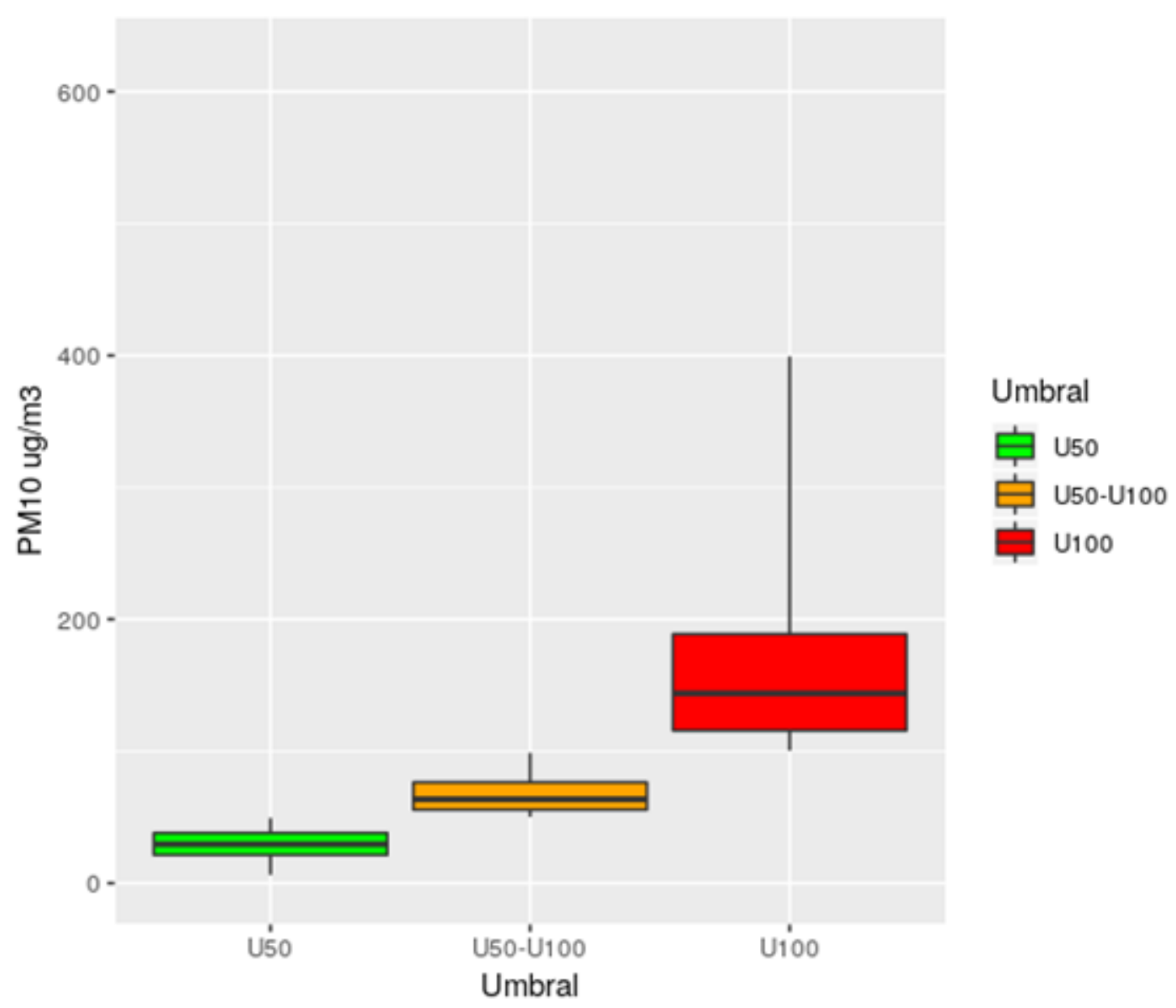

Figura 9. Boxplot de los valores de PM10 $\left(\mu \mathrm{g} / \mathrm{m}^{3}\right)$ correspondientes a los episodios de intrusión sahariana agrupados por umbrales.

\subsubsection{Estacionalidad de las intrusiones}

Se observa que los episodios más intensos (en torno al $8 \%$ del total), aquellos que han superado $\operatorname{los} 100 \mu \mathrm{g} / \mathrm{m}^{3}$ (U100), se han producido en un 5.8\% en el periodo diciembre-marzo, en un $1.3 \%$ 
en el periodo junio-septiembre, en un $0.9 \%$ en octubre-noviembre, y en un $0.2 \%$ en abril-mayo, respecto al total de días.

Los episodios en los que se ha registrado valores de PM10 entre 50 y $100 \mu \mathrm{g} / \mathrm{m}^{3}$ (U50-U100) sucedieron en un $9.4 \%$ en el periodo diciembre-marzo, en un $7.6 \%$ en el periodo junioseptiembre, en un $2.8 \%$ en octubre-noviembre, y en un $2.2 \%$ en abril-mayo, respecto al total de días.

Por último, los episodios en los que el PM10 ha sido inferior a $50 \mu \mathrm{g} / \mathrm{m}^{3}$ (U50) han ocurrido en un $20.5 \%$ en el periodo diciembre-marzo, en un $36.0 \%$ en el periodo junio-septiembre, en un $7.7 \%$ en octubre-noviembre, y en un $5.6 \%$ en abril-mayo, respecto al total de días.

\subsubsection{Efecto de las intrusiones por Islas}

En la tabla 3 se muestra la distribución por rangos de PM10 y por isla:

\begin{tabular}{|c|c|c|c|}
\hline ISLA & U50 & U50-U100 & U100 \\
\hline Lanzarote & $81 \%$ & $14 \%$ & $5 \%$ \\
\hline Fuerteventura & $68 \%$ & $24 \%$ & $8 \%$ \\
\hline Gran Canaria & $67 \%$ & $23 \%$ & $9 \%$ \\
\hline Tenerife & $69 \%$ & $23 \%$ & $8 \%$ \\
\hline La Gomera $\left(^{*}\right)$ & $57 \%$ & $30 \%$ & $13 \%$ \\
\hline La Palma & $79 \%$ & $15 \%$ & $6 \%$ \\
\hline El Hierro $\left.{ }^{*}\right)$ & $75 \%$ & $15 \%$ & $10 \%$ \\
\hline
\end{tabular}

Tabla 3. Porcentajes de distribución por islas y por umbrales. (*) El Hierro y La Gomera están afectadas por un menor número de intrusiones que el resto de las islas, al comenzar a medir sus estaciones a partir de 2012 y 2013 respectivamente.

La Figura 10 representa el percentil 01, cuartiles y percentil 99 de los valores PM10 por Umbral e Isla: 

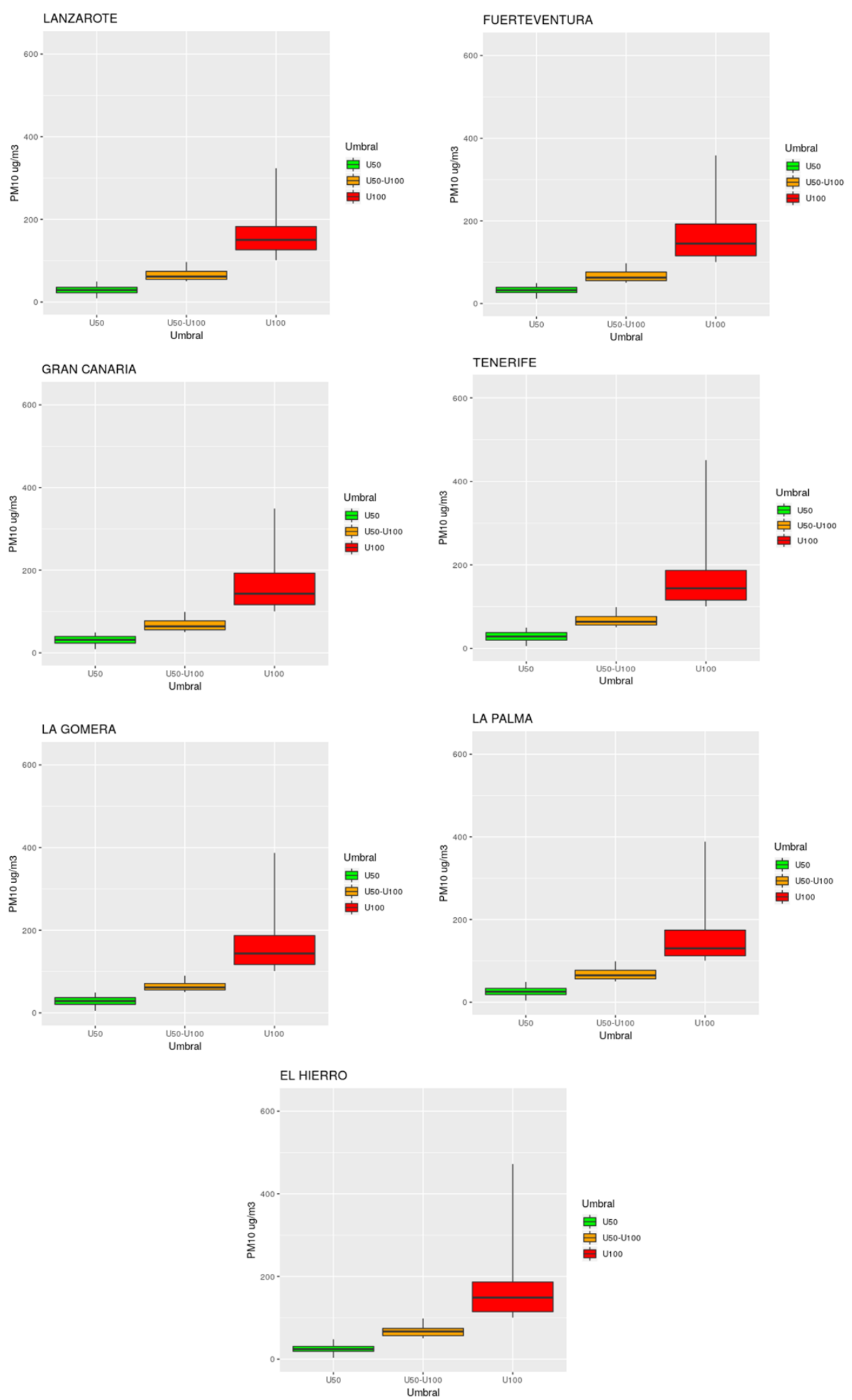

Figura 10. Boxplot de PM10 $\left(\mu \mathrm{g} / \mathrm{m}^{3}\right)$ (de los episodios de intrusión sahariana agrupados por umbrales. 
Se observa que los episodios en los que se registró PM10 superior a $100 \mu \mathrm{g} / \mathrm{m}^{3}$ (U100), presentan una mayor variabilidad en cuanto a los valores de PM10. Estos episodios intensos en un $75 \%$ de los casos no alcanzan los valores de $200 \mu \mathrm{g} / \mathrm{m}^{3}$.

\subsection{Episodios sin intrusión africana}

Como se detalló en el apartado 2.4.1, para seleccionar los días en los que no hay intrusión se establece un criterio muy riguroso, y es que ninguna de las trayectorias asociadas a la masa de aire sobre las Islas Canarias haya pasado por África en los 5 días anteriores. Esto se hace seleccionando los días en los que el máximo de esta matriz de índices índice ARTI es cero, es decir, ninguna trayectoria en el entorno de Canarias desde la superficie hasta los 5000 metros de altitud tiene un recorrido sobre África. Con estos datos se han calculado los estadísticos para toda la serie, por estación, y agrupados por Isla.

A continuación, en la Figura 11 se muestra los gráficos boxplot de PM10 para cada estación y con un color determinado para cada isla:

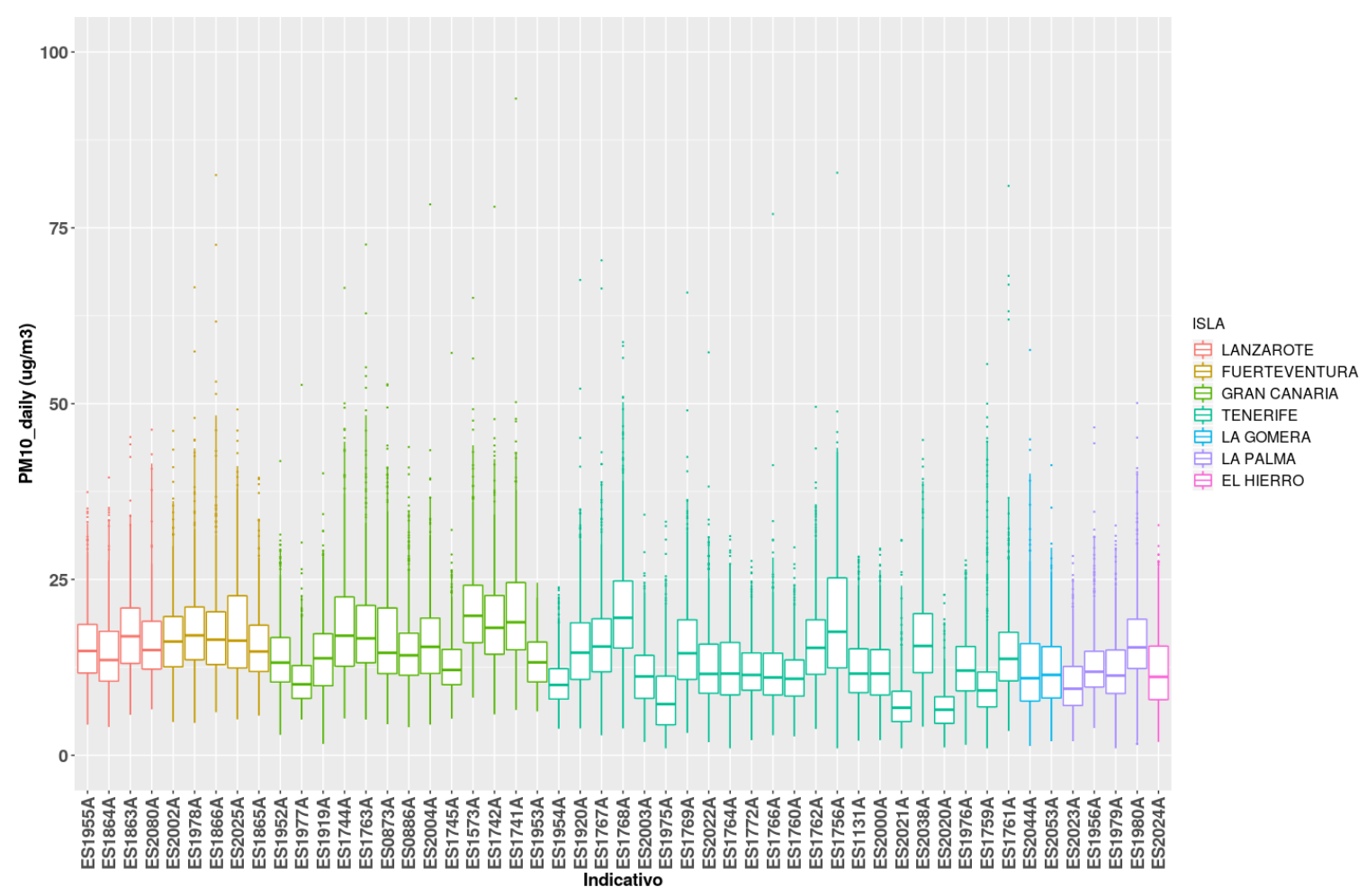

Figura 11. Boxplot de PM10 $\left(\mu \mathrm{g} / \mathrm{m}^{3}\right)$ por estaciones e islas.

De estos gráficos se puede concluir que para todas las estaciones el percentil 75 se encuentra por debajo de $25 \mu \mathrm{g} / \mathrm{m}^{3}$. Valores superiores a $50 \mu \mathrm{g} / \mathrm{m}^{3}$ se corresponden con "outliers" de la serie. No se observan valores superiores a $100 \mu \mathrm{g} / \mathrm{m}^{3}$ en los episodios sin intrusión africana. 


\subsection{Superaciones de umbrales por isla}

Utilizando todas las estaciones de la Red de Vigilancia de Calidad del Aire del Gobierno de Canarias se ha calculado (Figura 12) el número de superaciones que se producen en el periodo 2010-2017 para los umbrales establecidos en el "Índice Nacional de Calidad del Aire", que para el PM10 son de $0-20 \mu \mathrm{g} / \mathrm{m}^{3}$, de $20-35 \mu \mathrm{g} / \mathrm{m}^{3}$, de $35-50 \mu \mathrm{g} / \mathrm{m}^{3}$, de $50-100 \mu \mathrm{g} / \mathrm{m}^{3}$ y de $100-1200$ $\mu \mathrm{g} / \mathrm{m}^{3}$.

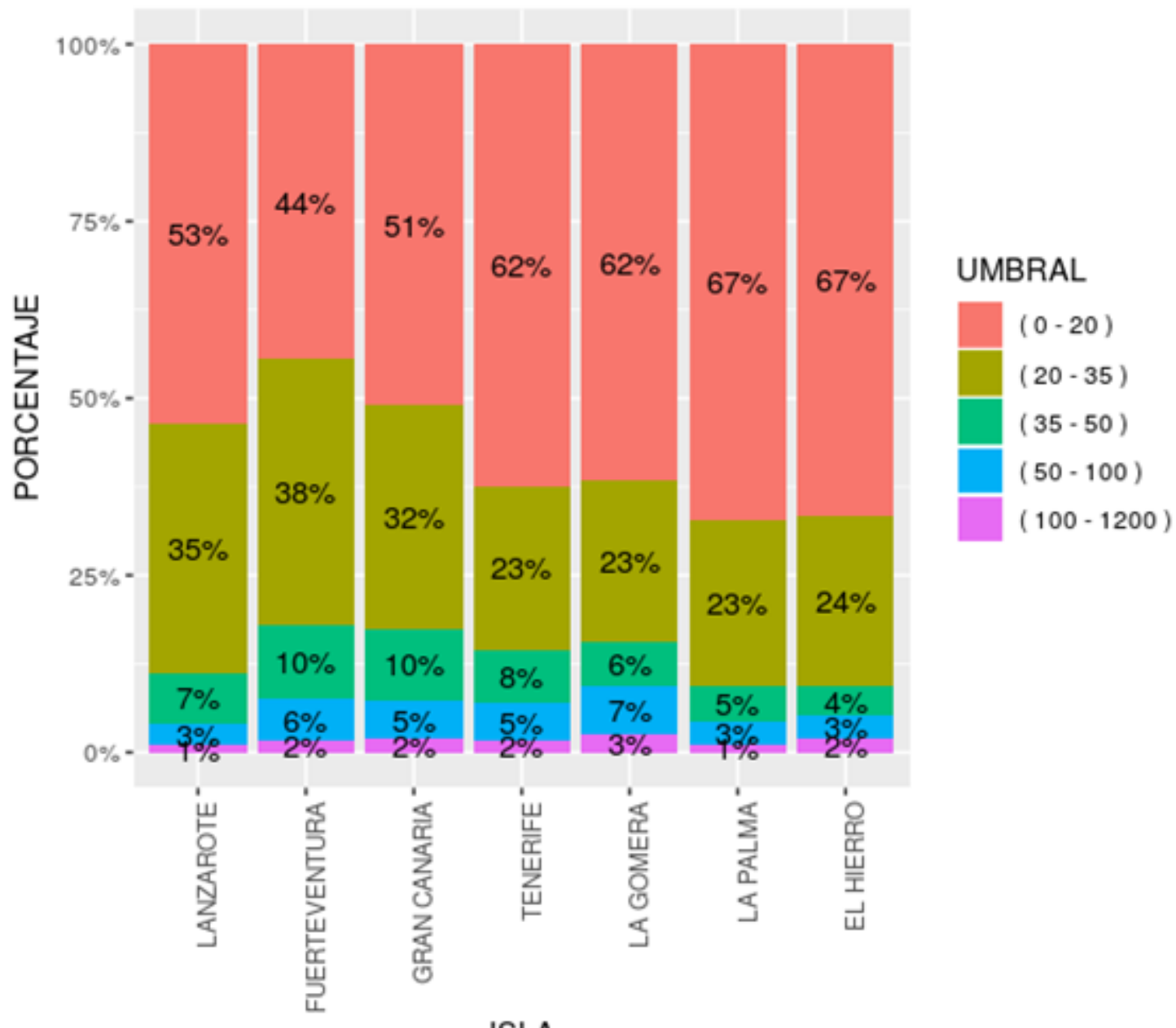

ISLA

Figura 12. Porcentajes de superación de diferentes umbrales de PM10 por isla.

Se observa que para el rango de $100-1200 \mu \mathrm{g} / \mathrm{m}^{3}$ el porcentaje de ocurrencia es igual o inferior al 3\%. Los rangos de $35-50 \mu \mathrm{g} / \mathrm{m}^{3}$, de $50-100 \mu \mathrm{g} / \mathrm{m}^{3}$ acaecen en porcentajes igual o inferior al $10 \%$. Para el rango de $20-35 \mu \mathrm{g} / \mathrm{m}^{3}$ se percibe diferencias entre las islas orientales y las occidentales. Mientras que las orientales muestran porcentajes de PM10 en el intervalo 20-35 $\mu \mathrm{g} / \mathrm{m}^{3}$ superior al $30 \%$, las occidentales no llegan al $25 \%$. Acorde con lo anterior, para el rango $0-20 \mu \mathrm{g} / \mathrm{m}^{3}$ de PM10, las islas occidentales muestran porcentajes por encima del $60 \%$ mientras que en el caso de las islas orientales los porcentajes se sitúan por debajo del 53\%. 


\section{CASOS DE ESTUDIO}

En este apartado se describen los patrones sinópticos presentes en cada uno de los cuatro episodios tipo a través de reanálisis meteorológicos de modelos numéricos de predicción y las observaciones. Para ello, se analizan variables de modelos de interés desde el punto de vista sinóptico y datos de observación proveniente de distintas fuentes: red de calidad del aire (PM10), imágenes de satélite, datos de AOD y datos de visibilidad.

\subsection{Episodios que afectan con mayor intensidad a las Islas más occidentales}

\subsubsection{Episodio del 4 al 6 de febrero de 2013}

\section{Entorno sinóptico}

En la Figura 13 se muestra la presión a nivel de superficie (contornos en negro) y en sombreado la temperatura en el nivel de $850 \mathrm{hPa}$. El patrón sinóptico que se expone a continuación, indicaba la presencia de un anticiclón de $1036 \mathrm{hPa}$ situado al norte de Azores y que se extendía hasta el norte de África, donde se formaba el dipolo orográfico en el Atlas africano, el flujo reinante en niveles bajos sobre las islas era de componente este. Al sur de Canarias, se constata una dorsal cálida en $850 \mathrm{hPa}$ señal de la entrada de la masa de aire cálida africana.

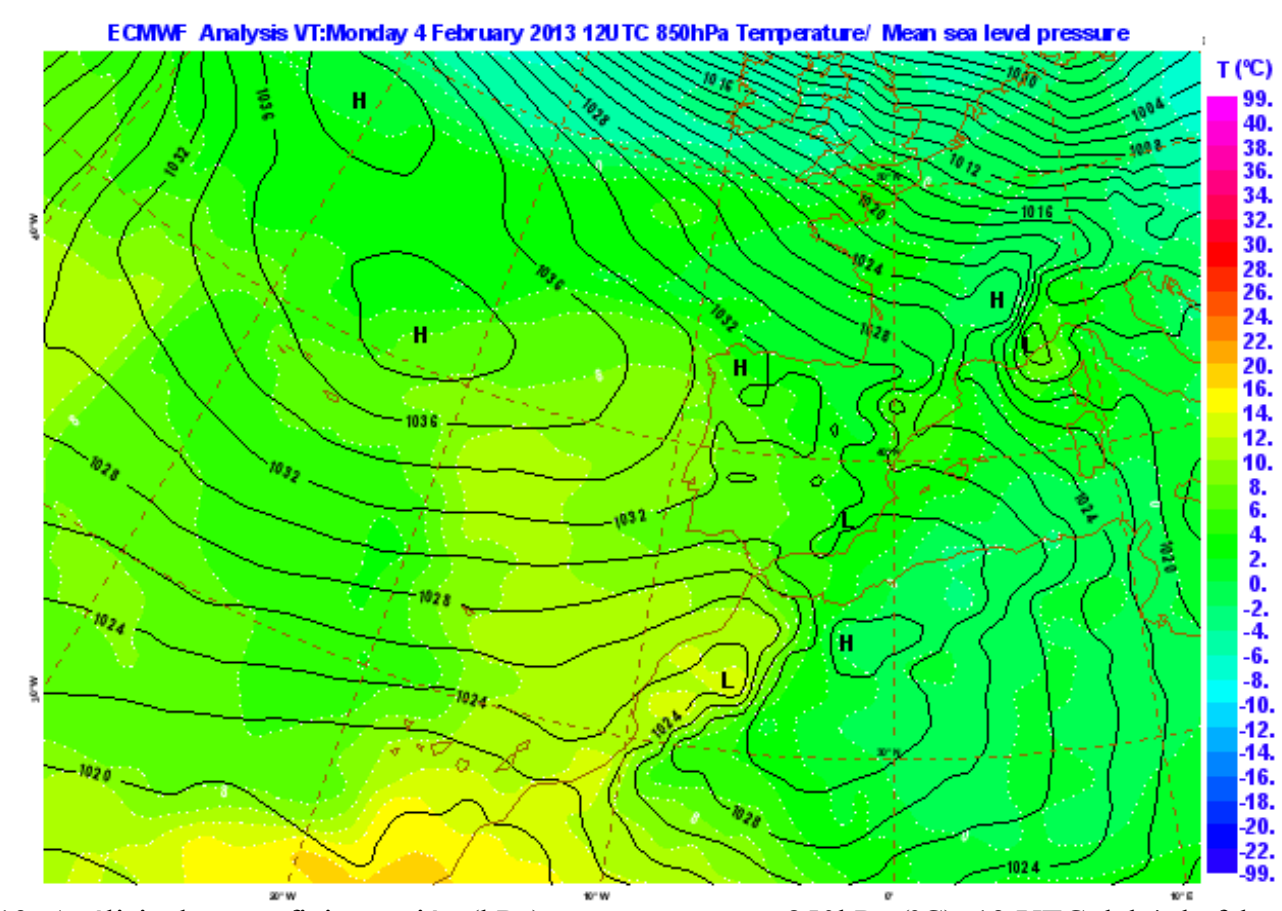

Figura 13. Análisis de superficie presión (hPa), y temperatura a $850 \mathrm{hPa}\left({ }^{\circ} \mathrm{C}\right) .12$ UTC del 4 de febrero de 2013.

A continuación, se muestra el mapa del nivel de 500 hPa (Figura 14). En él se representa la temperatura sombreada y la altura geopotencial en contornos en negro. La troposfera media en el entorno sinóptico del área de interés, mostraba una circulación en omega, con dorsal cálida 
que se extendía desde el continente africano hacia el sur de Azores y la Península, señal que evidencia el desplazamiento hacia el océano de la masa de aire continental africana.

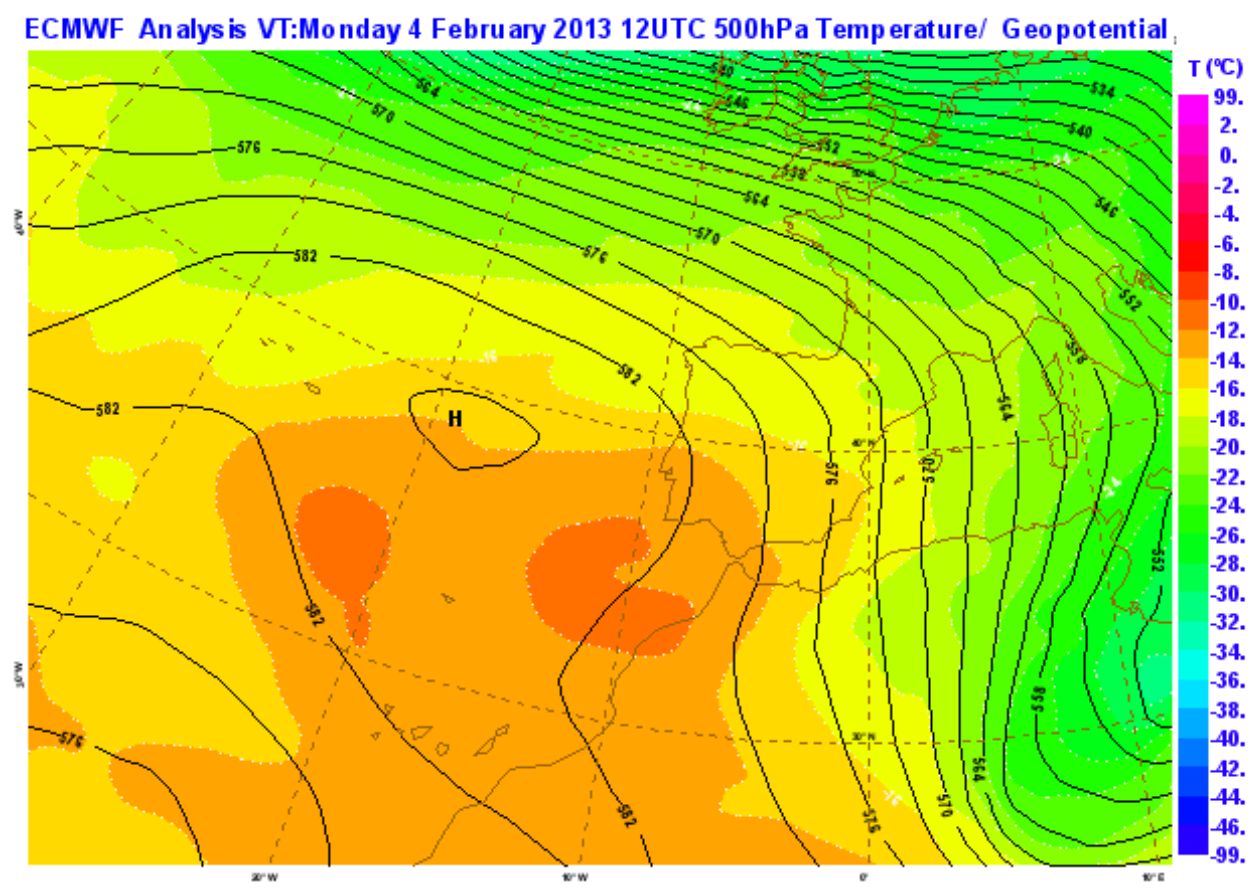

Figura 14. Análisis temperatura $\left({ }^{\circ} \mathrm{C}\right)$ y geopotencial $(\mathrm{mgp})$ a $500 \mathrm{hPa} .12$ UTC del 4 de febrero de 2013.

En la Figura 15 se muestra la altura media del geopotencial de $700 \mathrm{hPa}$ durante el episodio. Durante esta intrusión de polvo, se observó el alta de Azores afectando a las islas y bajos valores de geopotencial sobre el continente europeo extendiéndose hasta la cuenca mediterránea y la costa norte de África. Se observa en este nivel como el alta quedaba confinada a la zona de Azores y oeste de Portugal, y por tanto la entrada de masa de aire sahariana tuvo lugar en niveles inferiores asociada al viento intenso debido al anticiclón norafricano de superficie.

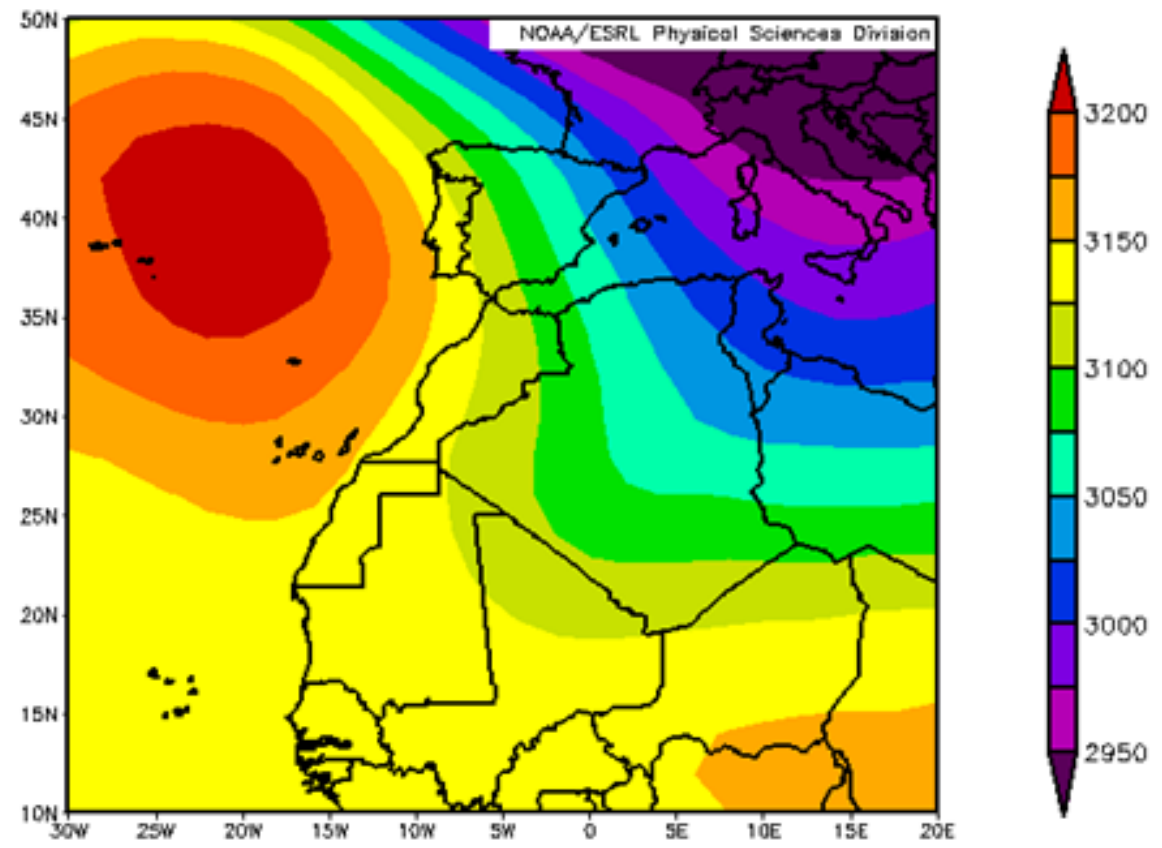

Figura 15. Altura geopotencial media (mgp) en 700 hPa (20th Century Reanalysis V2c), del 4 al 6 de febrero de 2013. 


\section{$\underline{\text { Observación }}$}

\section{PM10}

Los datos recogidos en la red de calidad del aire durante el episodio muestran que las concentraciones más elevadas del episodio afectaron a las islas occidentales (ver Figura 16) durante el día 5 de febrero y los picos máximos tuvieron lugar en la isla de Tenerife con valores de hasta $610 \mu \mathrm{g} / \mathrm{m}^{3}$. El valor más elevado del índice ARTI en el punto de la matriz más cercano a Tenerife (punto de la matriz denominado grid_8, este punto de grid se sitúa en N28.3-W16.3) para ese día fue $92 \%$ (esto expresa el porcentaje de tiempo que una masa de aire viaja sobre África antes de alcanzar el punto receptor) a 1000 metros. 


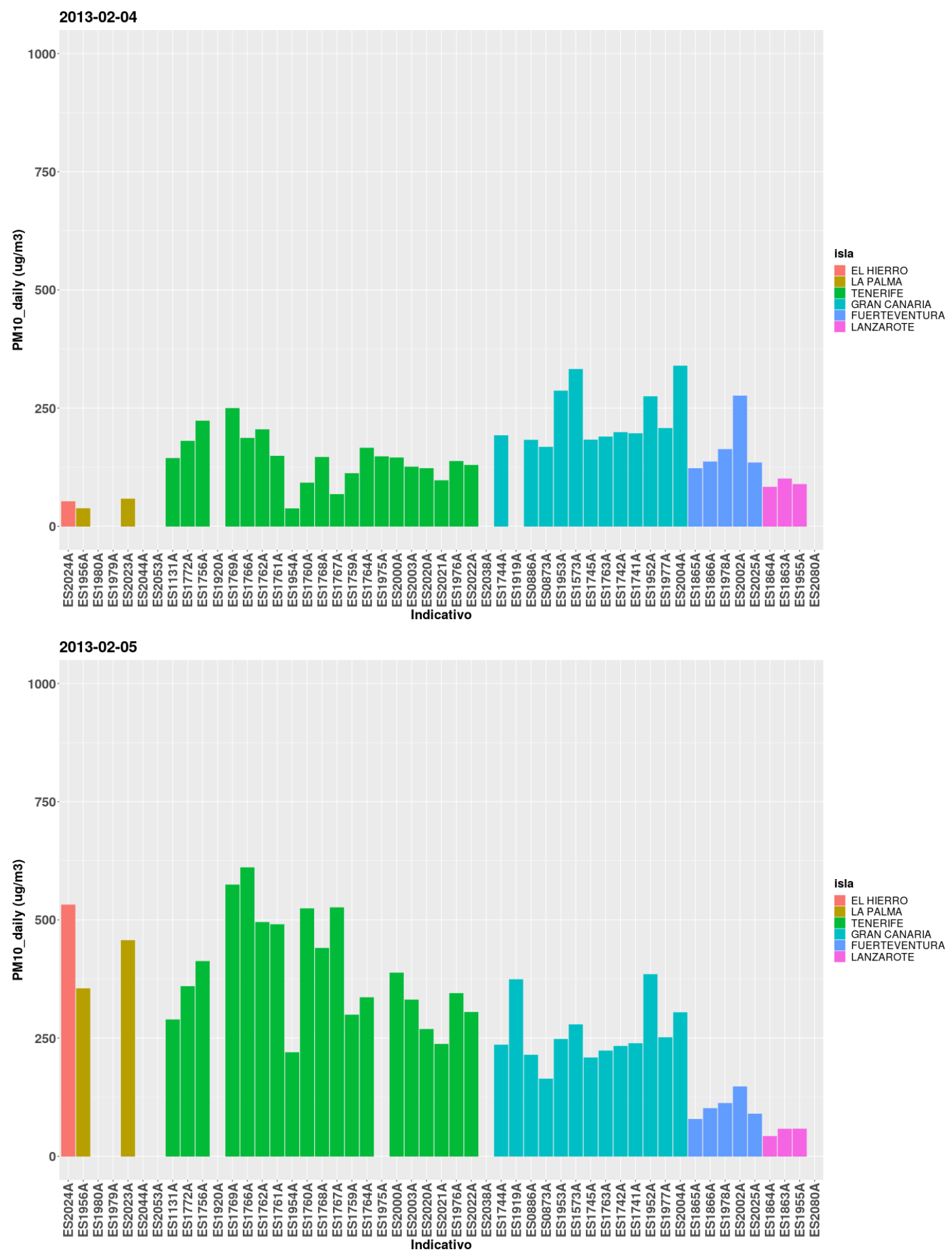

Figura 16. Valores máximos de PM10 $\left(\mu \mathrm{g} / \mathrm{m}^{3}\right)$ registrados por islas durante el evento del 4 al 6 de febrero de 2013.

\section{Visibilidad}

El mapa (Figura 17) muestra la visibilidad mínima registrada durante el episodio en decámetros. A pesar de que los valores más altos registrados de PM10 durante el episodio se obtuvieron 
durante el día 5 de febrero y en las islas occidentales, los mínimos de visibilidad tuvieron lugar el día anterior (4 de febrero) y en Gran Canaria, donde la visibilidad se vio reducida hasta $1 \mathrm{~km}$.

VIS18 [4 de febrero de 2013]
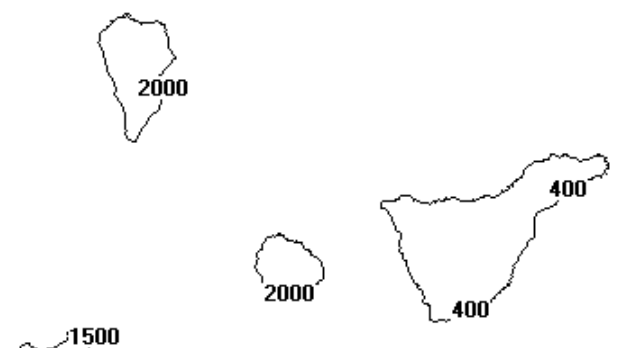

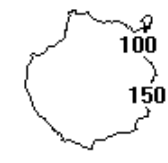

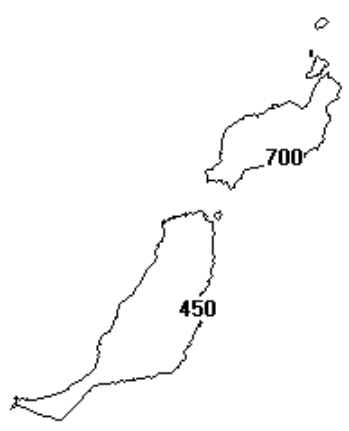

Figura 17: Visibilidad mínima (en decámetros) durante el periodo del 4 al 6 de febrero de 2013.

\section{MODIS}

La imagen de MODIS (Figura 18) de color real o color natural para el día 4 de febrero, muestra el transporte de polvo desde el continente africano hacia Canarias. En el momento de la captura se aprecia el polvo afectando a Lanzarote, Fuerteventura y a la vertiente este de Gran Canaria. En esta zona oriental del archipiélago, el AOD era aproximadamente de 1.1, mientras que en la parte occidental era de 0.38 , hay que recordar que en días limpios de polvo el AOD es inferior a 0.05 .

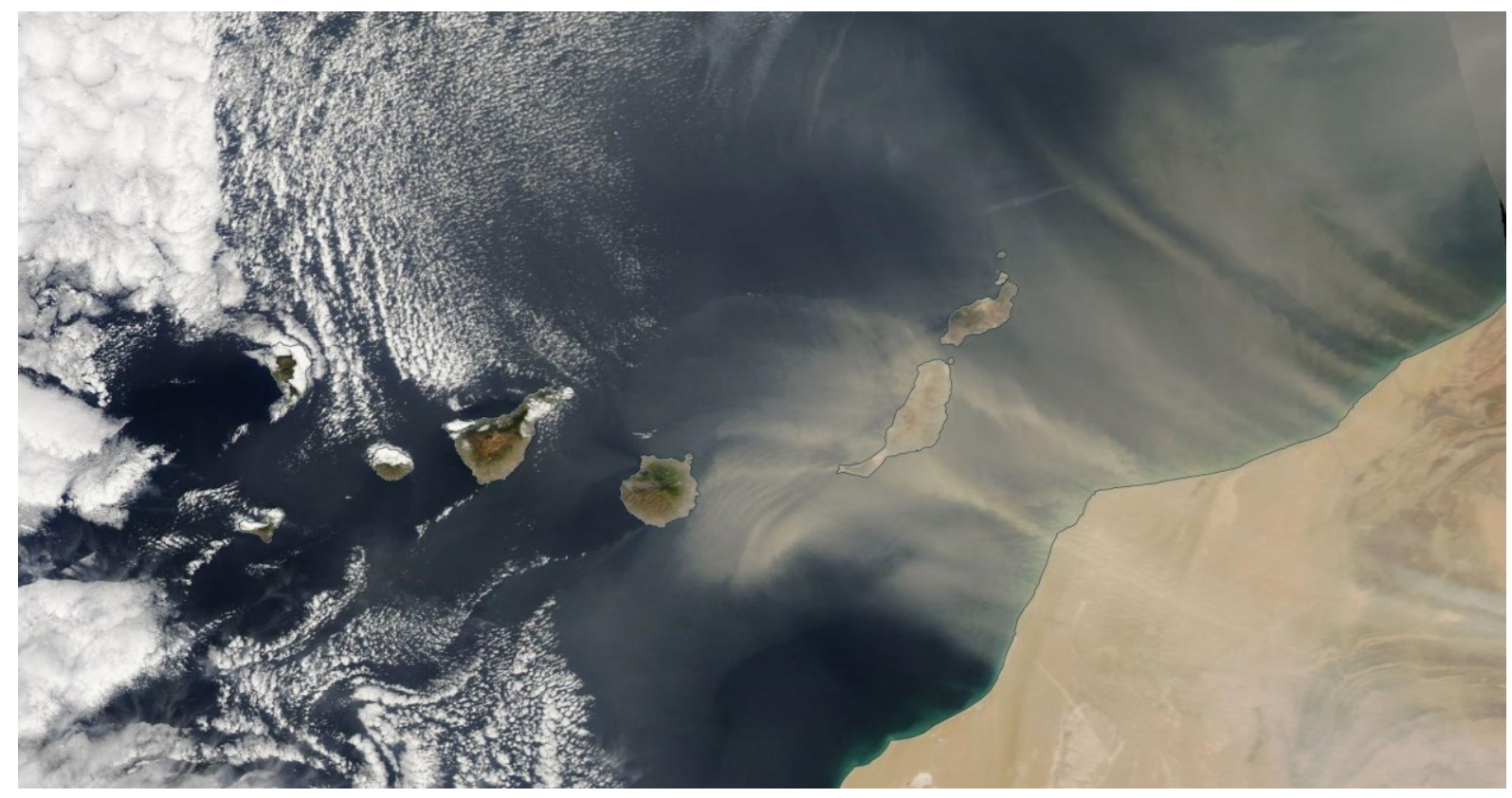

Figura 18. Imagen MODIS del 4 de febrero de 2013. 


\subsubsection{Episodio del 25 al 28 de diciembre de 2015}

\section{Entorno sinóptico}

En la Figura 19 se observa, por un lado, un sistema de bajas presiones que se situaba sobre Azores de $1006 \mathrm{hPa}$ y un alta sobre la península ibérica y norte de África de unos $1034 \mathrm{hPa}$. Cuña anticiclónica que se extendía hasta Canarias con presión en superficie de 1022 a $1024 \mathrm{hPa}$ y flujo de componente sur débil en niveles bajos sobre las islas.

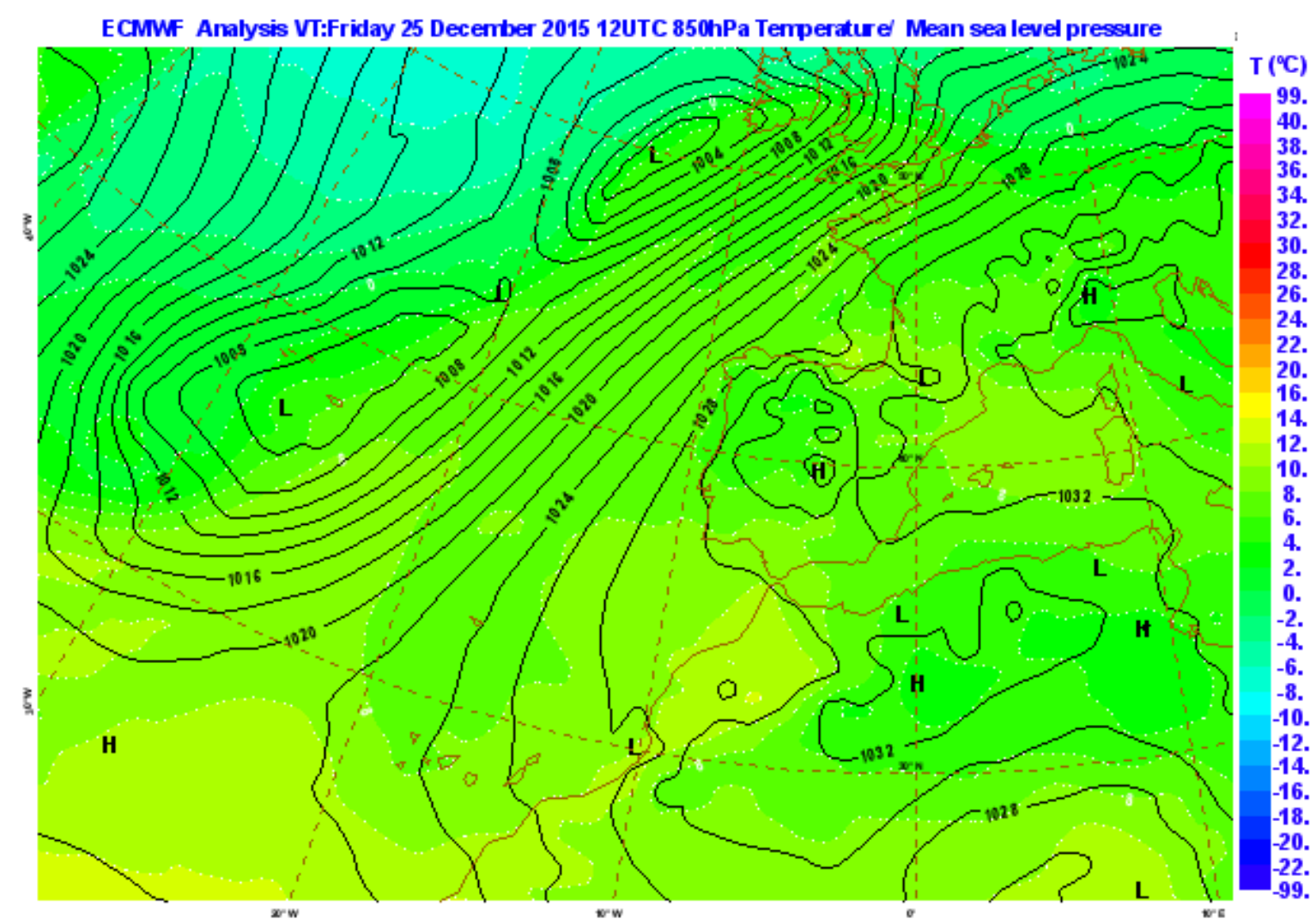

Figura 19. Análisis depresión en superficie $(\mathrm{hPa})$, y temperatura a $850 \mathrm{hPa}\left({ }^{\circ} \mathrm{C}\right) 12 \mathrm{UTC}$ del 25 de diciembre de 2015.

En el nivel de $500 \mathrm{hPa}$ (Figura 20) destaca la presencia de la dorsal cálida, con temperaturas en torno a $-10^{\circ} \mathrm{C}$, en el entorno de Canarias con flujo del suroeste débil. La dorsal cálida era señal inequívoca del desplazamiento sobre el archipiélago de la masa de cálida sahariana. Además, en este nivel se observa una dana, con temperaturas alrededor de $-18^{\circ} \mathrm{C}$ a $-20^{\circ} \mathrm{C}$, al sur de Baleares. 


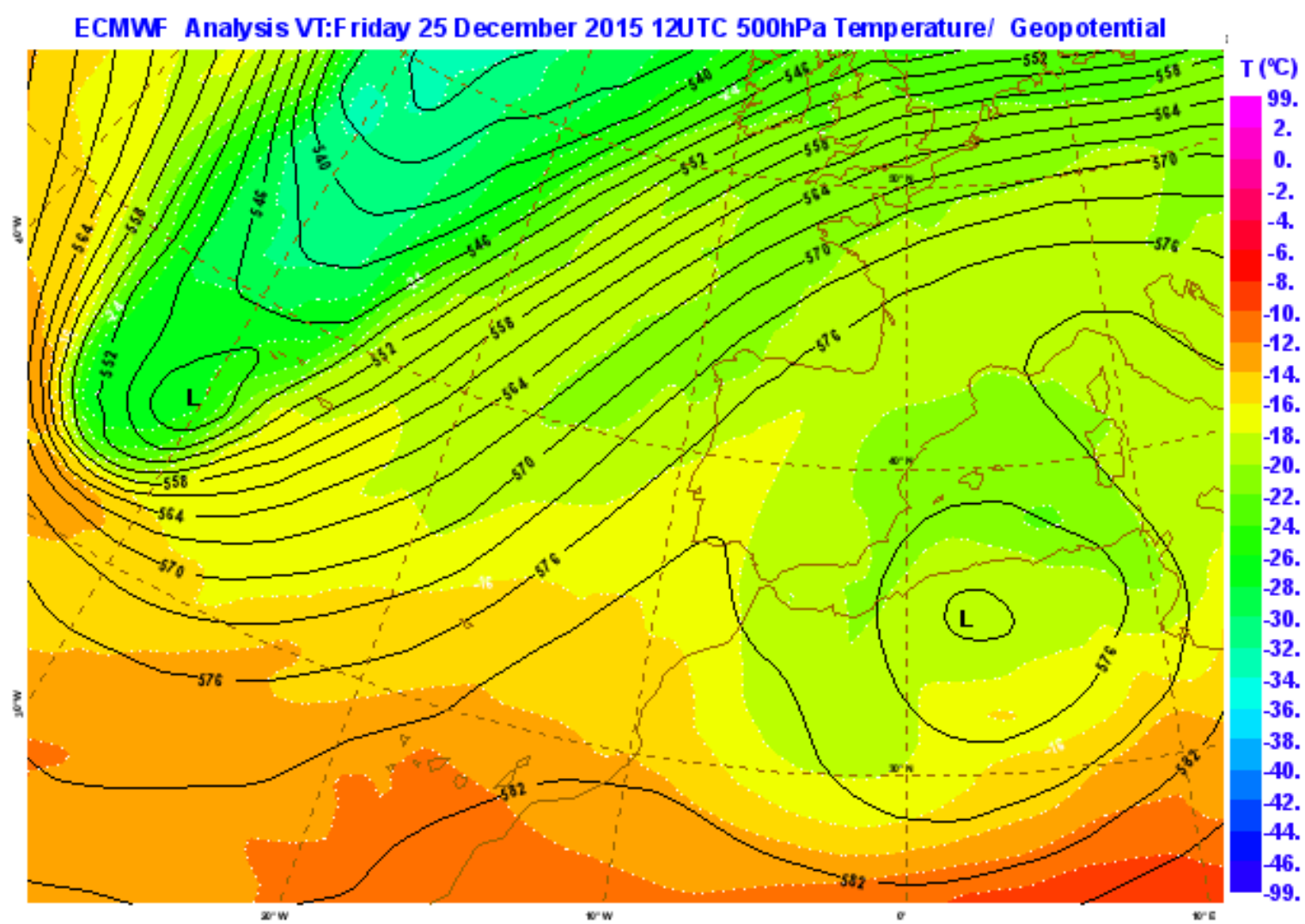

Figura 20. Análisis de temperatura $\left({ }^{\circ} \mathrm{C}\right)$ y geopotencial (mgp) a 500 hPa, 12 UTC del 25 de diciembre de 2015.

En la Figura 21, se observa predominio de altos valores de geopotencial en el nivel de $700 \mathrm{hPa}$ sobre el continente africano durante el episodio, con escaso gradiente latitudinal sobre África y bajos valores sobre el Atlántico Norte.

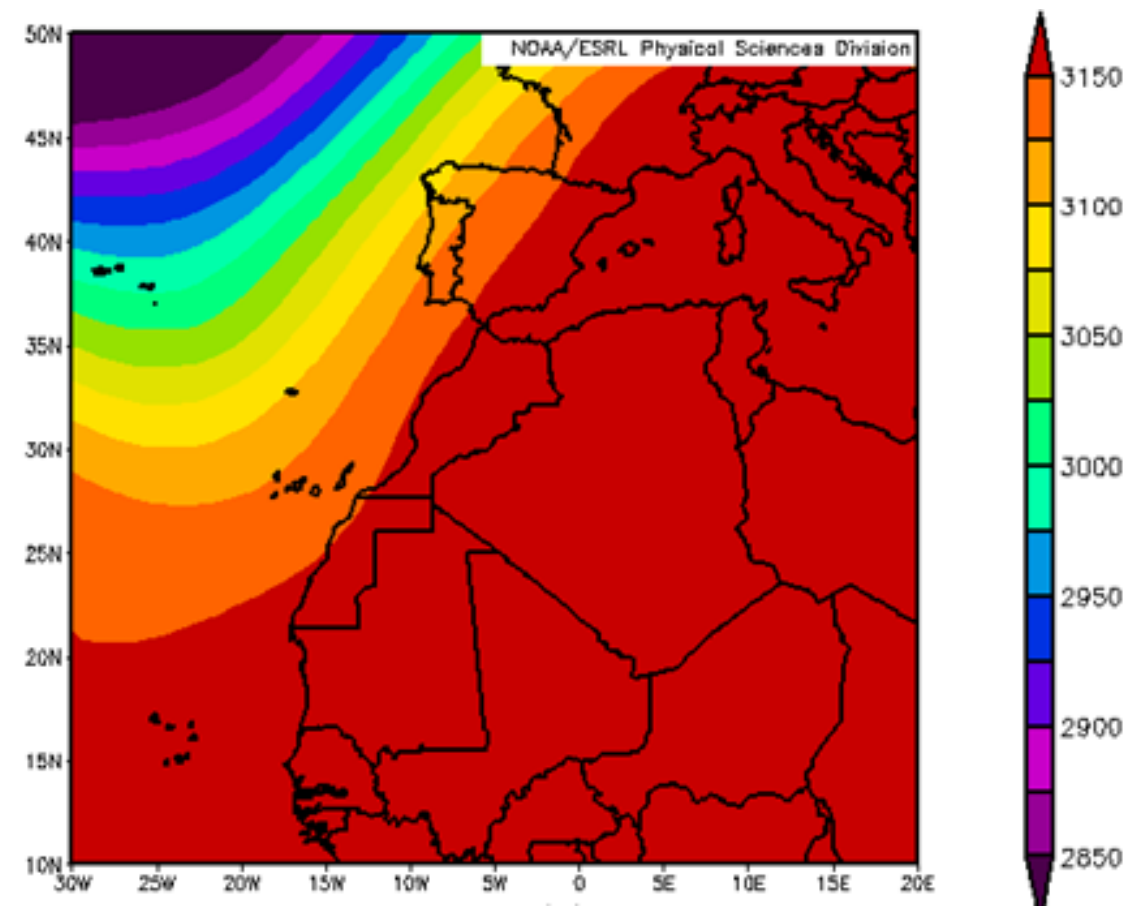

Figura 21. Altura geopotencial media en $700 \mathrm{hPa}$ (20th Century Reanalysis V2c ) del 25 al 28 de diciembre de 2015. 
Observación

PM10

Los datos registrados en la red de calidad del aire durante el episodio, muestran que las concentraciones más elevadas del evento afectaron a las islas occidentales (ver Figura 22) durante el día 26 de diciembre, con picos máximos en la isla de Tenerife de hasta $439 \mu \mathrm{g} / \mathrm{m}^{3}$. El valor más elevado del índice ARTI en el punto de la matriz más cercano a Tenerife (punto de la matriz denominado grid_8, este punto de grid se sitúa en N28.3-W16.3) para ese día fue $91 \%$ y tuvo lugar a 500 metros. 


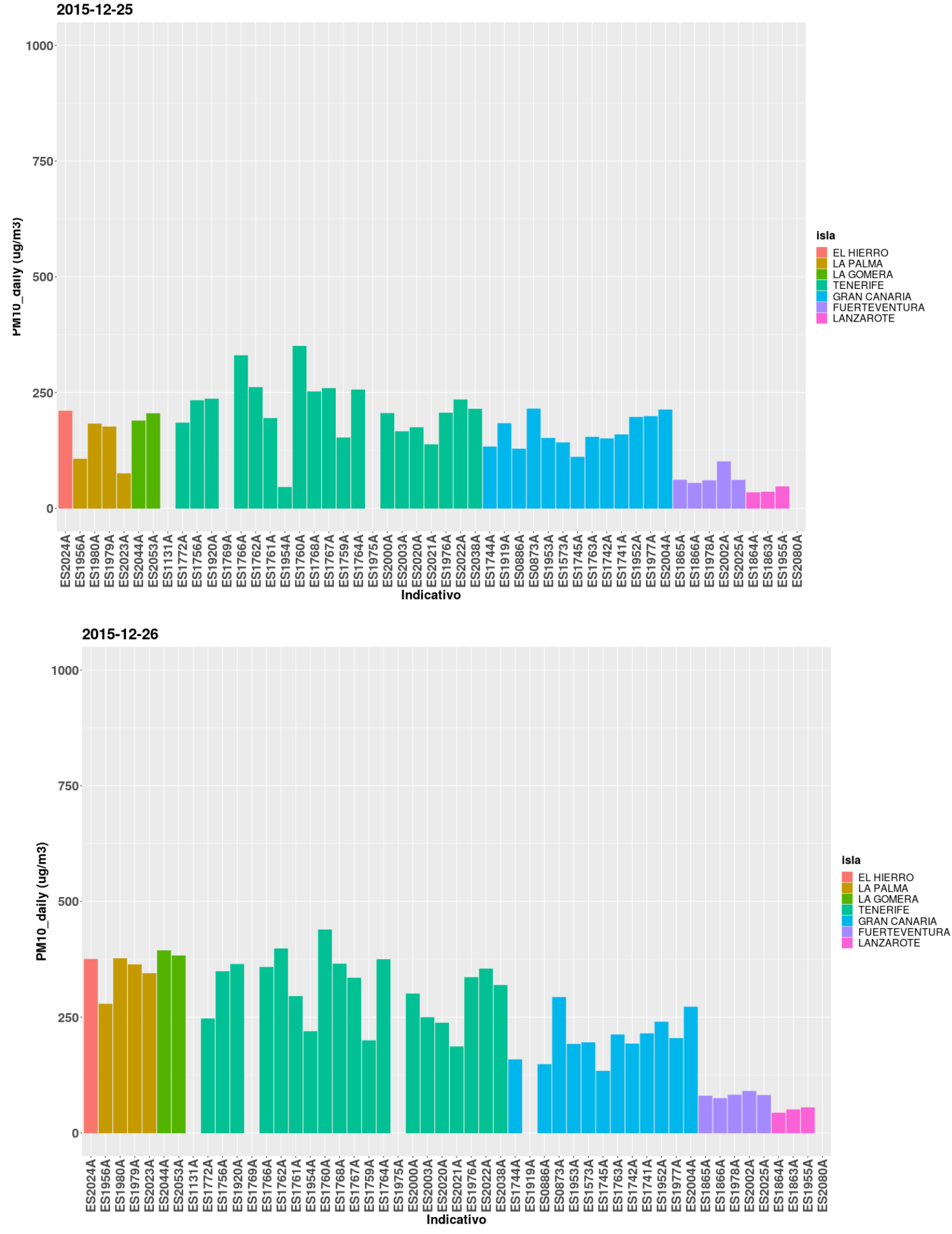

Figura 22. Valores máximos de PM10 $\left(\mu \mathrm{g} / \mathrm{m}^{3}\right)$ registrados por islas durante el evento del 24 al 28 de diciembre de 2015 . 


\section{Visibilidad}

Al igual que en el episodio anterior, los mínimos de visibilidad (Figura 23) tuvieron lugar el día 25 de diciembre en Gran Canaria, y esta se redujo hasta $2.8 \mathrm{~km}$. Sin embargo, las concentraciones más elevadas de PM10 fueron registradas durante el día 26 en la isla de Tenerife. La no coincidencia entre los valores de concentración máxima registrada y los mínimos de visibilidad, deja evidencias de la dificultad de predicción de variables subjetivas, como es el caso de la visibilidad.

VIS18 [25 de diciembre de 2015]
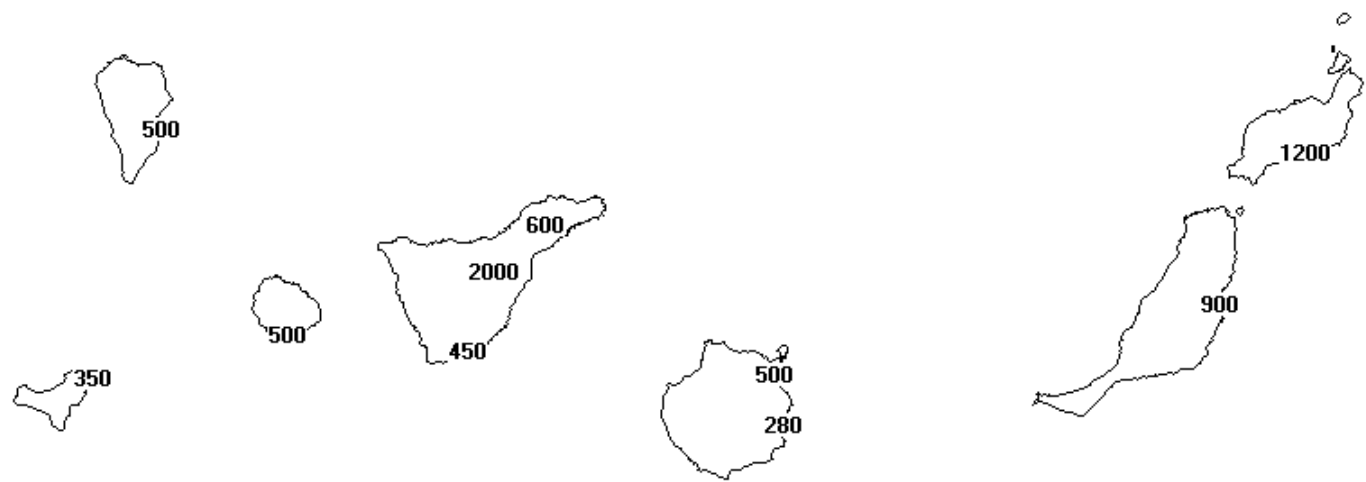

Figura 23. Visibilidad mínima (en decámetros) durante el periodo del 25 al 28 de diciembre de 2015.

\section{MODIS}

A continuación, se muestra la secuencia de imágenes de MODIS para los días 25,26 y 27 de diciembre (Figuras 24, 25 y 26). Es interesante ver como una banda de polvo barre de forma retrógrada (en el caso del polvo africano lo habitual es el desplazamiento del este hacia el oeste $\mathrm{y}$ en este caso es de oeste a este) las islas. Este inhabitual desplazamiento fue debido al acoplamiento de la banda de polvo con una estructura frontal asociada a una borrasca extratropical. En las imágenes se puede apreciar como el polvo afectaba a todas las islas el día 25 (con un AOD de 1.13 en todo el archipiélago), el día 26 afectaba principalmente a la mitad occidental (un AOD de 1.13 en las islas occidentales y Gran Canaria y un AOD de 0.35 en Fuerteventura y Lanzarote), mientras que el día 27 tenía un mayor impacto en las islas orientales (AOD de 0.06 en las islas occidentales y de un orden superior, AOD entre 0.45 y 0.70 , en las orientales). 


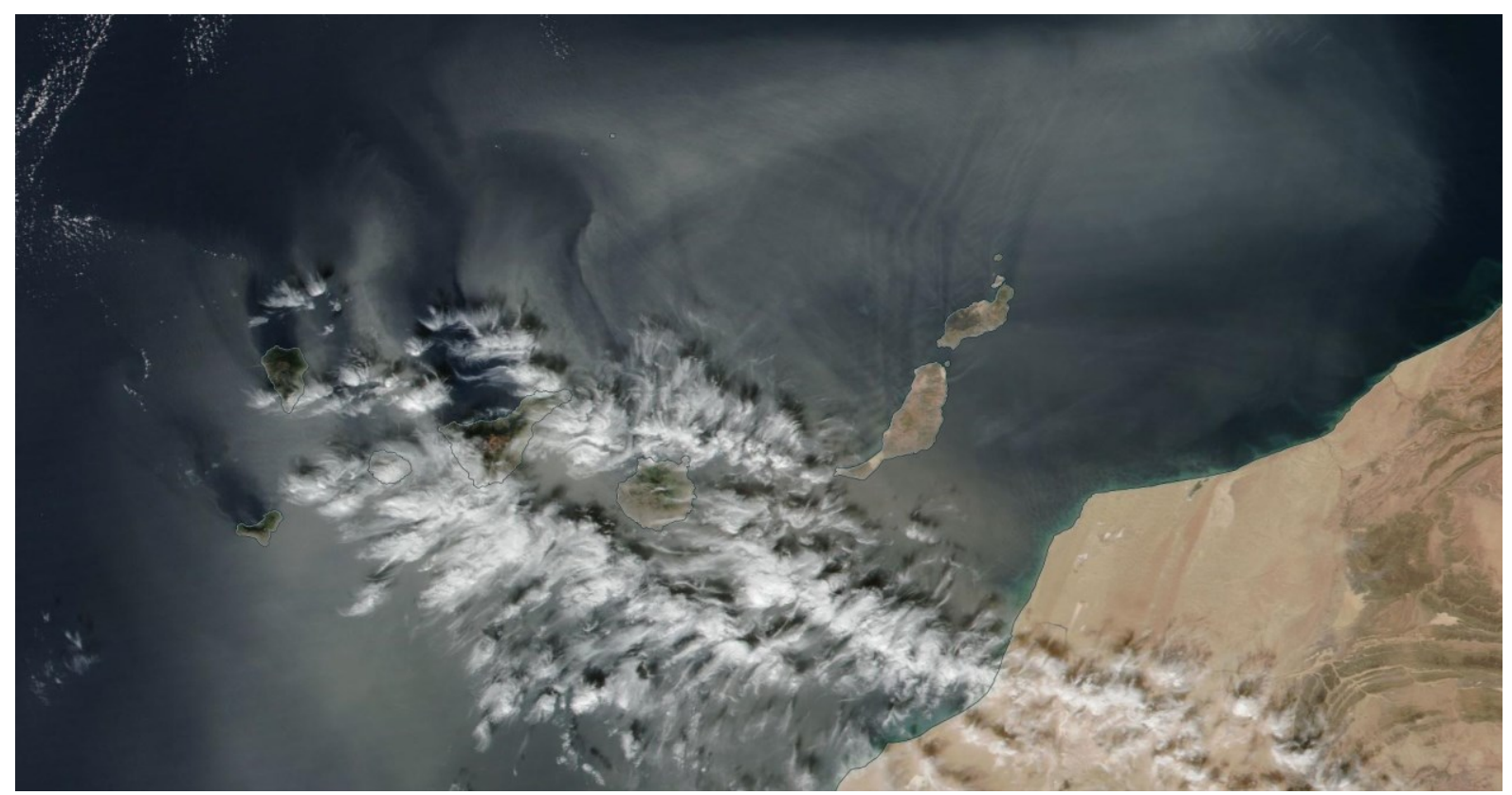

Figura 24. Imagen MODIS del 25 de diciembre de 2015.

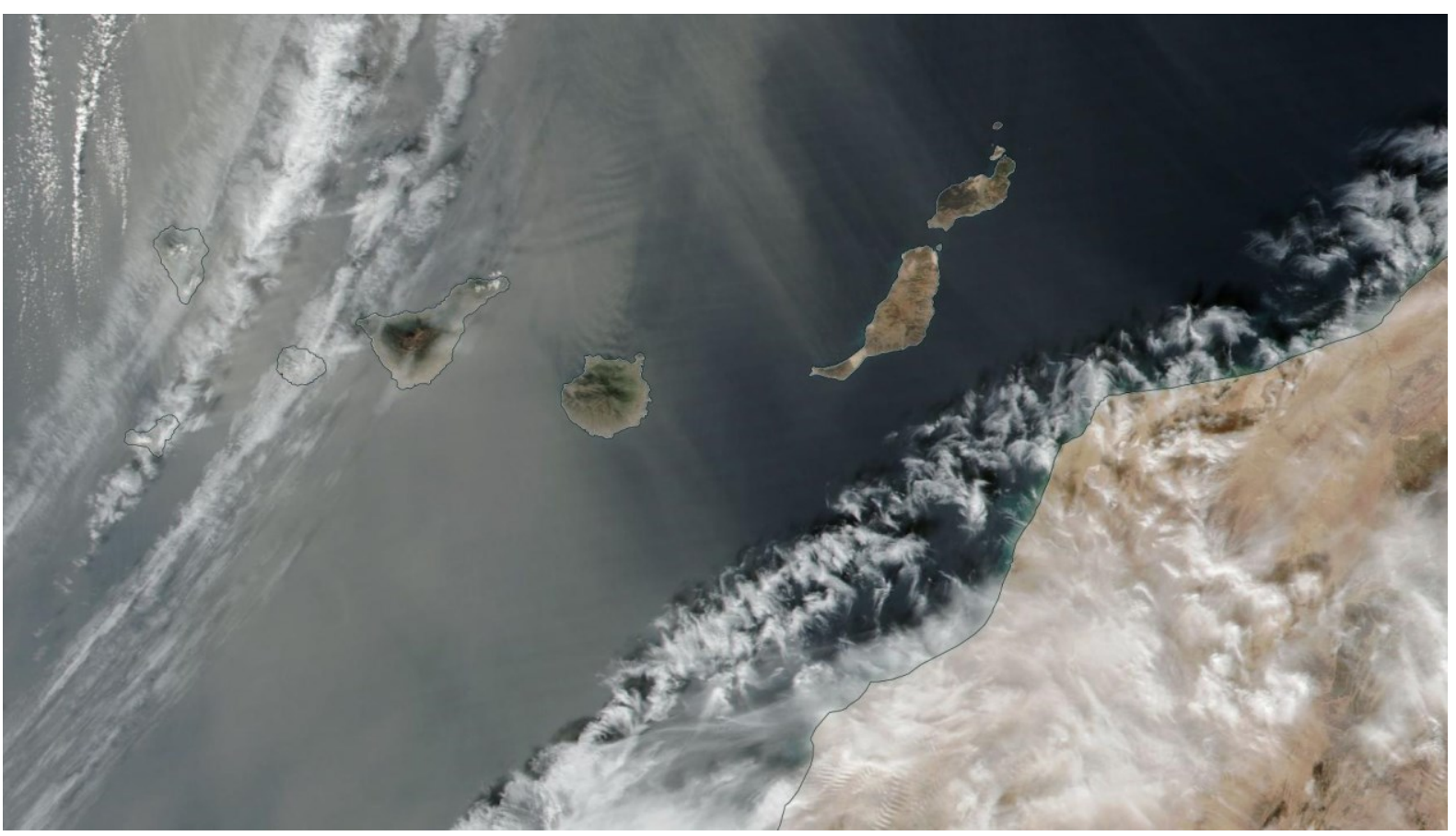

Figura 25. Imagen MODIS del 26 de diciembre de 2015. 


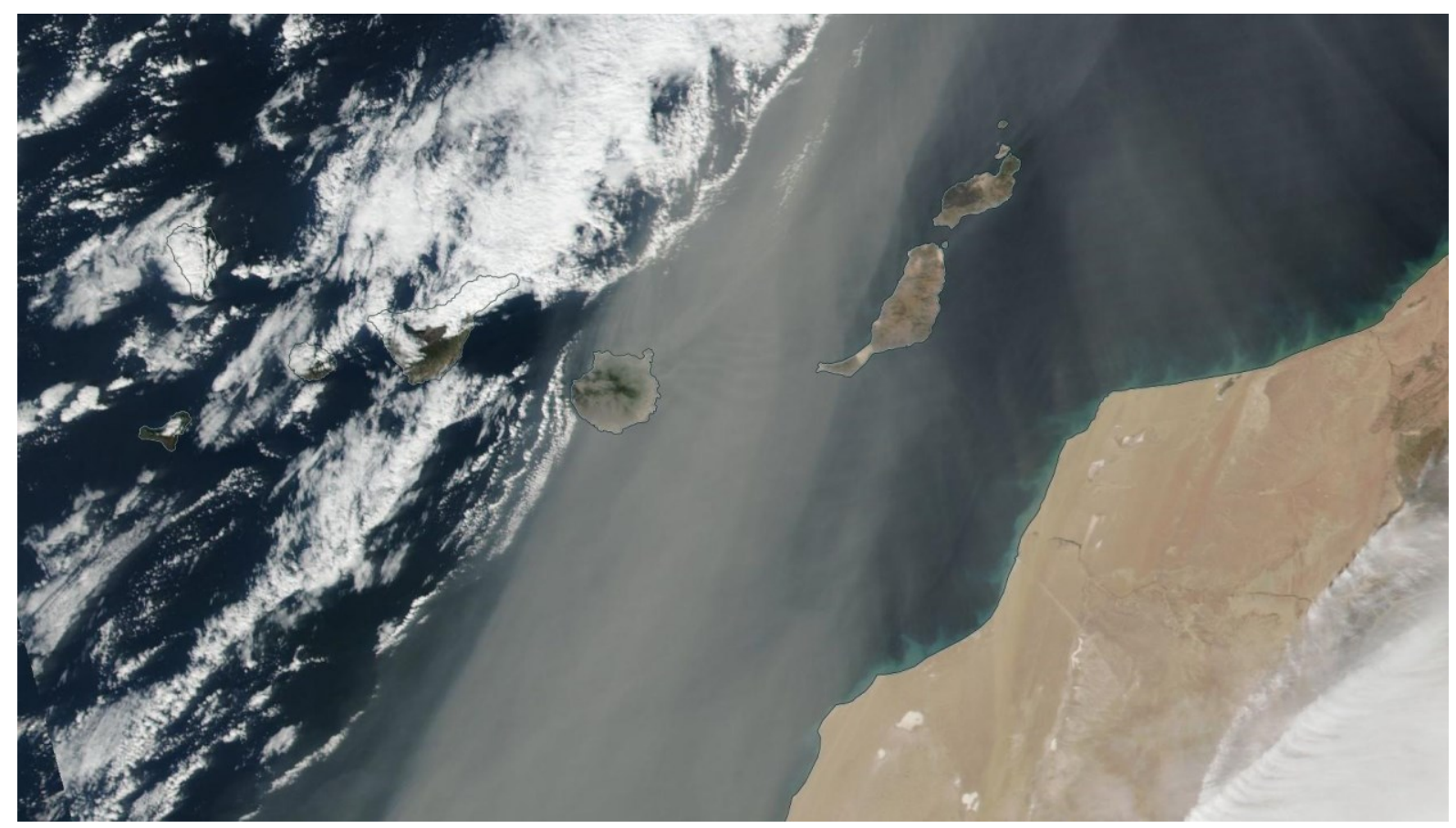

Figura 26. Imagen MODIS del 27 de diciembre de 2015.

\subsection{Episodios que afectan con mayor intensidad a las Islas más orientales}

\subsubsection{Episodio del 26 al 28 de noviembre de 2013}

\section{Entorno sinóptico}

En el análisis, correspondiente a las 12 UTC del día 26 de noviembre de 2013 (Figura 27), se observa un potente anticiclón de $1042 \mathrm{hPa}$ situado sobre las islas británicas que se extendía hacia el sur de Europa y dipolo orográfico en el Atlas con flujo de componente este sobre Canarias. 


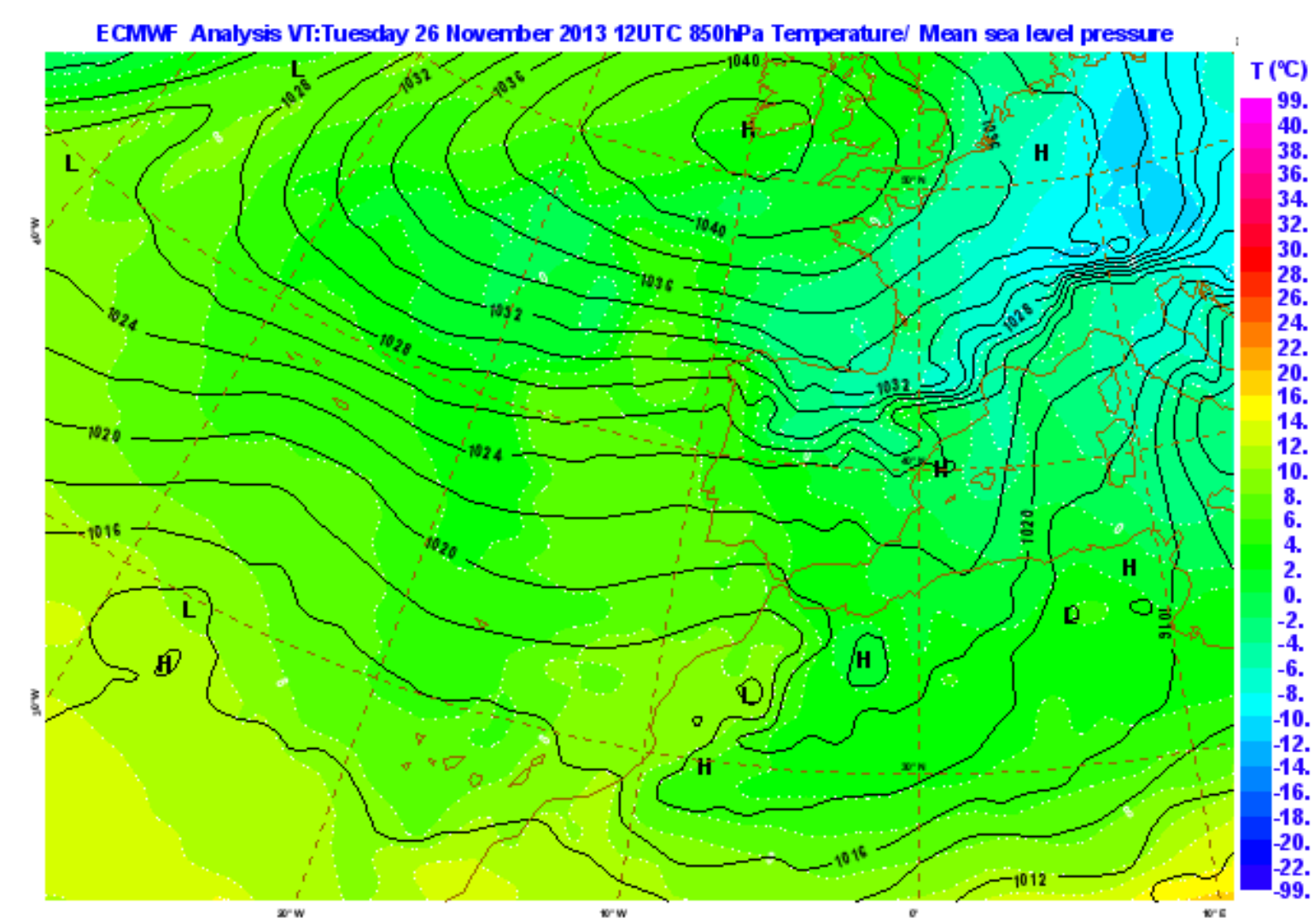

Figura 27. Análisis de presión en superficie $(\mathrm{hPa})$, y temperatura a $850 \mathrm{hPa}\left({ }^{\circ} \mathrm{C}\right) 12 \mathrm{UTC}$ del 26 de noviembre de 2013.

El nivel de 500hPa (Figura 28) muestra una dana situada al sur de Azores con temperaturas entre -22 a $-24{ }^{\circ} \mathrm{C}$. Además, en este nivel se observa sobre Canarias flujo del oeste y al este de las islas dorsal cálida señal de la masa de aire sahariana. 


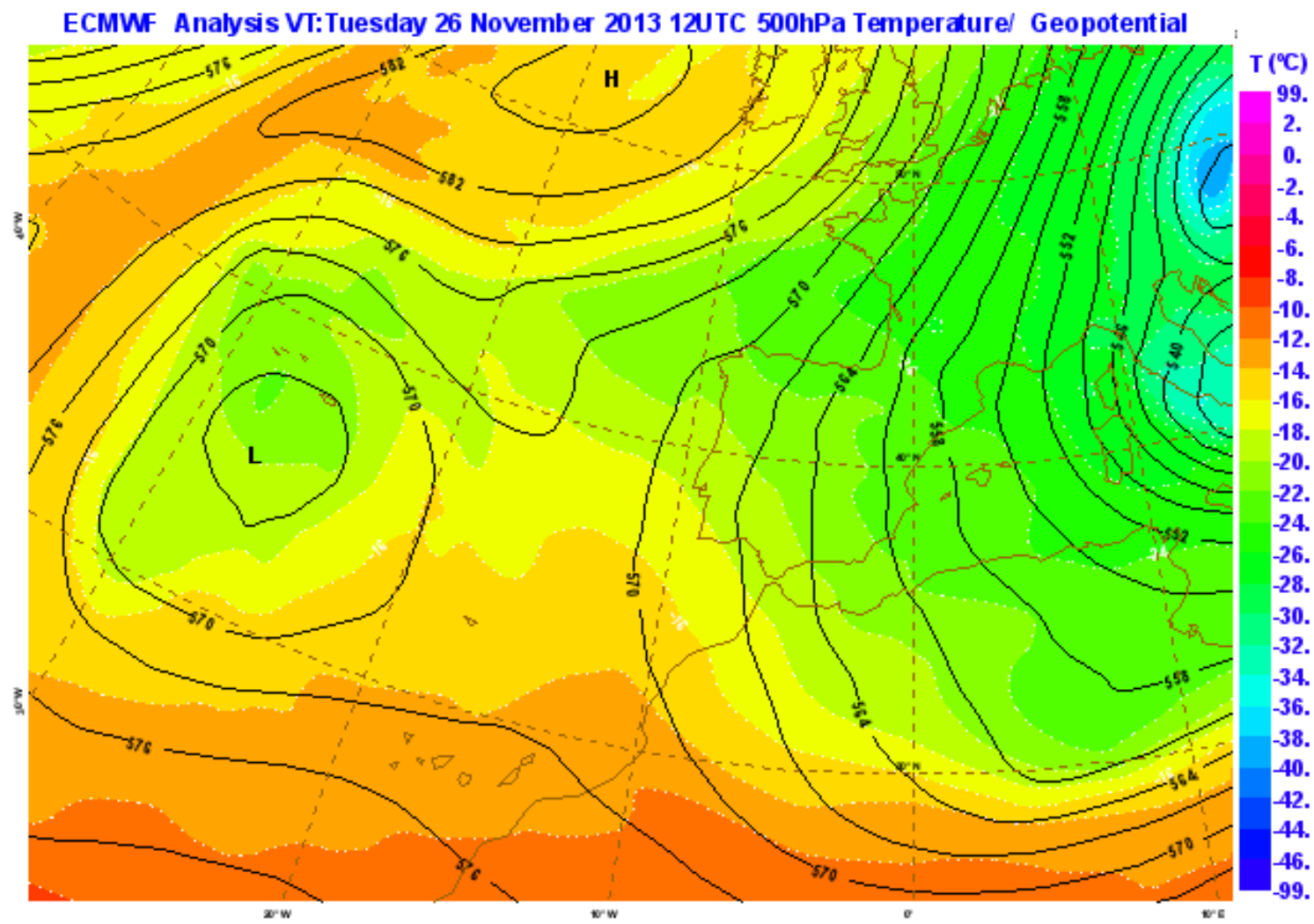

Figura 28. Análisis de temperatura $\left({ }^{\circ} \mathrm{C}\right)$ y geopotencial (mgp) a $500 \mathrm{hPa} .12$ UTC del 26 de noviembre de 2013.

El geopotencial medio en $700 \mathrm{hPa}$ (Figura 29) durante el episodio mostraba un marcado gradiente meridional, con valores bajos sobre Canarias y la cuenca mediterránea y altos valores de geopotencial en el interior del continente africano.

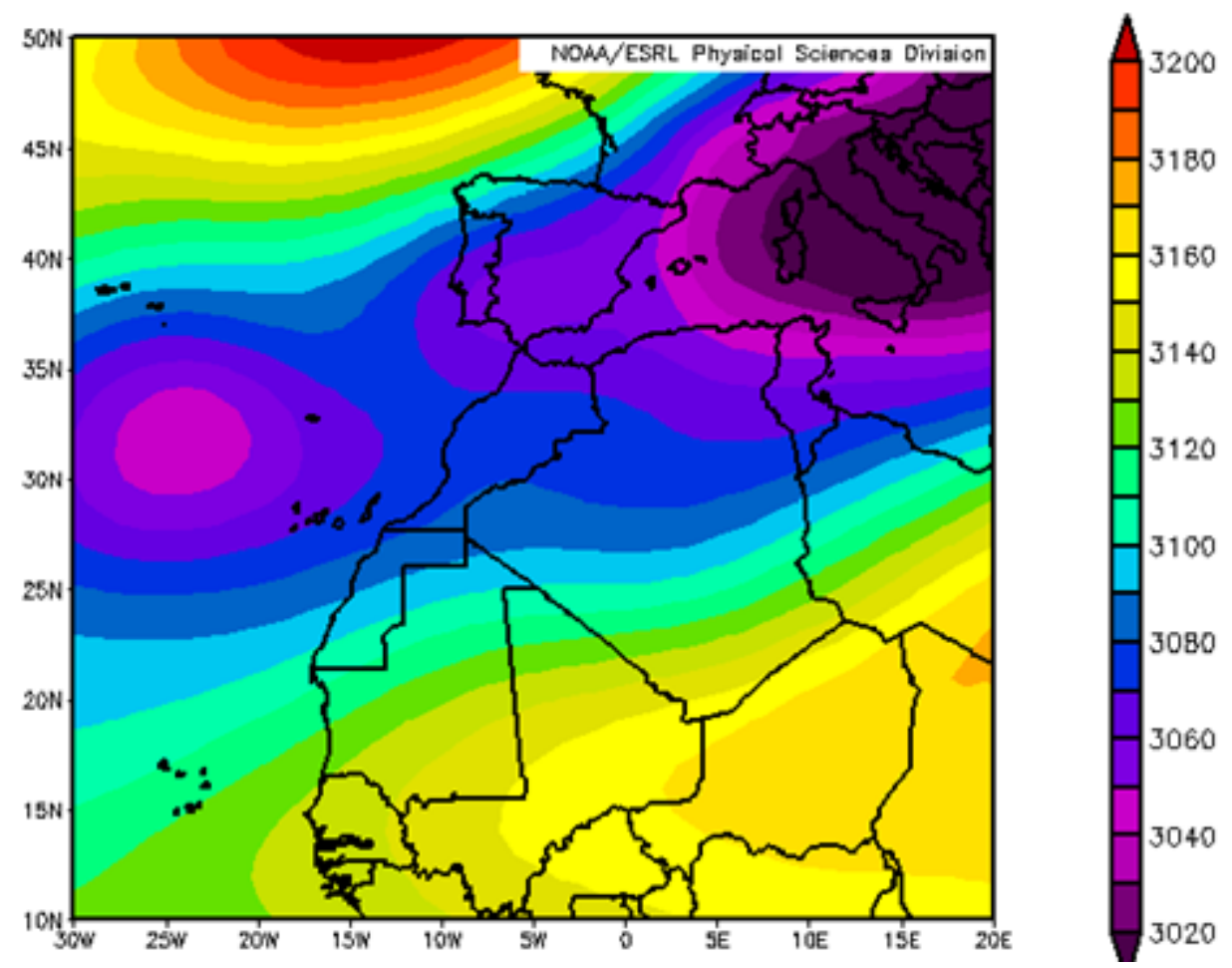

Figura 29. Altura geopotencial media en $700 \mathrm{hPa}$ (20th Century Reanalysis V2c), del 26 al 28 de noviembre de 2013. 


\section{Observación}

\section{PM10}

Los valores recogidos por la red de estaciones de calidad del aire (Figura 30) muestran que los valores más elevados se registraron en Fuerteventura el día 27, con valores de hasta 219 $\mu \mathrm{g} / \mathrm{m}^{3}$. 


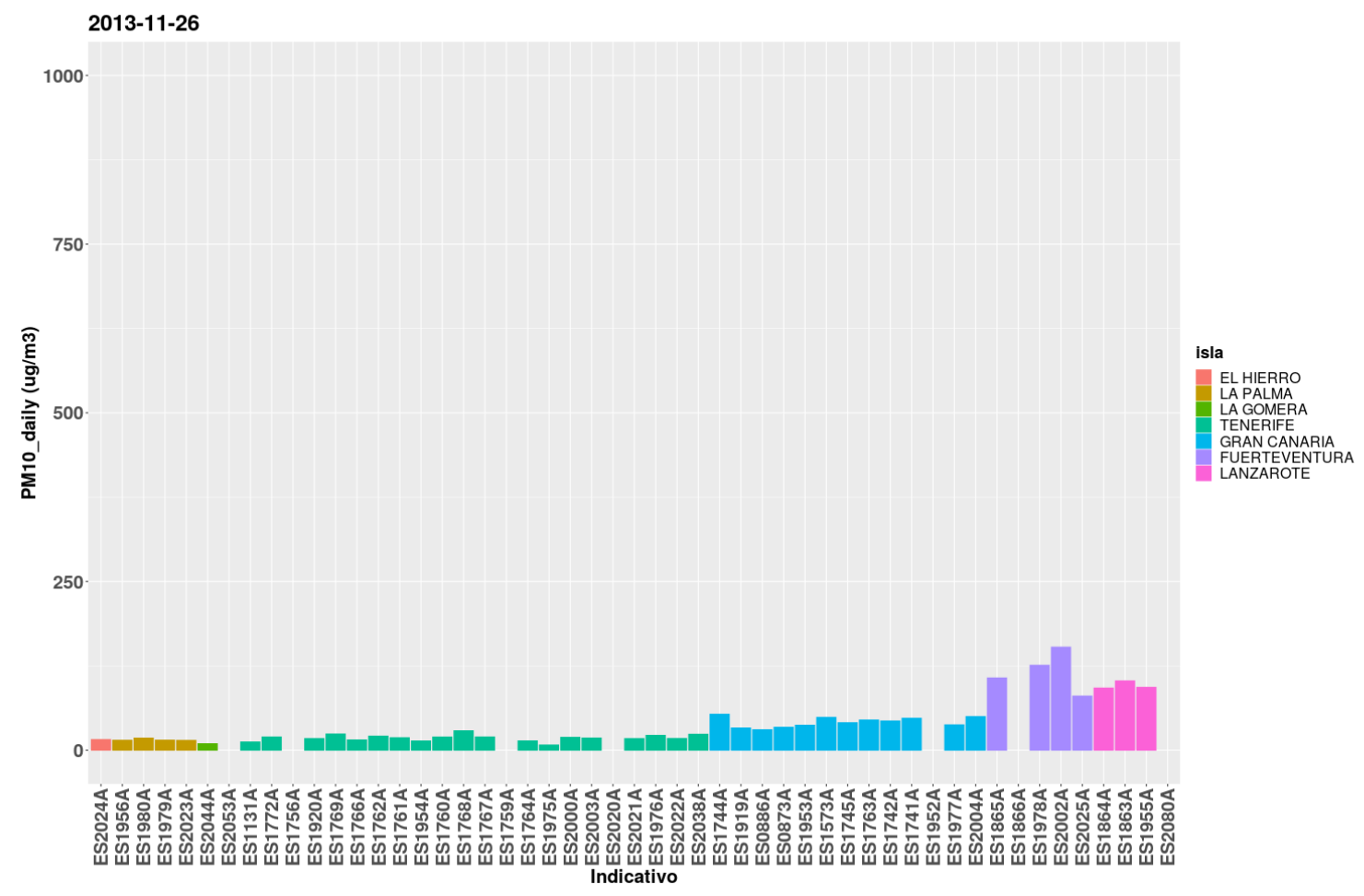

2013-11-27

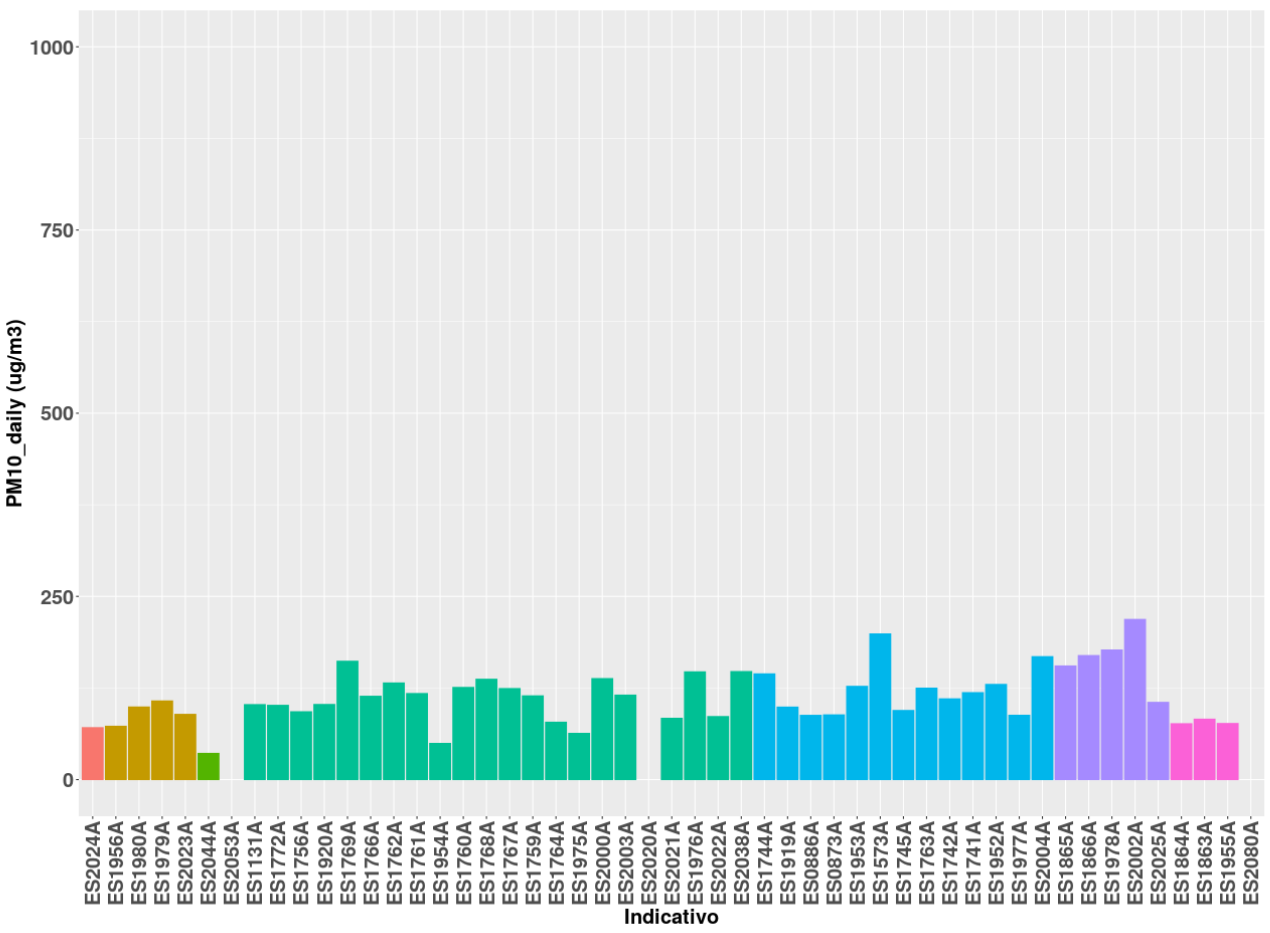

Figura 30. Valores máximos de PM10 $\left(\mu \mathrm{g} / \mathrm{m}^{3}\right)$ registrados por islas durante el evento del 25 al 28 de noviembre de 2013.

De los valores de índice ARTI en los puntos de grid 17,14 y 11 se desprende que la intrusión de polvo tuvo lugar principalmente en los niveles de 1000 a 1500 metros, donde se obtuvieron valores del índice $98 \%$, $96 \%$, y $73 \%$, respectivamente, para los puntos de grid antes citados. 
Los valores de índice ARTI para este episodio muestran un descenso marcado hacia el oeste y hacia el norte.

\section{Visibilidad}

En este episodio hubo concordancia entre los valores máximos de PM10 medidos por la red de calidad del aire y los datos de visibilidad (Figura 31). Los mínimos de visibilidad del episodio tuvieron lugar el día 27 en las islas orientales. El mínimo de visibilidad se registró en Fuerteventura y fue de $4.5 \mathrm{~km}$.

VIS18 [27 de noviembre de 2013]
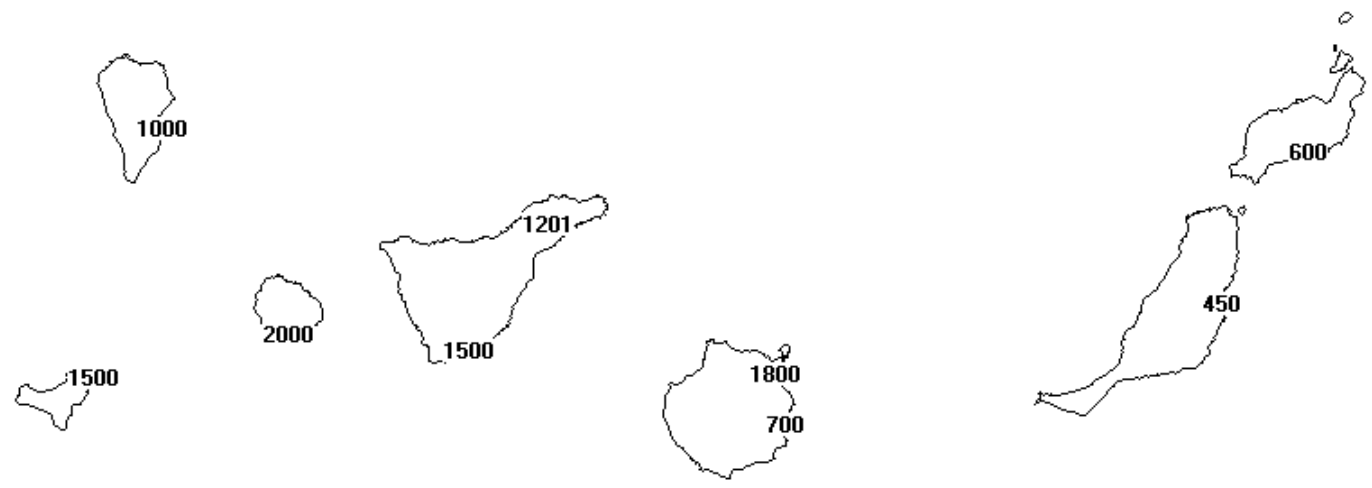

Figura 31. Visibilidad mínima (en decámetros) durante el periodo del 26 al 28 de noviembre de 2013.

\section{MODIS}

La imagen del satélite MODIS (Figura 32) correspondiente al día 27 de noviembre de 2013, muestra la inyección de polvo proveniente del continente africano. En el momento de la captura, la intrusión afectaba a las islas de Lanzarote y Fuerteventura con valores de AOD de 0.7 . 


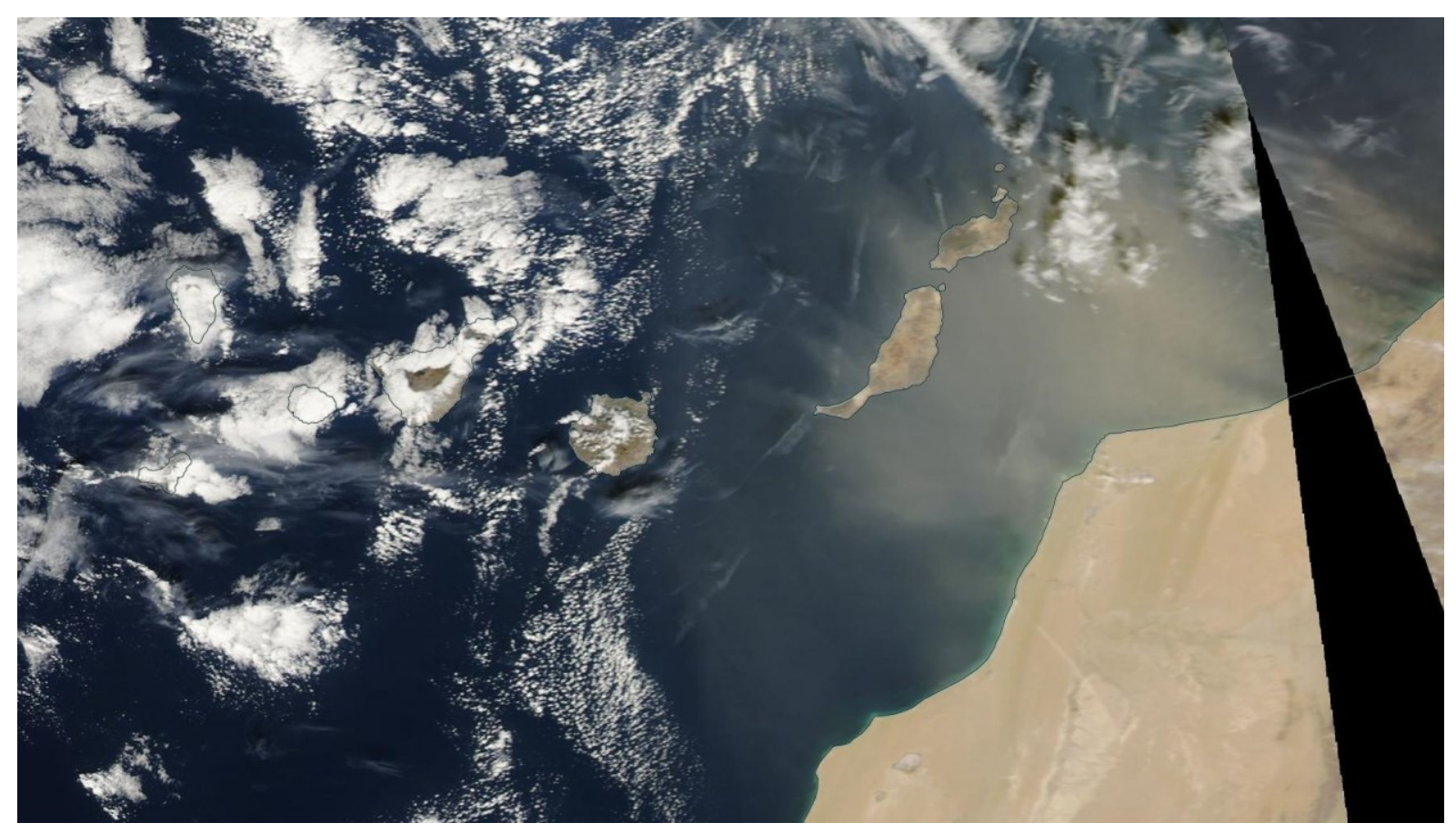

Figura 32. Imagen MODIS del 27 de noviembre de 2013.

\subsubsection{Episodio del 4 al 6 de enero de 2013}

\section{Entorno sinóptico}

El entorno sinóptico muestra un alta de $1040 \mathrm{hPa}$ situada al norte de la península ibérica (Figura 33) y que se extendía hasta Canarias con presión en superficie de $1028 \mathrm{hPa}$. Sobre las islas Canarias, el viento era de componente este. 
ECMWF Analysis VT:F riday 4 January 2013 12UTC 850hPa Temperature/ Mean sea level pressure

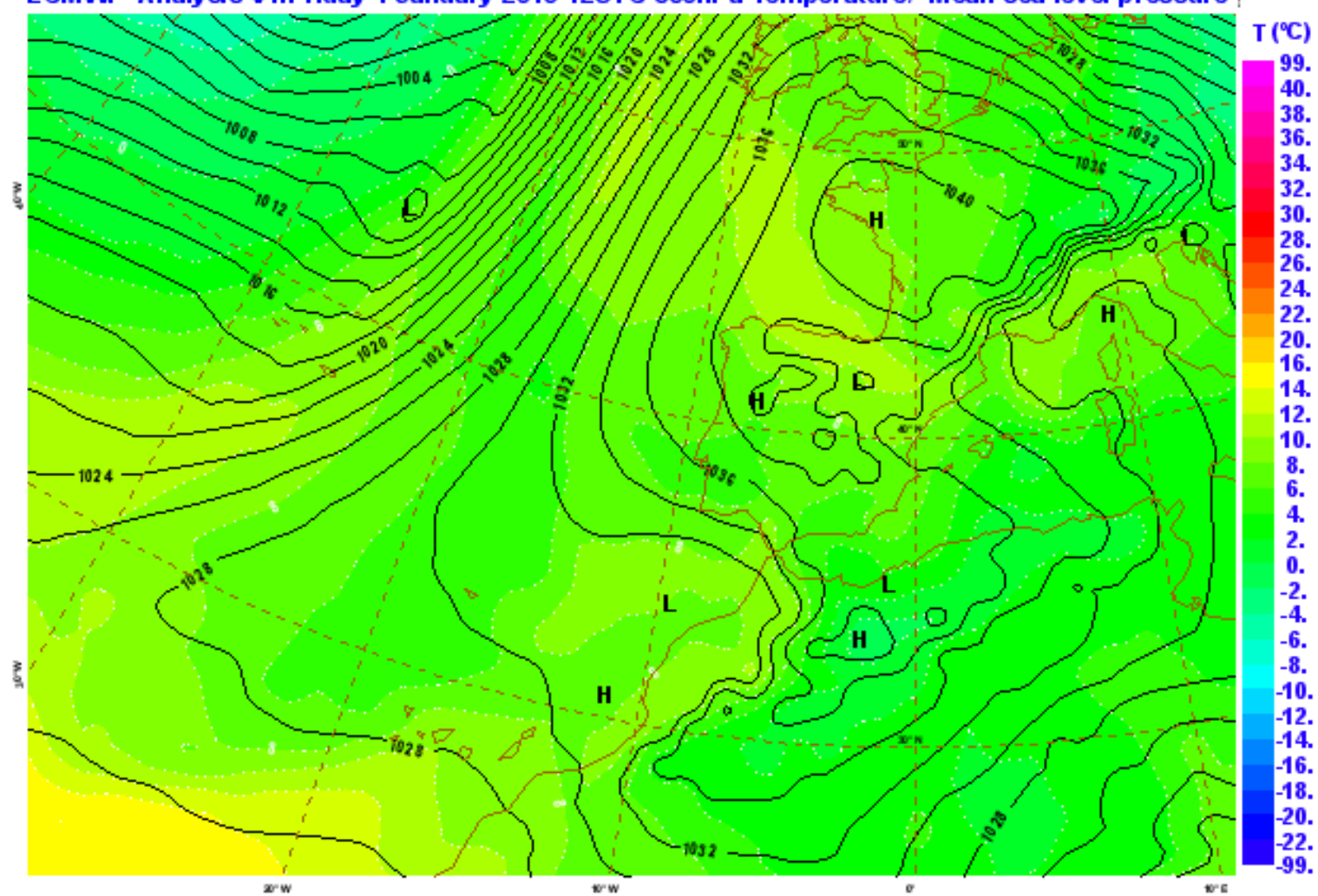

Figura 33. Análisis de presión en superficie $(\mathrm{hPa})$, y temperatura a $850 \mathrm{hPa}\left({ }^{\circ} \mathrm{C}\right) .12$ UTC del 4 de enero de 2013.

En el nivel de 500 hPa (Figura 34), se observa el alta en el Cantábrico y circulación en omega desde el Atlántico Norte hasta el continente europeo y África. Canarias se veía afectada por un núcleo relativamente más frío que su entorno y con escasa circulación en este nivel. 


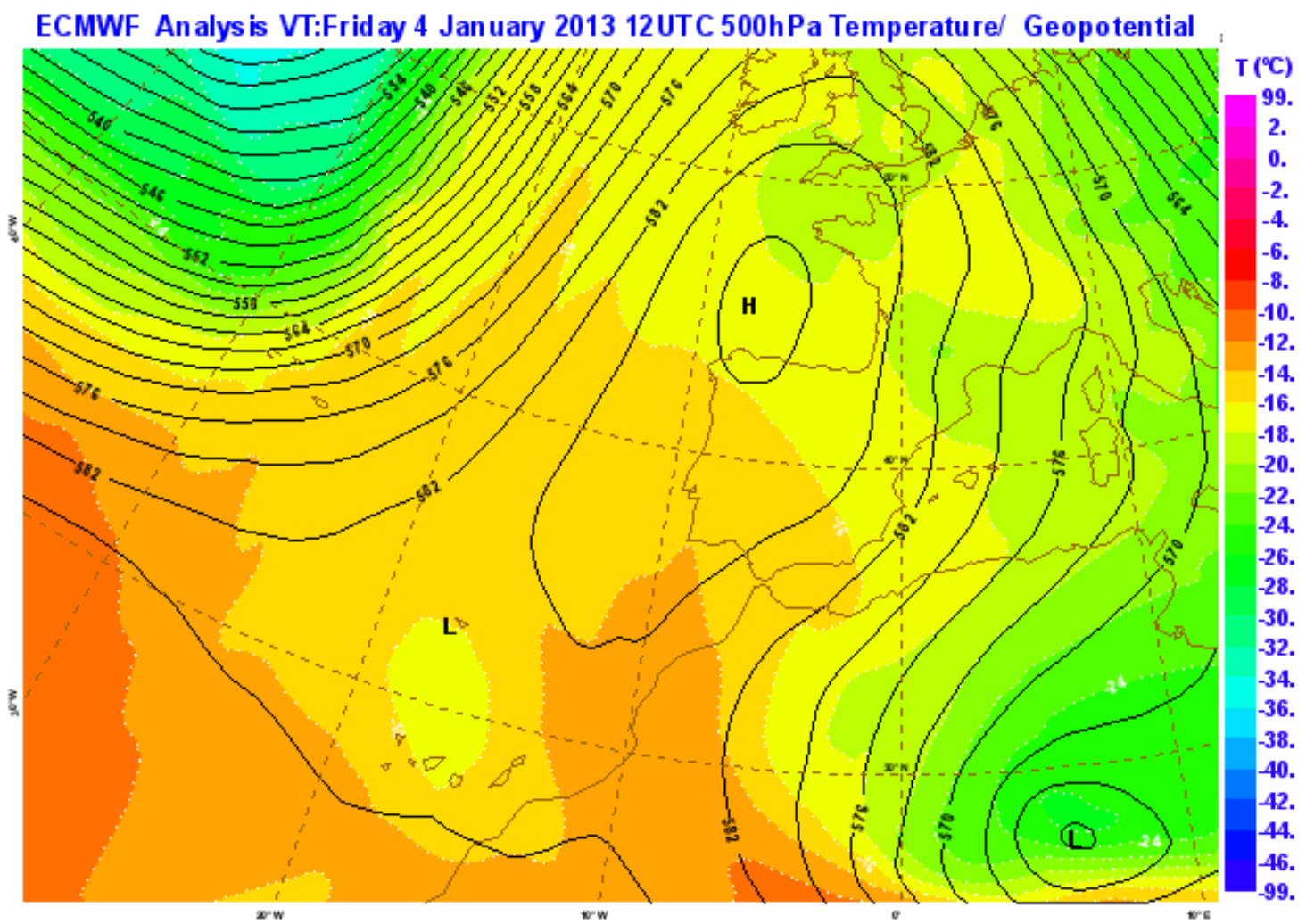

Figura 34. Análisis de temperatura $\left({ }^{\circ} \mathrm{C}\right)$ y geopotencial (mgp) a 500 hPa, 12 UTC del 4 de enero de 2013.

El gradiente medio de geopotencial en $700 \mathrm{hPa}$ (Figura 35) muestra el escenario de alta de bloqueo sobre el continente europeo, con altos valores sobre la Península y Francia extendiéndose hacia Canarias.

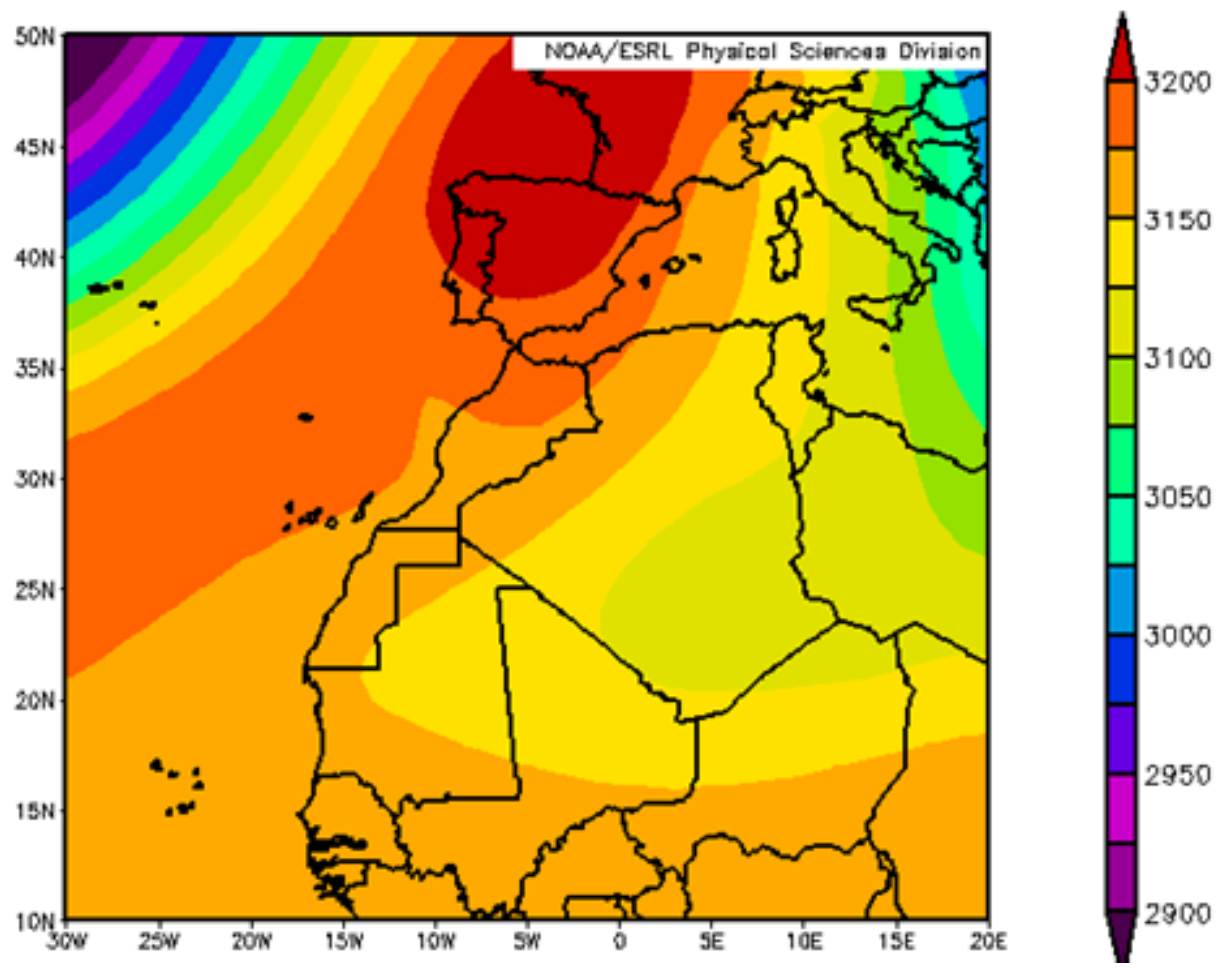

Figura 35. Altura geopotencial media en $700 \mathrm{hPa}$ (20th Century Reanalysis V2c), del 4 al 6 de enero de 2013. 
Observación

PM10

Los datos registrados en la red de calidad del aire (Figura 36) muestran que las concentraciones más elevadas de PM10 durante el episodio tuvieron lugar en Lanzarote y Fuerteventura, con picos máximos de hasta $138 \mu \mathrm{g} / \mathrm{m}^{3}$. 


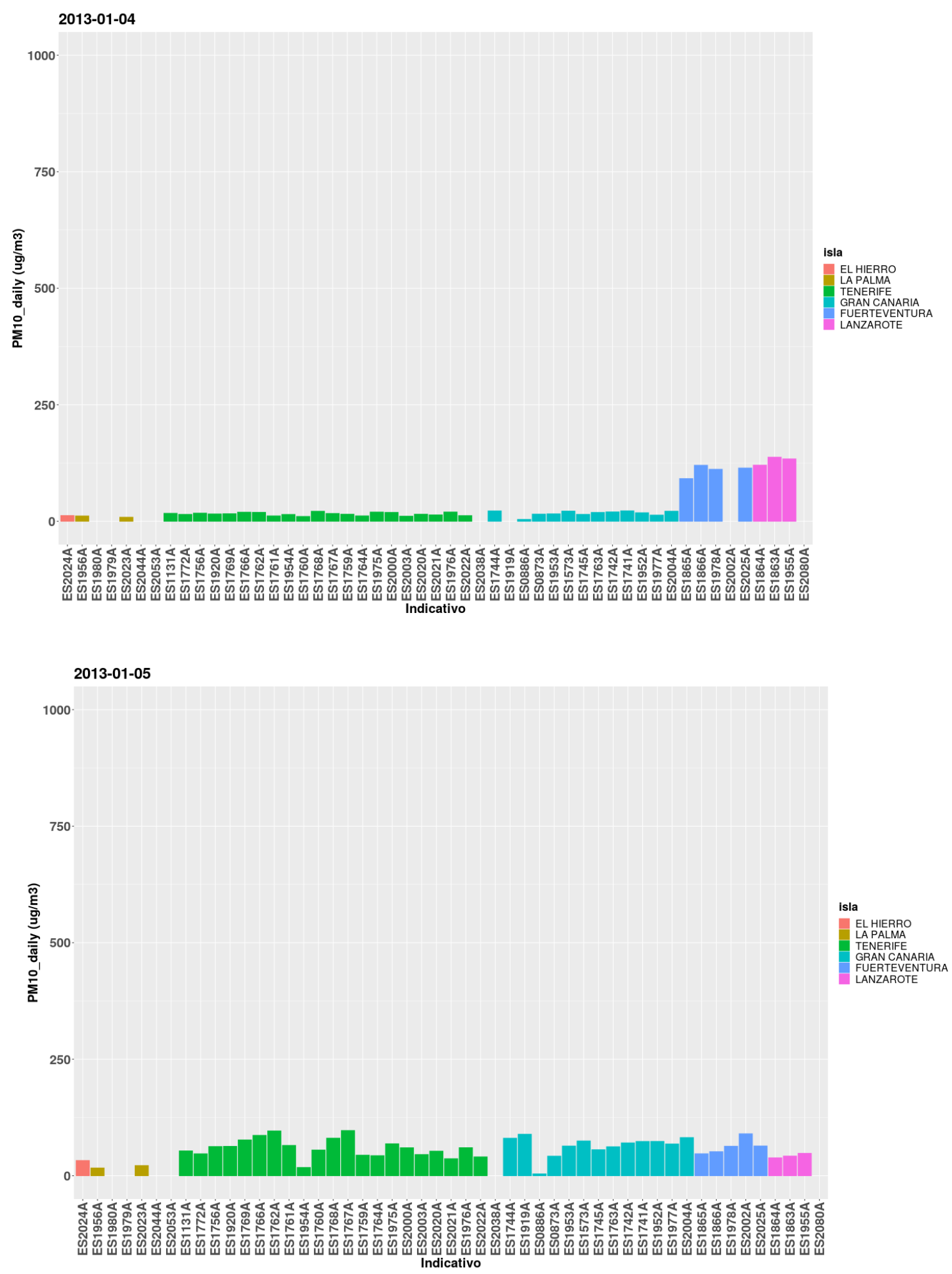

Figura 36. Valores máximos de PM10 $\left(\mu \mathrm{g} / \mathrm{m}^{3}\right)$ registrados por islas durante el evento del 3 al 6 de enero de 2013.

Los valores de índice ARTI muestran un rango de valores entre $96 \%$ (grid_13 a 1500 metros), y $65 \%$ (grid_18 a 1000 metros). Estos valores indican que la intrusión se inició por el sur de las islas orientales y se desplazó hacia el norte, registrándose los valores máximos de PM10 en Lanzarote y Fuerteventura. 


\section{Visibilidad}

En cuanto a la visibilidad (Figura 37), los mínimos registrados durante el episodio acaecieron durante el día 4 de enero de 2013 en las islas de Lanzarote y Fuerteventura, donde la visibilidad se redujo a 6 y $7 \mathrm{~km}$, respectivamente.

VIS18 [4 de enero de 2013)
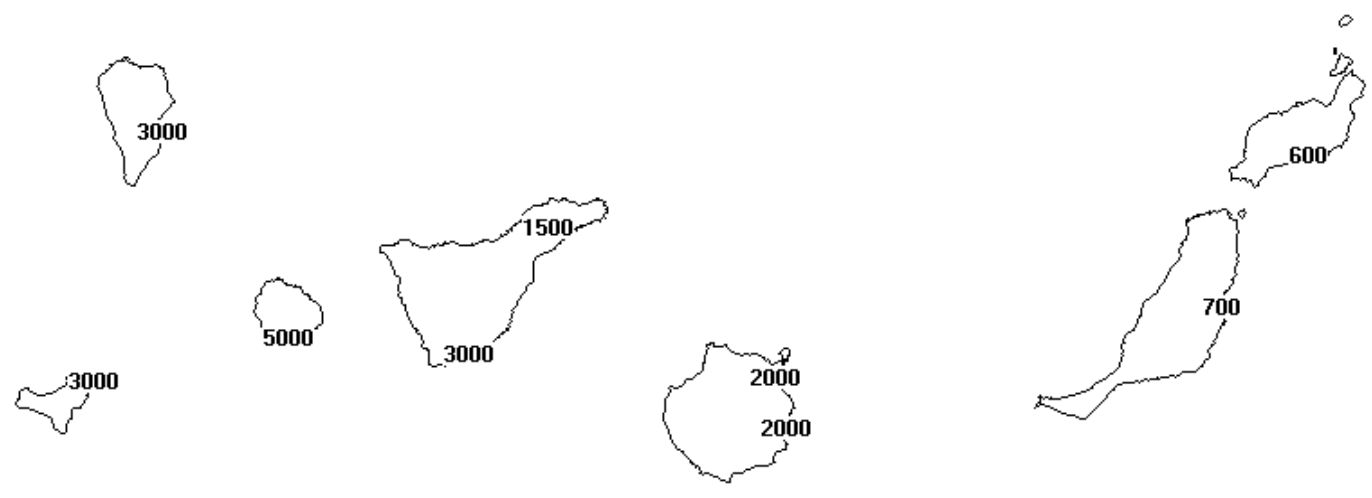

Figura 37. Visibilidad mínima (en decámetros) durante el periodo del 4 al 6 de enero de 2013.

\section{MODIS}

La imagen de MODIS (Figura 38) correspondiente al día 4 de enero de 2013, muestra nubosidad de tipo alto sobre las islas más orientales y varias bandas de polvo al norte y este de Lanzarote con AOD de 0.7, mientras que en el resto del archipiélago el AOD era menor a 0.1.

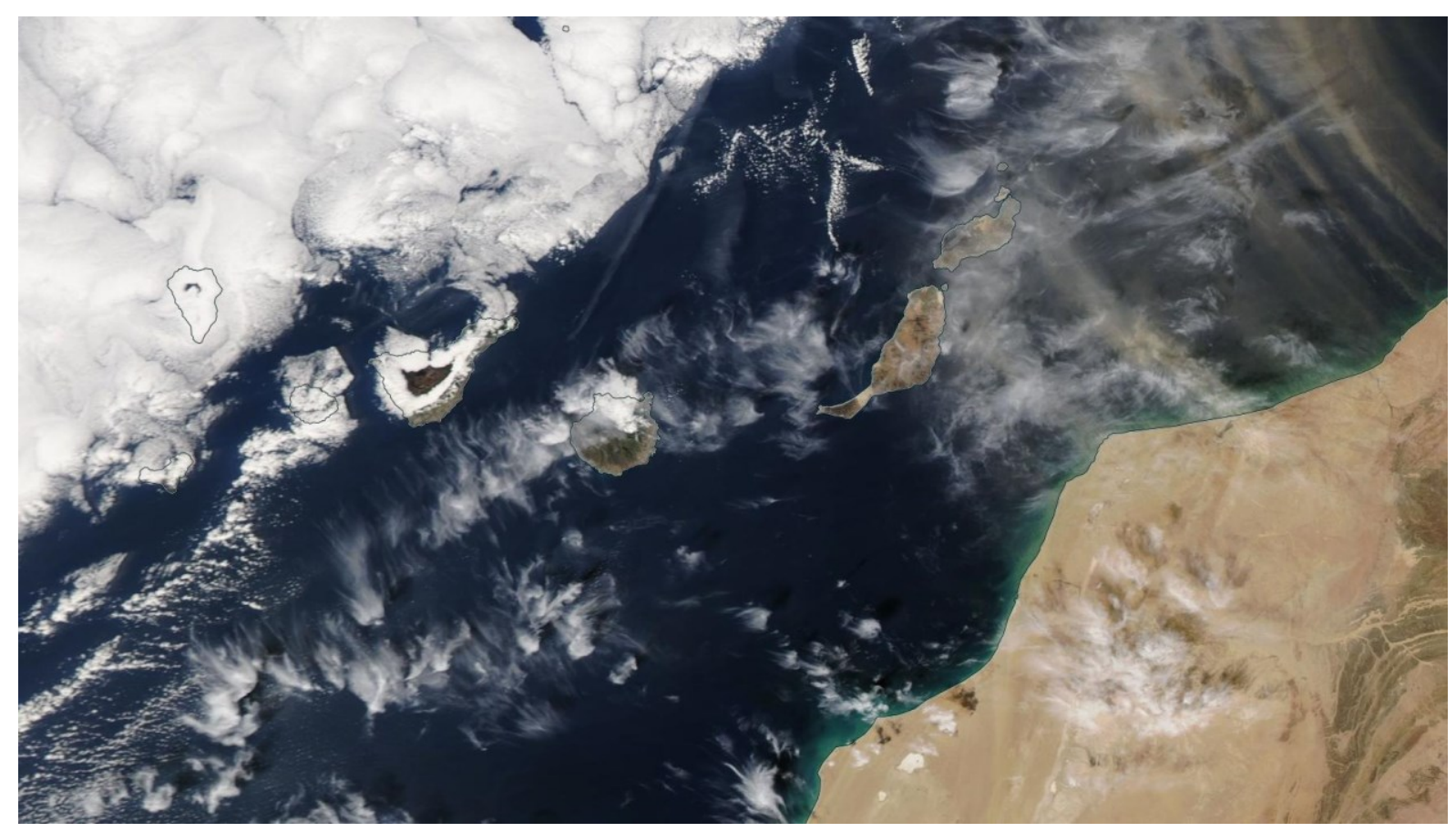

Figura 38. Imagen MODIS del 4 de enero de 2013. 


\subsection{Episodios que afectan de manera generalizada a todo el archipiélago}

\subsubsection{Episodio del 6 al 8 de marzo de 2015}

\section{Entorno sinóptico}

La Figura 39 muestra la presencia de un anticiclón de $1032 \mathrm{hPa}$ situado en el Mediterráneo y una estructura de "V invertida" al este de Canarias. Esta estructura es debida a la perturbación del campo de presión en el nivel de superficie, generada por el dipolo orográfico y por la baja que se situaba al sur de Canarias. Dorsal térmica en el nivel de $850 \mathrm{hPa}$ situada entre Canarias y la costa africana que marcaba la entrada de la masa de aire cálida sahariana sobre el archipiélago.

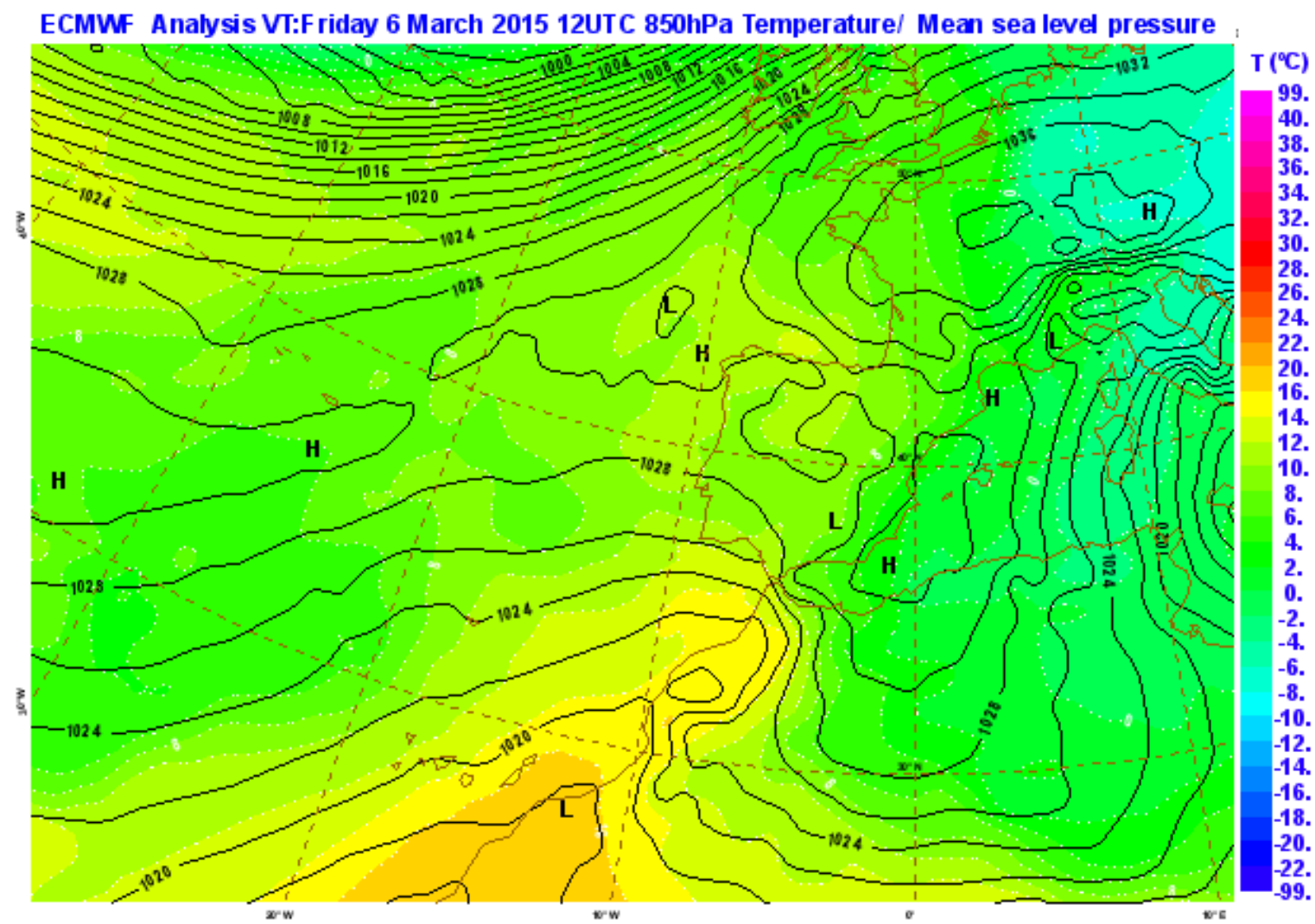

Figura 39. Análisis de presión en superficie $(\mathrm{hPa})$, y temperatura a $850 \mathrm{hPa}\left({ }^{\circ} \mathrm{C}\right) .12 \mathrm{UTC}$ del 6 de marzo de 2015.

El nivel de $500 \mathrm{hPa}$ (Figura 40) muestra una dana situada al oeste de Madeira con núcleo frío de entre -24 a $-26^{\circ} \mathrm{C}$. El flujo era del suroeste sobre las islas Canarias en este nivel. 


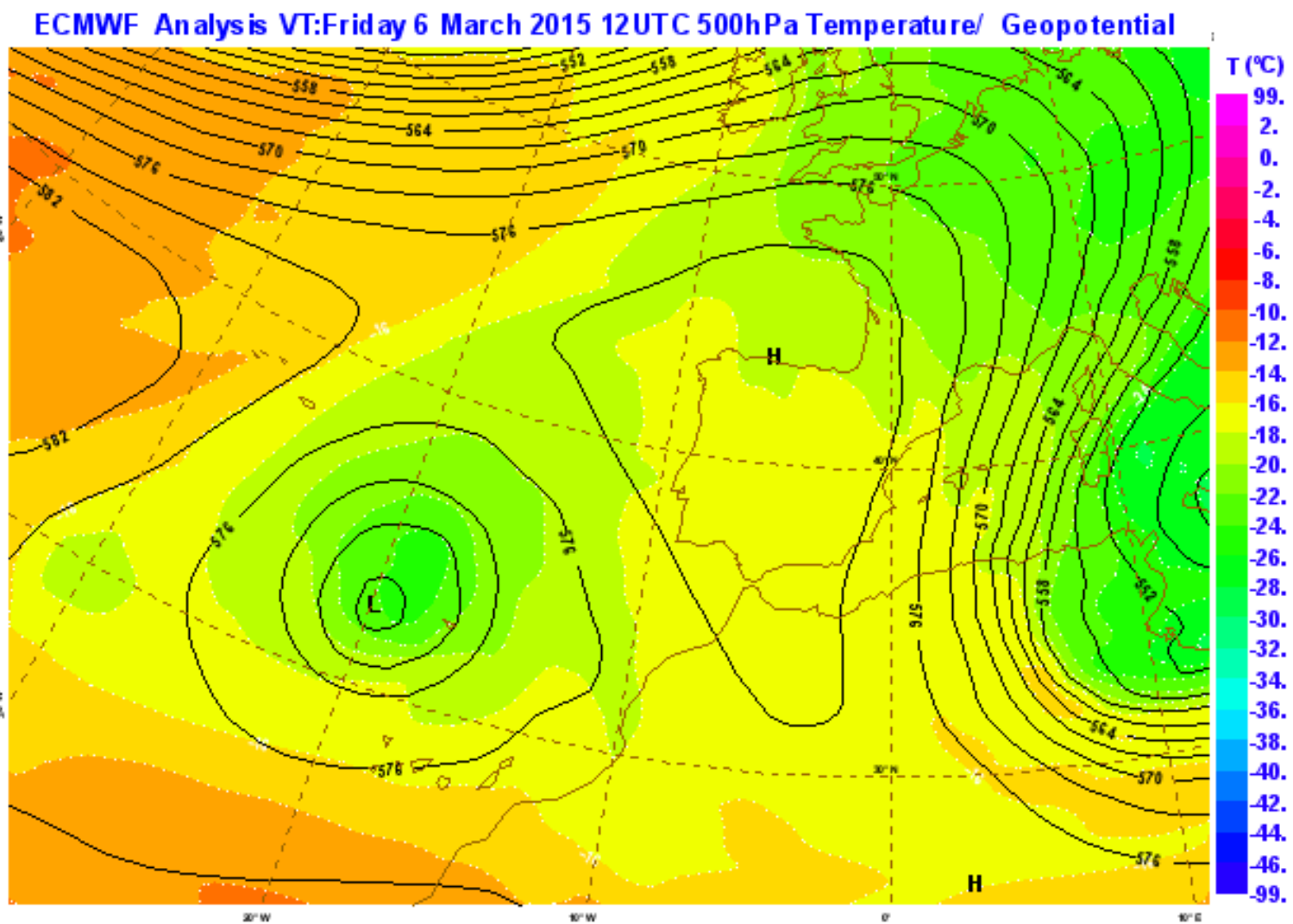

Figura 40. Análisis de temperatura $\left({ }^{\circ} \mathrm{C}\right)$ y geopotencial (mgp) a $500 \mathrm{hPa}$, , 12 UTC del 6 de marzo de 2015.

En la siguiente imagen (Figura 41) se observa el geopotencial medio en $700 \mathrm{hPa}$ durante el episodio de intrusión de polvo. Al sur de Canarias se observa el reflejo de la baja en altura y una baja más profunda al sur de Italia.

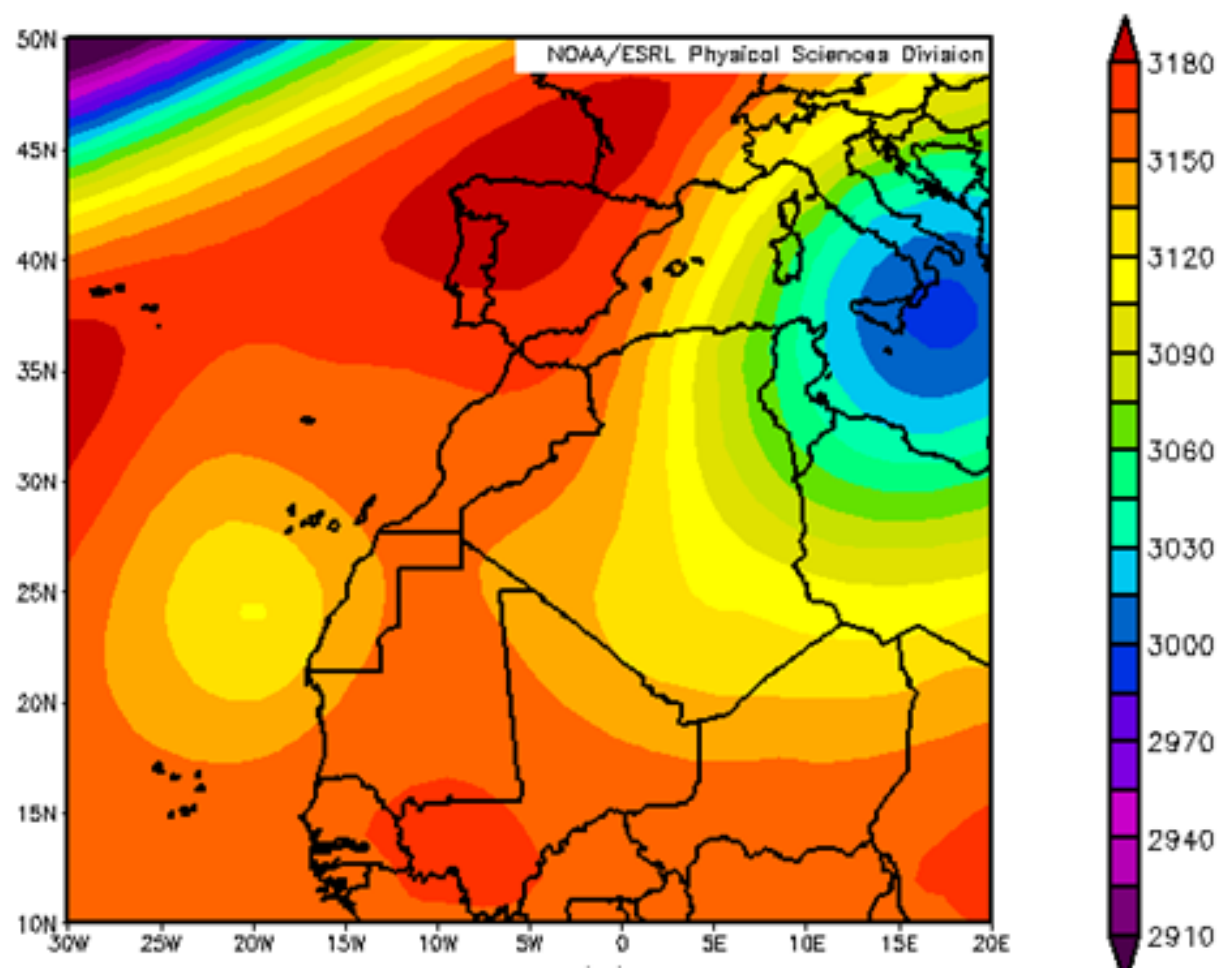

Figura 41. Altura geopotencial media en 700 hPa (20th Century Reanalysis V2c), del 6 al 8 de marzo de 2015. 


\section{Observación}

\section{PM10}

Durante este episodio de intrusión de polvo que afectó de manera generalizada a todas las islas, los valores más elevados de PM10 (Figura 42) se registraron en la isla de Fuerteventura durante el día 7 y estos máximos alcanzaron un máximo de $332 \mu \mathrm{g} / \mathrm{m}^{3}$.

Los valores de índice ARTI muestran valores elevados del índice desde 500 hasta 4500 metros, lo que denota que fue una intrusión importante abarcando desde niveles bajos a medios de la troposfera. Los valores están por encima de $90 \%$ incluso para el punto grid_1, que es el punto más occidental. 


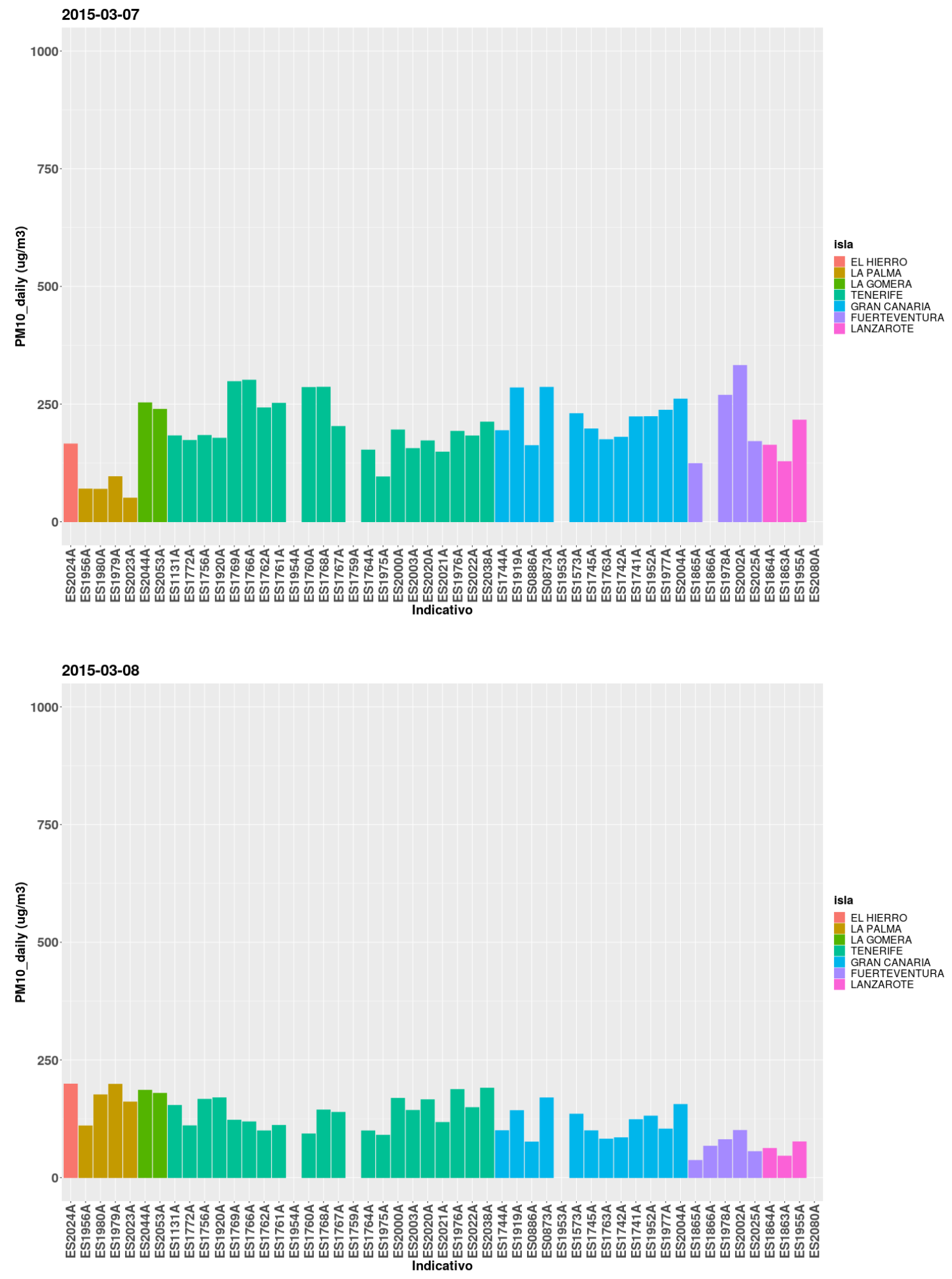

Figura 42. Valores máximos de PM10 $(\mu \mathrm{g} / \mathrm{m} 3)$ registrados por islas durante el evento del 6 al 9 de marzo de 2015.

\section{Visibilidad}

En el siguiente mapa (Figura 43) se muestran los mínimos de visibilidad registrados durante el episodio. Se constata que la intrusión afectó a todas las islas y los mínimos de visibilidad se 
obtuvieron en Tenerife Sur y en el aeropuerto de Gran Canaria, durante el día 7 de marzo de 2015, donde las visibilidades llegaron a mínimos de $1.5 \mathrm{~km}$ y $2.9 \mathrm{~km}$, respectivamente.

VIS18 (7 de marzo de 2015)
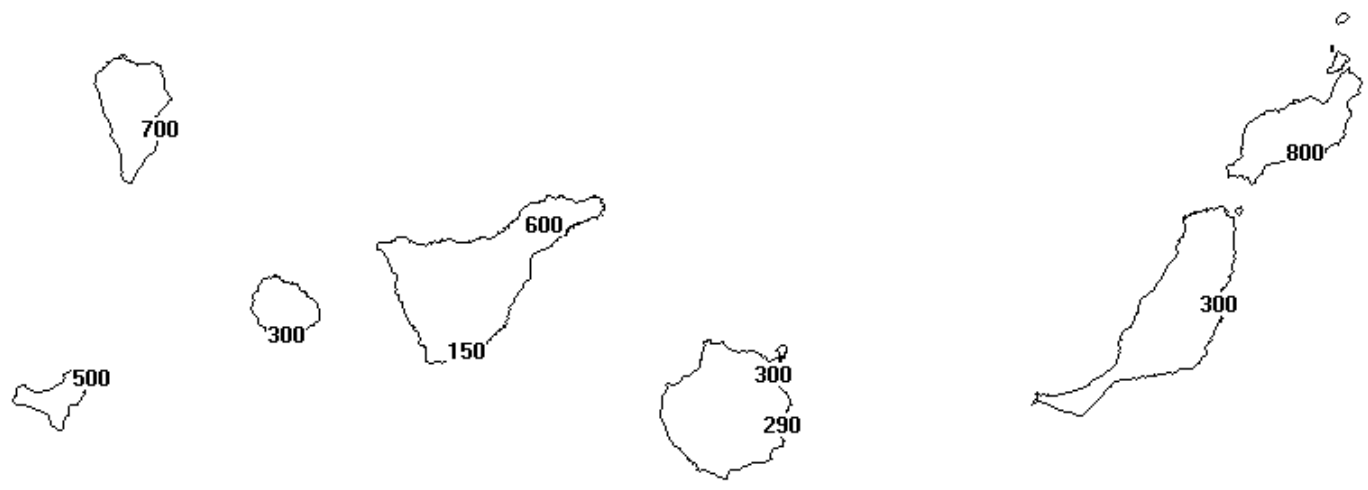

Figura 43. Visibilidad mínima (en decámetros) durante el periodo del 6 al 8 de marzo de 2015.

\section{MODIS}

En la imagen de satélite (Figura 44) se aprecia la presencia de polvo y nubosidad sobre Canarias. La intrusión tuvo lugar por el sur del archipiélago, de ahí que, tanto La Palma como Lanzarote fueran las islas menos afectadas. Los valores promedios de AOD fueron de 0.7.

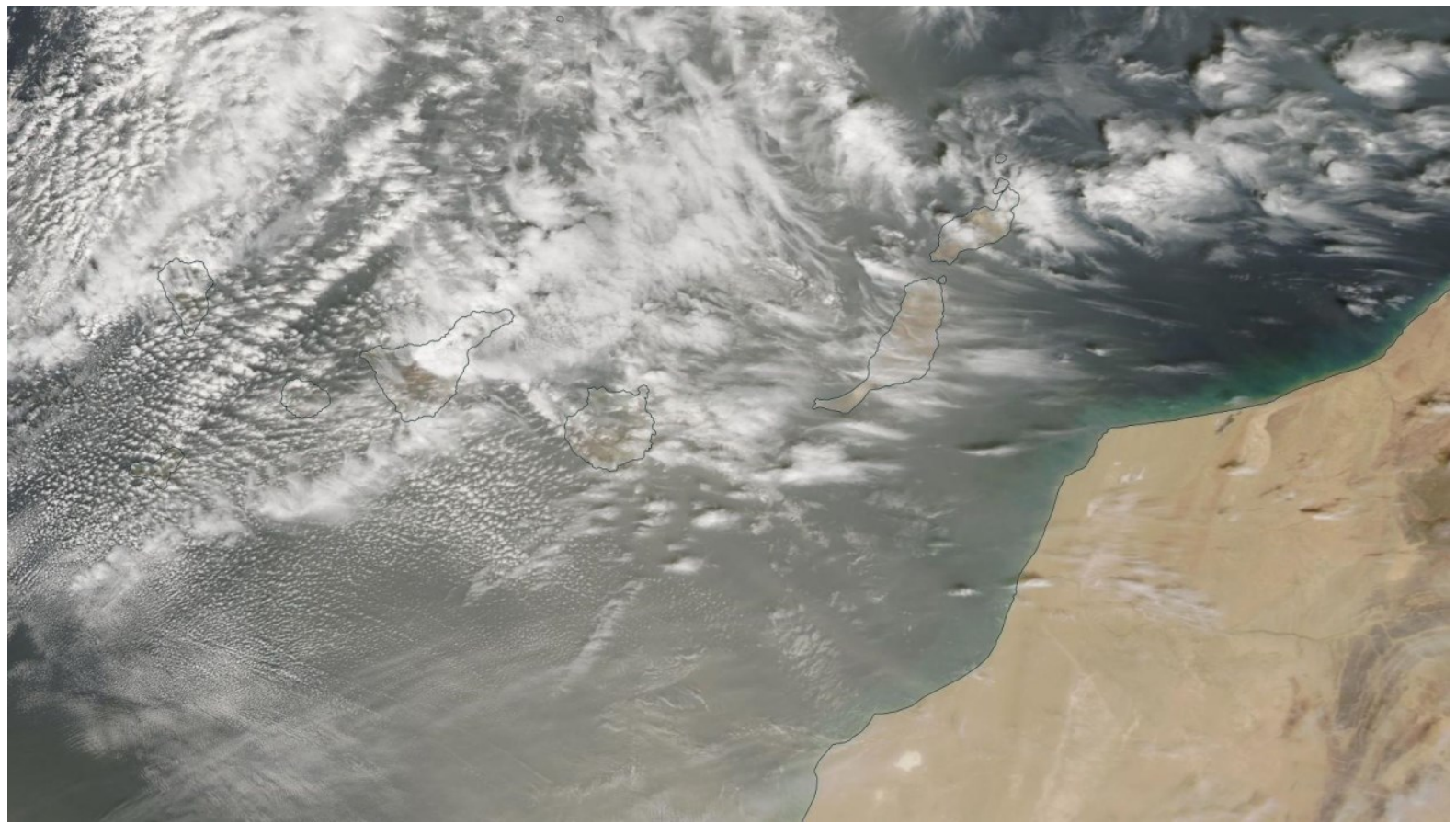

Figura 44. Imagen MODIS del 7 de marzo de 2015. 


\subsubsection{Episodio del 12 al 13 de agosto de 2015}

\section{Entorno sinóptico}

El entorno sinóptico muestra por un lado, alta de $1028 \mathrm{hPa}$ situada al noroeste de Azores (Figura 45) y por otro lado, bajas térmicas ubicadas sobre la península ibérica y sobre África. El flujo t sobre Canarias tenía una componente terral y dorsal térmica en $850 \mathrm{hPa}$ con su eje orientado noroeste-sureste desde el sur de Madeira hasta el continente africano. La temperatura en 850 hPa muestra que Canarias estaba siendo afectada por la masa de aire cálida continental.

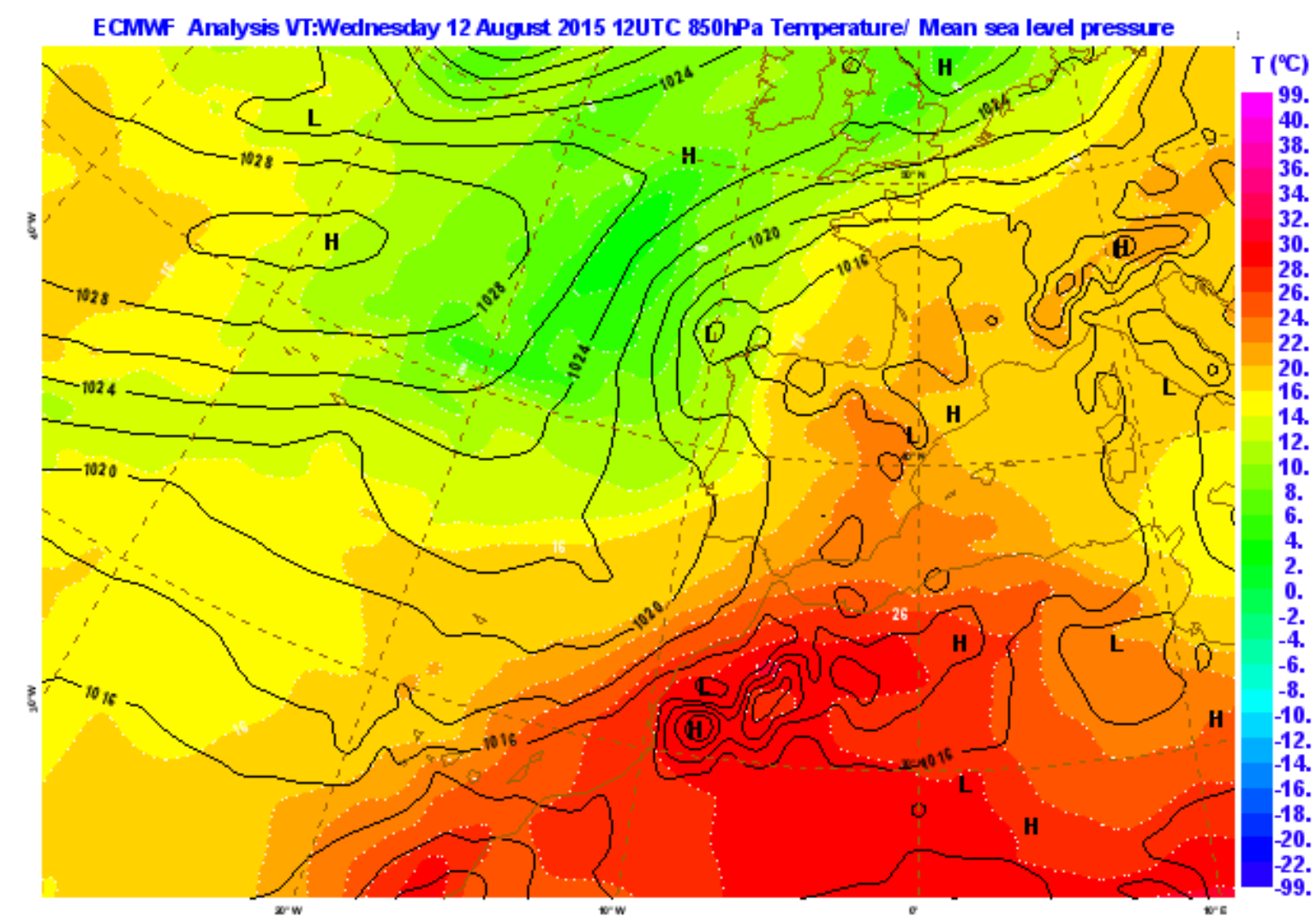

Figura 45. Análisis de presión en superficie $(\mathrm{hPa})$, y temperatura a $850 \mathrm{hPa}\left({ }^{\circ} \mathrm{C}\right) .12 \mathrm{UTC}$ del 12 de agosto de 2015.

En el nivel de $500 \mathrm{hPa}$ (Figura 46) se observa que, Canarias quedaba situada al oeste del eje de la dorsal, que presenta su eje orientado norte-sur adentrándose en el continente europeo. Además, en este nivel se aprecia una dana al oeste de las costas gallegas con núcleo frío de -16 a $-18^{\circ} \mathrm{C}$. 


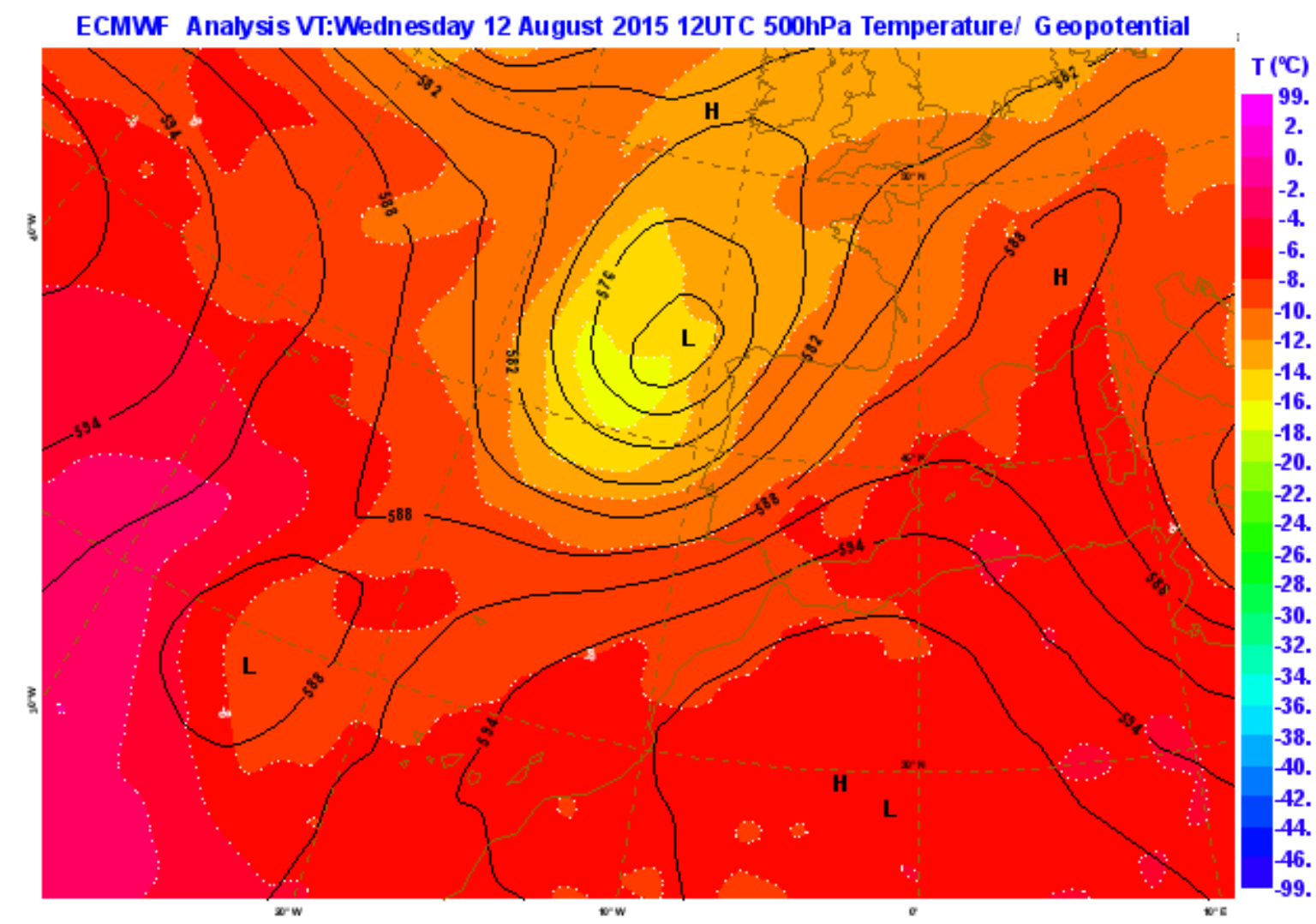

Figura 46. Análisis de temperatura $\left({ }^{\circ} \mathrm{C}\right)$ y geopotencial $(\mathrm{mgp})$ a $500 \mathrm{hPa}, 12$ horas del 12 de agosto de 2015.

En la Figura 47 se constata valores elevados del geopotencial medio en $700 \mathrm{hPa}$ en el norte de África y un marcado gradiente latitudinal durante el episodio de intrusión de polvo. Este intenso dipolo del norte de África (ver índice NAFDI, sección 2.3.3), permite encontrar un simple modelo conceptual para unir la variabilidad a largo plazo en la exportación de polvo en el Sáhara con la variabilidad a gran escala meteorológica en África noroccidental. 


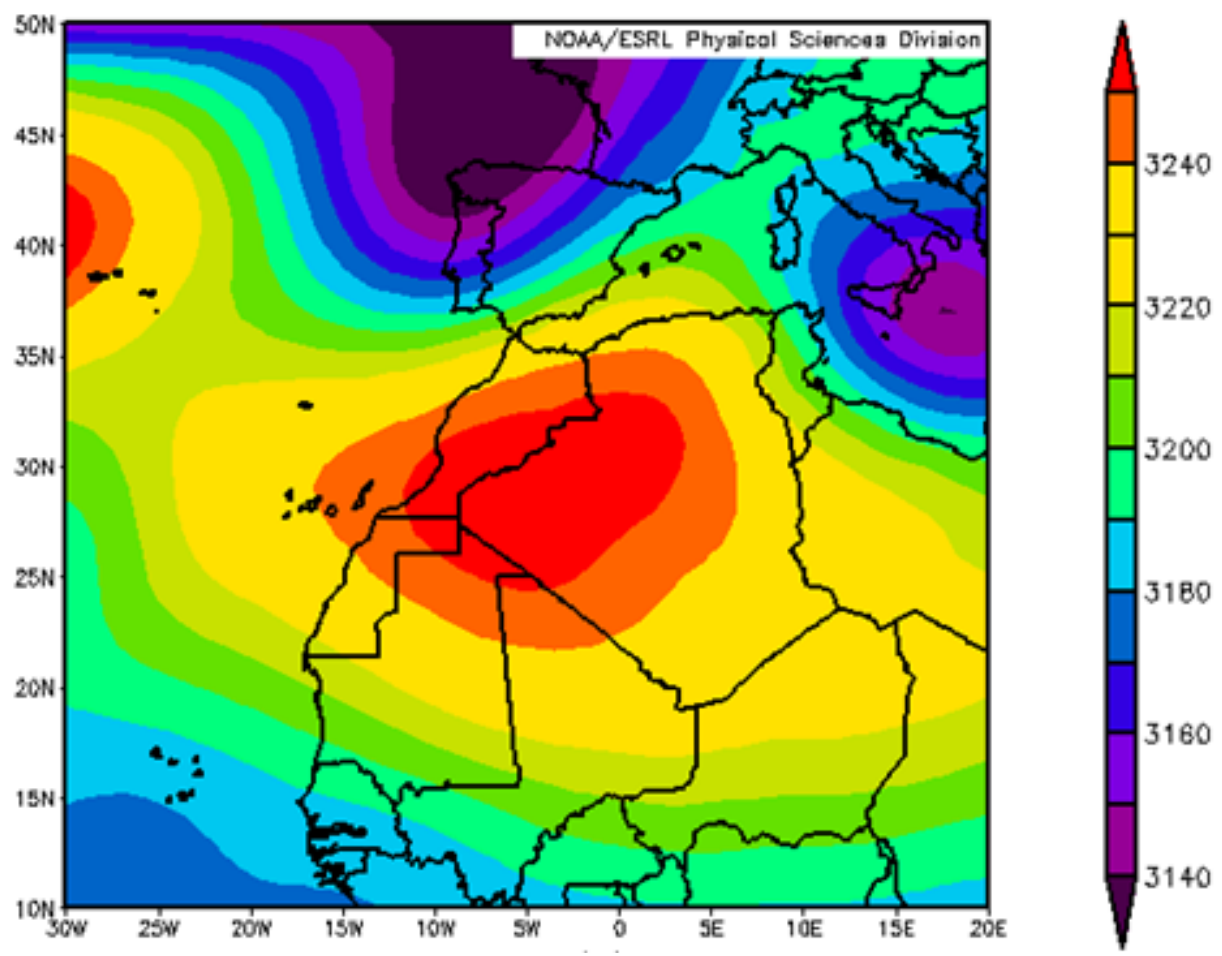

Figura 47. Altura geopotencial media en $700 \mathrm{hPa}$ (20th Century Reanalysis V2c ) del 12 al 13 de agosto de 2015.

\section{Observación}

\section{PM10}

Los datos de la red de calidad del aire (Figura 48) muestran que los valores más elevados de PM10 durante el episodio fueron registrados durante el día 13 en la isla de La Gomera con valores de hasta $146 \mu \mathrm{g} / \mathrm{m}^{3}$. Para el punto de la matriz más cercano a la isla de la Gomera (grid_5) el índice ARTI presentaba unos valores de $89 \%$ a 1500 metros. 


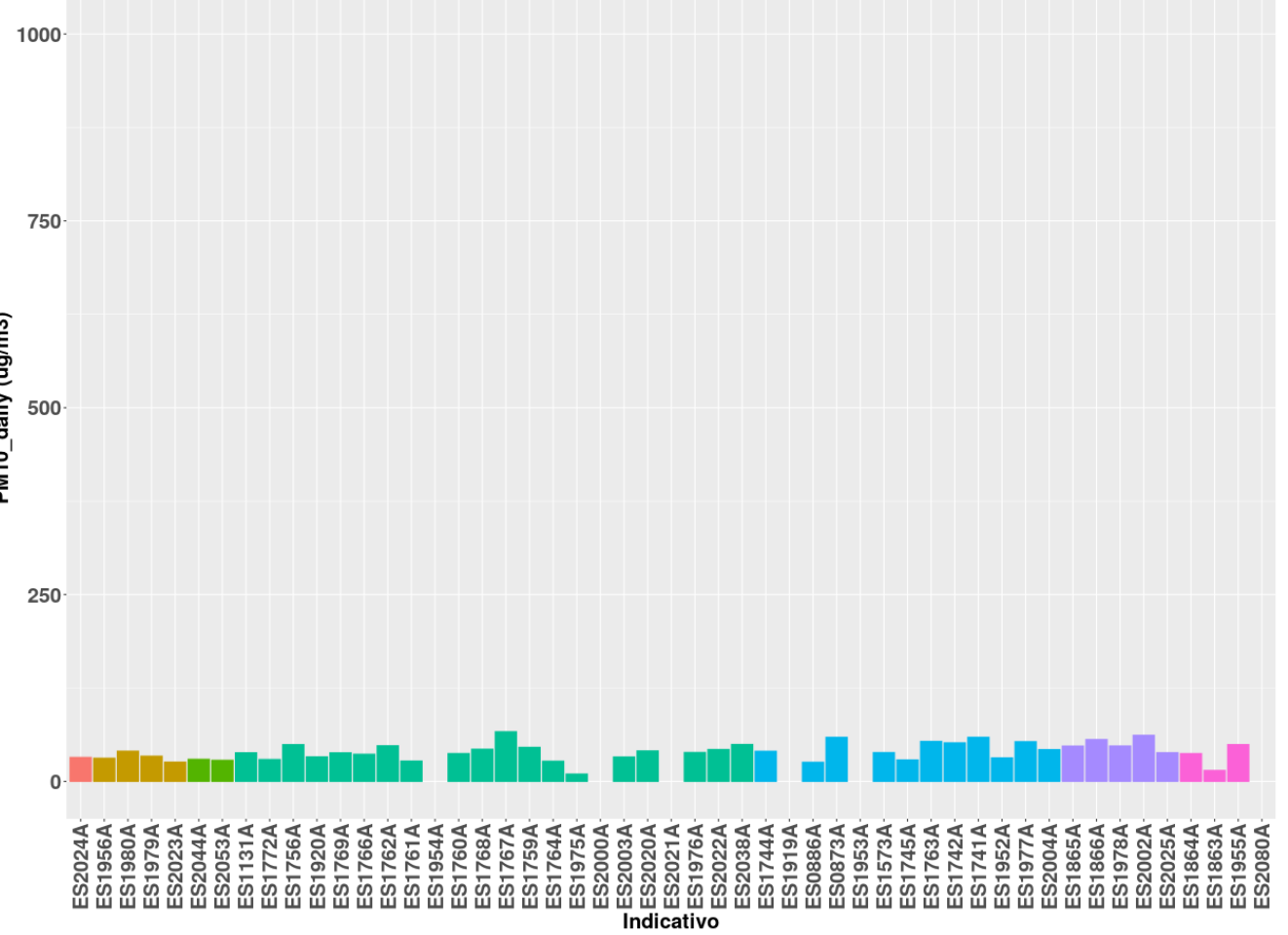

2015-08-13

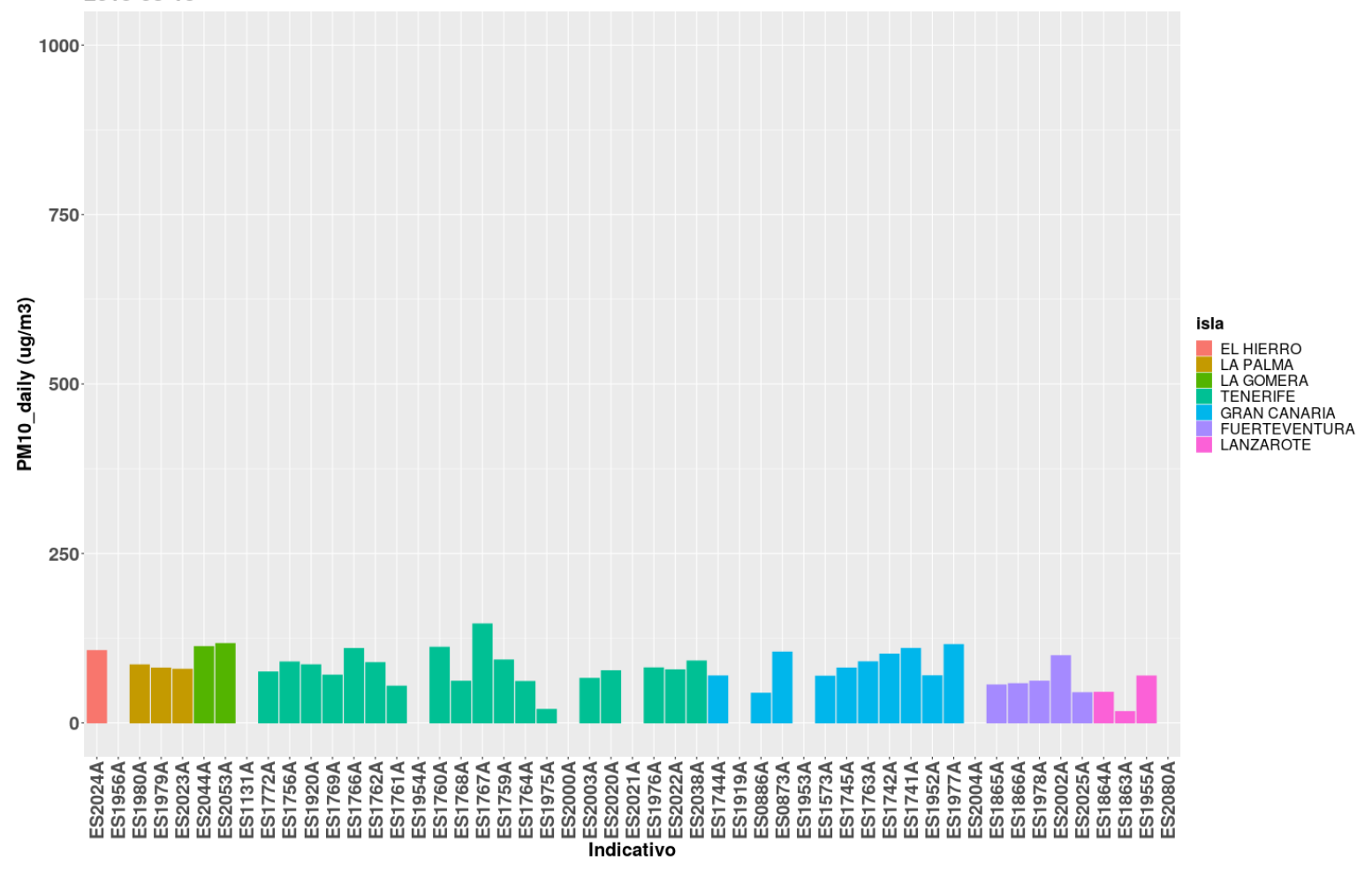

Figura 48. Valores máximos de PM10 ( $\mu \mathrm{g} / \mathrm{m} 3)$ registrados por islas durante el evento del 12 al 14 de agosto de 2015. 


\section{Visibilidad}

A continuación se muestran los mínimos de visibilidad (Figura 49) registrados durante el episodio. Destaca la reducción de visibilidad que experimentó Izaña, donde la visibilidad llegó a mínimos de 200 metros. Al tratarse de una intrusión de verano, el máximo de concentración de polvo en suspensión se encuentra entre 2500 y $3000 \mathrm{~m}$ de altitud.

VIS18 [13 de agosto de 2015]
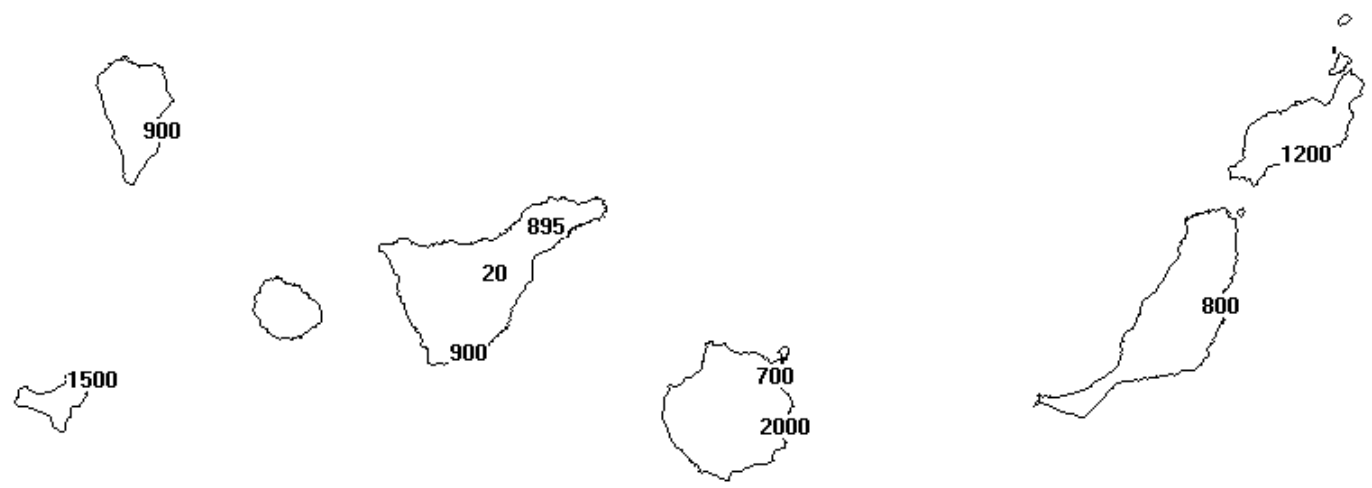

Figura 49. Visibilidad mínima (en decámetros) durante el periodo del 12 y 13 de agosto de 2015.

\section{MODIS}

En la imagen de satélite (Figura 50) correspondiente al 13 de agosto de 2015, se observa que en el momento de la captura, la intrusión de polvo estaba afectando principalmente a las islas centrales a Lanzarote y Fuerteventura, con valores de AOD cercanos a 1.

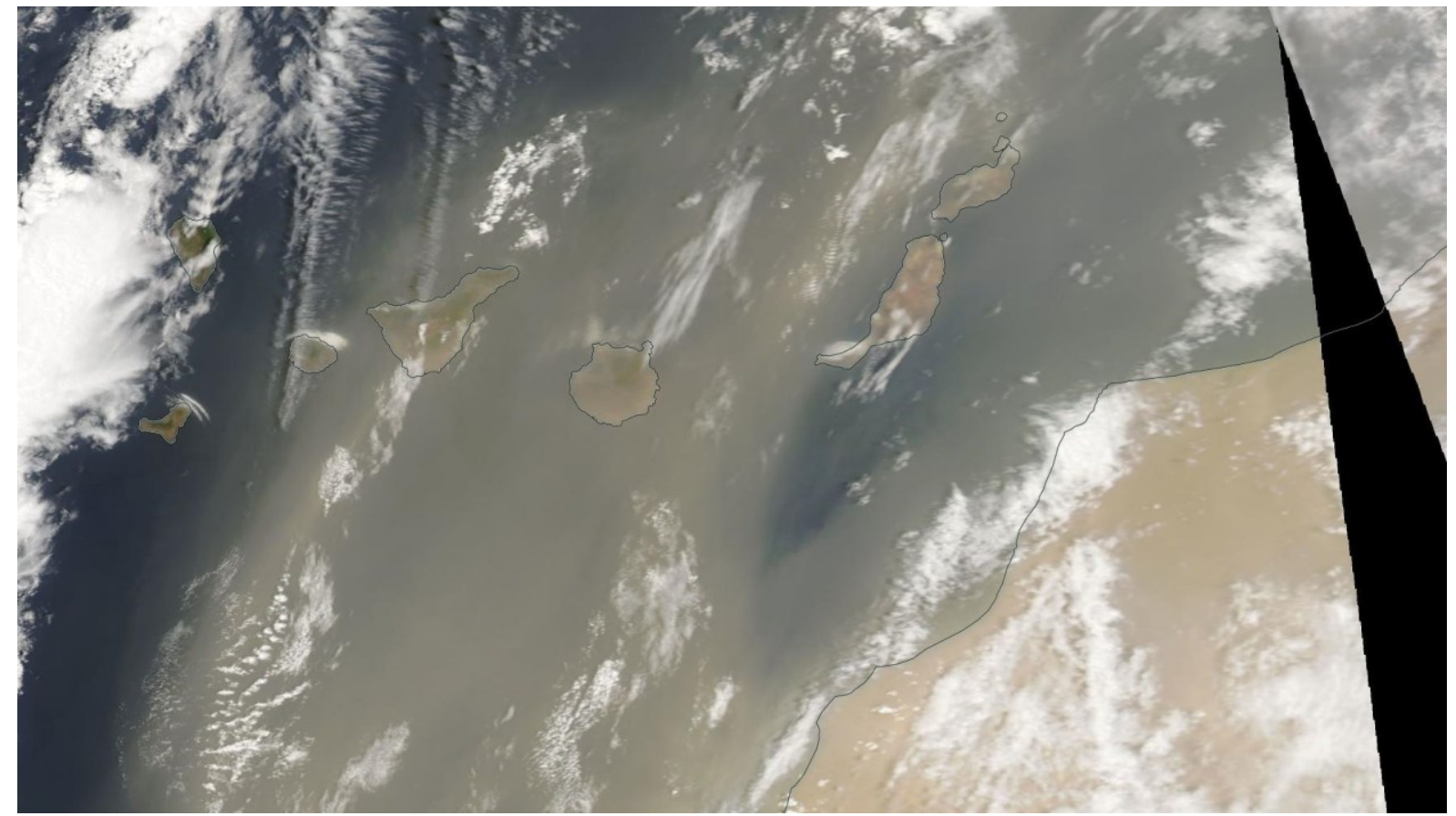

Figura 50. Imagen MODIS del 13 de agosto de 2015. 
A continuación en la Tabla 4, se muestra un cuadro resumen con todos los episodios analizados como casos de estudio:

\begin{tabular}{|l|l|l|l|l|l|l|l|}
\hline $\begin{array}{c}\text { Situación/ } \\
\text { mes }\end{array}$ & $\begin{array}{l}\text { Sinop. } \\
\text { Sfc }\end{array}$ & $\begin{array}{c}\text { Sinop. } \\
\mathbf{5 0 0} \mathbf{h P a}\end{array}$ & $\begin{array}{c}\text { Sinop. } \\
\mathbf{7 0 0} \mathbf{~ h P a}\end{array}$ & $\begin{array}{c}\text { Islas } \\
\text { afectadas }\end{array}$ & $\begin{array}{c}\text { Medias } \\
\text { diarias } \\
\text { PM10 máx. }\end{array}$ & $\begin{array}{c}\text { Visibilidad } \\
\text { mínima } \\
\text { (km)/ } \\
\text { isla }\end{array}$ & $\begin{array}{c}\text { Índice } \\
\text { ARTI \%/ } \\
\text { nivel (m) }\end{array}$ \\
\hline 4.1.1/Feb. & $\mathrm{H}$ & $\mathrm{D}$ & $\mathrm{B}$ & Occidentales & $610 \mu \mathrm{g} / \mathrm{m}^{3}$ & $1 / \mathrm{GC}$ & $92 / 1000$ \\
\hline 4.1.2/Dic. & $\mathrm{H}$ & $\mathrm{D}$ & $\mathrm{H}$ & Occidentales & $439 \mu \mathrm{g} / \mathrm{m}^{3}$ & $2.8 / \mathrm{GC}$ & $91 / 500$ \\
\hline 4.2.1/Nov & $\begin{array}{l}\text { Dipolo } \\
\text { Orogr. }\end{array}$ & $\begin{array}{l}\text { África } \\
\text { Ana }\end{array}$ & $\begin{array}{l}\text { Grad. } \\
\text { Lat. }+\end{array}$ & Orientales & $219 \mu \mathrm{g} / \mathrm{m}^{3}$ & $4.7 / \mathrm{FV}$ & $98 / 1000$ \\
\hline 4.2.2/Mar & H & D & B & Orientales & $138 \mu \mathrm{g} / \mathrm{m}^{3}$ & $6 / \mathrm{LZ}$ & $96 / 1500$ \\
\hline 4.3.1/Mar & $\begin{array}{l}\text { Dipolo } \\
\text { Orogr. }\end{array}$ & Madeira & L & Todas & $332 \mu \mathrm{g} / \mathrm{m}^{3}$ & $1.5 / \mathrm{TF}$ & $>90 / 500$ \\
\hline 4.3.2/Ago & H & D & DA & Todas & $146 \mu \mathrm{g} / \mathrm{m}^{3}$ & $0.2 / \mathrm{TF}$ & $89 / 1500$ \\
\hline
\end{tabular}

Tabla 4. Resumen de los casos de estudio analizados

Donde:

$\mathrm{H}$, anticiclón sobre el norte de África.

D, Dorsal sobre Canarias, norte de África.

B, Patrón de bloqueo al sur de Europa.

L, Baja al norte de África.

dana, Depresión Aislada de Niveles Altos

Dipolo Orogr., Dipolo orográfico en el Atlas.

Grad. Lat. - + Marcado gradiente latitudinal con bajos valores de geopotencial en $700 \mathrm{hPa}$ al norte y altos al sur.

DA, Dipolo Africano, alta en el norte de África y baja al sur del alta.

GC, Gran Canaria.

FV, Fuerteventura.

LZ, Lanzarote.

TF, Tenerife.

Los valores del índice ARTI hacen referencia al punto de la matriz más cercano a la isla en la que se haya producido el valor medio diario más alto de PM10. 


\section{CONCLUSIONES}

Este trabajo recoge una primera caracterización espacio temporal de las intrusiones de polvo en Canarias. Esta caracterización se ha realizado a partir de datos cuantitativos medidos in-situ. En concreto se ha utilizado el PM10 medido en la red de calidad del aire del gobierno de Canarias. En este estudio Se ha introducido un método objetivo basado en el índice ARTI, que permite distinguir dos escenarios muy diferentes. Un escenario en el que con muy alta probabilidad podemos afirmar que no hay intrusión de polvo, y otro en el que con una alta probabilidad existe intrusión africana.

A continuación se resumen las principales conclusiones alcanzadas en este estudio:

- A lo largo de esta nota técnica se analizaron 8 años de datos. De todo el periodo, en torno al $16 \%$ del periodo corresponde al escenario en que con alta probabilidad no hay intrusión de polvo africano, frente a un $20 \%$ que corresponde a intrusión de polvo (se identificaron 123 episodios, un total de 574 días de intrusión de polvo).

- Los episodios analizados mostraron una duración media de 4.7 días. En promedio los episodios acaecidos durante los periodos abril-septiembre son los más largos, con una duración en promedio de 6 días. Sin embargo, los episodios más intensos (aquellos que han superado los $100 \mu \mathrm{g} / \mathrm{m}^{3}$ ), se han producido en el periodo diciembre-marzo.

- Para la caracterización del efecto de la intrusión en la calidad del aire se han utilizado umbrales del ICA. El $70 \%$ de los episodios no superaron los $50 \mu \mathrm{g} / \mathrm{m}^{3}$, en el $22 \%$ los valores de PM10 estuvieron entre $50 \mu \mathrm{g} / \mathrm{m}^{3}$ y $100 \mu \mathrm{g} / \mathrm{m}^{3}$ y el $8 \%$ mostró valores PM10 superiores a $100 \mu \mathrm{g} / \mathrm{m}^{3}$.

- En los episodios que no hay intrusión, se concluye que el $75 \%$ de los valores de fondo para todas las estaciones se encuentra por debajo de $25 \mu \mathrm{g} / \mathrm{m}^{3}$.

- Para finalizar se han analizado varios casos de estudio que ponen en relieve la dificultad de predecir la intensidad, duración y zonas afectadas durante los episodios de intrusión sahariana en las islas Canarias. Además, ha quedado reflejado que en numerosas ocasiones los mínimos de visibilidad registrados no coinciden geográficamente con los máximos registrados de PM10,y esto supone una dificultad añadida para la realización de un pronóstico de polvo basado en una variable subjetiva como es el caso de la visibilidad.

\section{CONSIDERACIONES PRÁCTICAS}

\subsection{Introducción}

En este apartado se realizan algunas consideraciones prácticas que puede servir de ayuda para aquellos predictores operativos que se enfrenten a la predicción y vigilancia de eventos de intrusión de polvo. A pesar de que el objetivo principal de este trabajo ha sido la caracterización 
de las intrusiones de polvo en Canarias, se han utilizado una serie de métodos y datos de utilidad tanto para la predicción como para la vigilancia de las intrusiones de polvo.

Este trabajo pone en relieve los problemas que ocasiona caracterizar una intrusión de polvo mediante la medida subjetiva de la visibilidad. Hay que tener en cuenta que en este trabajo los datos de visibilidad utilizados provienen de los partes SYNOP y por tanto las observaciones tienen lugar a las horas establecidas en dichos partes. De ahí que no tienen por qué coincidir espacialmente los mínimos de visibilidad con las concentraciones más elevadas de PM10. Las concentraciones de polvo y la visibilidad pude cambiar muy rápidamente durante una intrusión de aire africano

\subsection{1 índice ARTI}

Desde el punto de vista práctico destaca el índice ARTI, ya que su uso permite con una alta probabilidad, la distinción de episodios con o sin intrusión de polvo. Para este trabajo se ha utilizado para su cálculo datos provenientes del reanálisis global atmosférico ERA-Interim, pero se está trabajando en una versión que utilice las salidas de los modelos numéricos de predicción y esté disponible para que los predictores operativos lo puedan consultar. El índice ARTI viene expresado en tanto por cien y este porcentaje expresa al tiempo que una masa de aire ha estado sobrevolando África en los 5 días previos. Altos valores de índice ARTI por tanto demarcan un carácter de alta africanidad de la masa de aire.

\subsubsection{Redes de observación de Calidad del Aire}

Los datos provenientes de la Red de Vigilancia de la Calidad del Aire del Gobierno de Canarias están disponibles en las siguientes webs:

https://www3.gobiernodecanarias.org/medioambiente/calidaddelaire/datosHistoricosForm.do

\section{https://www3.gobiernodecanarias.org/medioambiente/calidaddelaire/datosOnLine.do}

En la primera web se puede acceder a datos de archivo, mientras que en la segunda se pueden acceder a datos en tiempo real de las últimas 24 horas. Se puede realizar consultas por estación o por contaminante.

\subsubsection{Red proyecto Globe}

En la siguiente web se pueden encontrar medidas de $A O D$ realizadas desde centros escolares situados en todas las islas del archipiélago canario. Además de estas estaciones escolares, se realizan medidas de $A O D$ desde el GPV de Canarias. Esta red forma parte de un proyecto educativo conjunto entre AEMET a través del CIAI (Centro de investigaciones Atmosféricas de Izaña) y la Consejería de Educación y Universidades del Gobierno de Canarias como parte del proyecto GLOBE.

\section{http://testbed.aemet.es/calimaview/}

\subsubsection{Observaciones "low-cost"}

El AOD es medido mediante un Calitoo (más información http://www.calitoo.fr/), que es un fotómetro de mano.

\subsubsection{Pronósticos de polvo mineral}

Los datos de predicción de AOD, concentración en superficie y la predicción extraída de la mediana del multimodelo se encuentran disponibles en la web del SDS-WAS ( https://sds- 
was.aemet.es/forecast-products/dust-forecasts/forecast-comparison). Las salidas del modelo NMMB-MONARCH, que es el modelo de referencia del Centro Operativo de la OMM (el Barcelona Dust Forecast Center), se pueden consultar en su web (https://dust.aemet.es/).

Los pronósticos de polvo mineral de cada modelo del SDS-WAS y del "Barcelona Dust Forecast Center" son evaluados mediante los datos de observación de la red AERONET.

En el siguiente link se accede a la red de AERONET para la evaluación de los modelos de polvo. (https://sds-was.aemet.es/forecast-products/dust-observations/aeronet)

En la Figura 51 se muestra un ejemplo de la evaluación del AOD procedente de los 12 modelos disponibles más la mediana del multimodelo del SDS-WAS y los datos de observación (triángulos amarillos) de AOD de AERONET para octubre de 2019 en la estación de Santa Cruz de Tenerife). También se muestra el exponente de Ångström (AE) que permite una primera discriminación entre polvo mineral y otros aerosoles. Medidas de AOD con valor de AE más pequeño que 0.6 (en gris) se considera que corresponden a polvo mineral atmosférico.

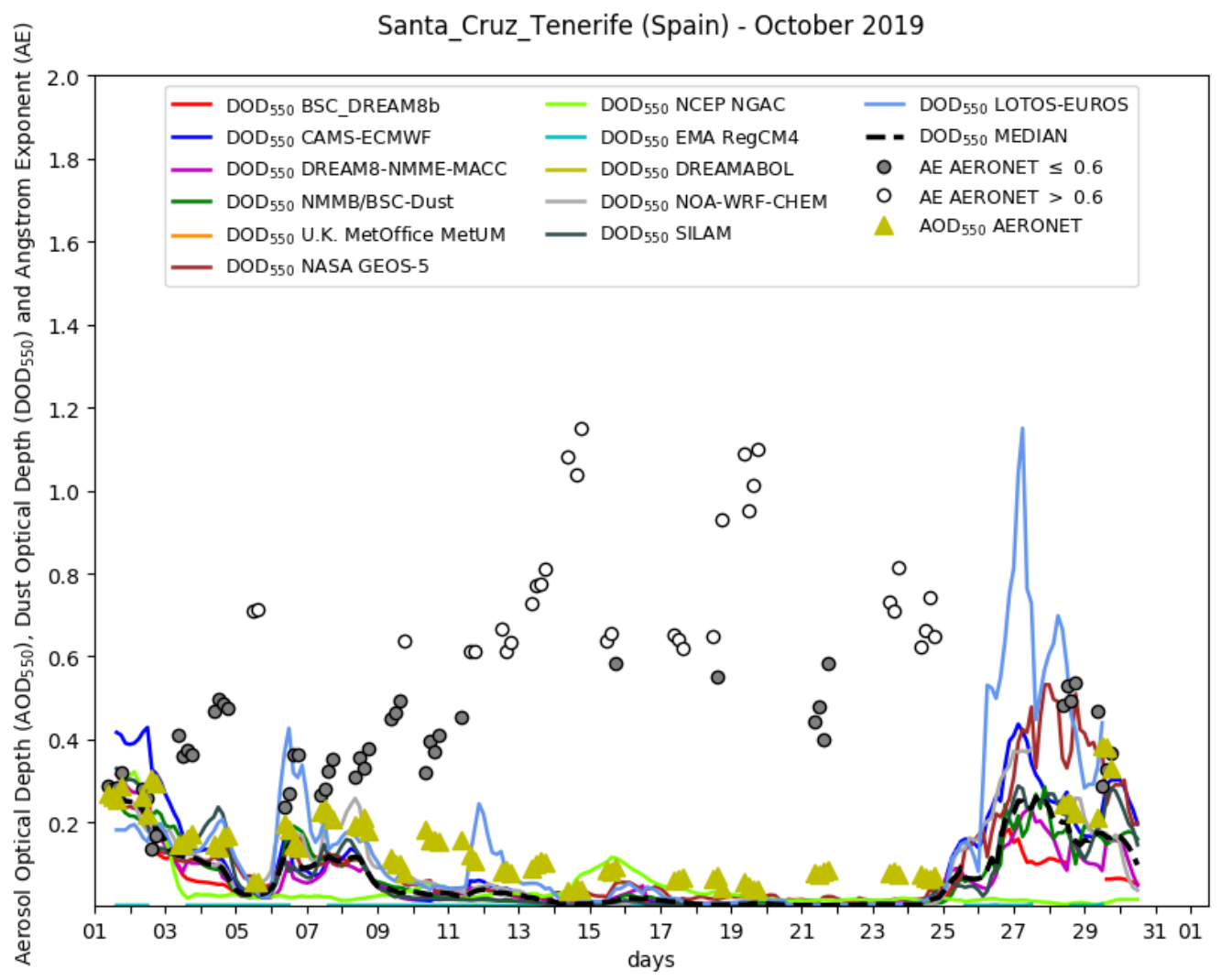

Figura 51. Comparación entre observación (AERONET, triángulos amarillos) y predicción de los modelos (sdswas, líneas de colores) para octubre 2019.

https://sds-was.aemet.es/forecast-products/forecast-evaluation/near-real-timeevaluation/aggregator v3

Hay que tener presente, que cuando se utiliza un modelo de predicción de polvo, este ofrece pronósticos de PM10 debido a polvo atmosférico exclusivamente. Sin embargo, las redes de 
observación mostradas anteriormente incluyen PM10 debido a la contribución de todo tipo de aerosoles, incluyendo el polvo mineral.

\subsection{Guía de apoyo para la predicción de calima}

En esta subsección se presenta una guía visual (Figura 52) de ayuda rápida que puede ser utilizada a la hora de realizar un pronóstico de intrusión sahariana en Canarias. Se describen a continuación de forma esquemática una serie de pasos a tener en cuenta:

1- Discriminar si con una alta probabilidad hay intrusión o no. Si el índice ARTI es igual a 0 con una alta probabilidad se estaría frente a un episodio de no intrusión. Valores de índice ARTI superiores a 0 indican que podría producirse una intrusión de polvo.

\section{Índice ARTI $=0 \rightarrow$ Episodio (con alta probabilidad) de no intrusión. Índice ARTI $>0 \rightarrow$ Episodio (con alta probabilidad) de intrusión.}

2- Si el índice ARTI $>0$. Estacionalidad de la intrusión y zonas afectadas:

- Verano (junio a septiembre): Las intrusiones suelen afectar a zonas altas del archipiélago.

- Invierno (diciembre a marzo): Son más intensos que los de verano y suelen afectar a las zonas bajas de las islas.

3- Tipo de pronóstico y variables relacionadas:

Cuantitativo: Columna atmosférica: AOD. Permitirá conocer si habrá intrusión de polvo en una determinada zona y en un instante de tiempo.

Ventaja $\rightarrow$ Mejor parámetro de aerosoles que pronostican los modelos.

Cuantitativo: Superficie: PM10. Si lo que se quiere determinar es la concentración en superficie de aerosoles, la variable a analizar es concentración en superficie (PM10) de los modelos. Además, el conocimiento del "background" de la zona de interés permite evaluar la calidad del aire.

Cuantitativo: Superficie: Coeficiente. Si lo que se desea estimar es la visibilidad, la variable a analizar es el coeficiente de extinción.

En el diagrama de la Figura 52, se incluyen las variables de modelos más relacionadas con el tipo de pronóstico que se quiera realizar. Es conveniente combinar la información de estas variables (AOD, coeficiente de extinción y PM10) con índice ARTI ya que permite conocer en qué niveles se produce una intrusión así como delimitar geográficamente el efecto de una intrusión. Además es de utilidad combinar con cortes verticales y secciones. 


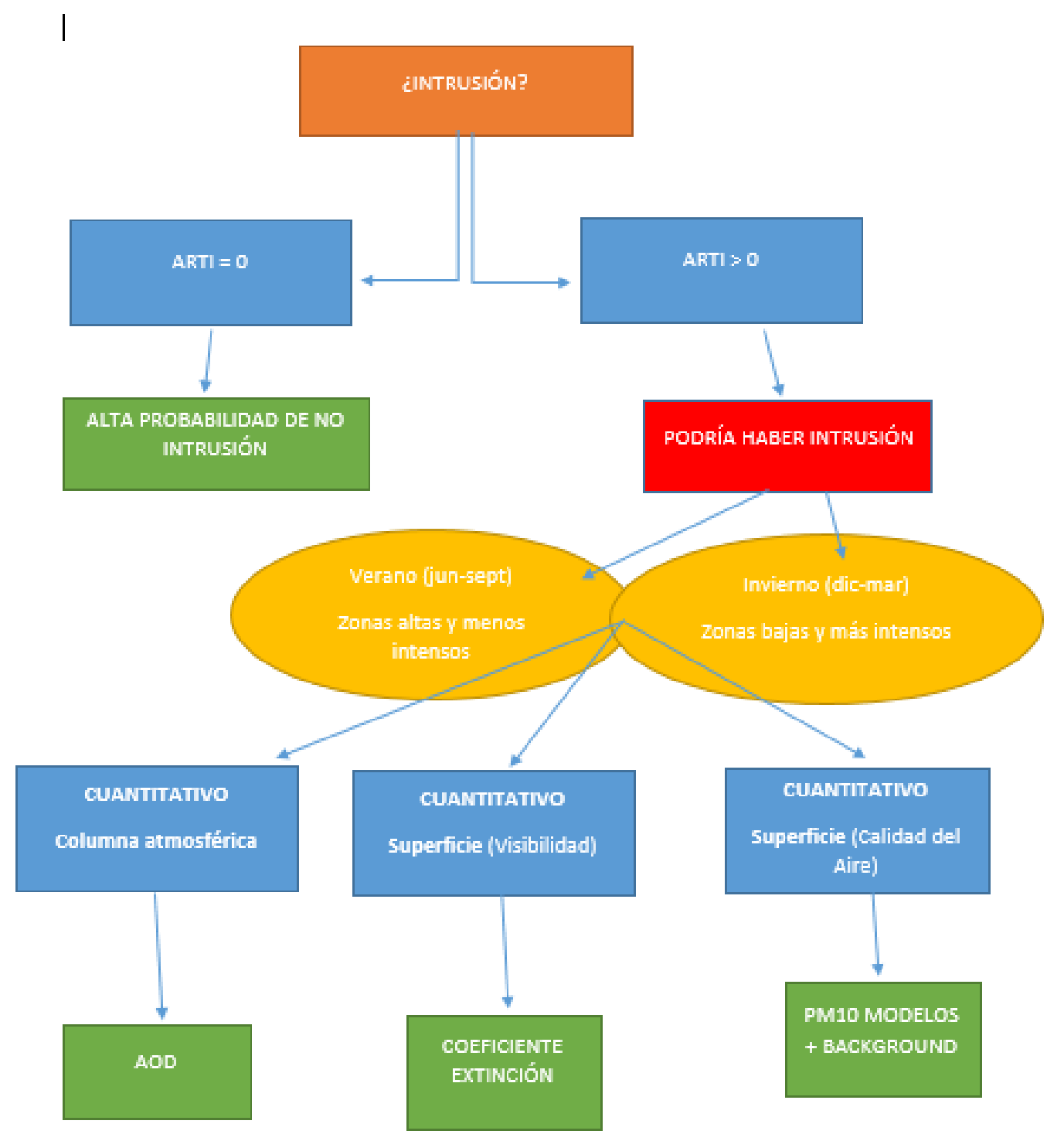

Figura 52. Diagrama de flujo que presenta una guía de ayuda visual para la predicción de intrusiones saharianas en Canarias. 


\section{Agradecimientos}

Esta Nota Técnica se ha desarrollado en el marco del Proyecto "Desarrollo un sistema de avisos de polvo atmosférico (PM10) para Canarias" del Plan Estratégico de AEMET 2019-2021 en el que participan los coautores de este Nota Técnica.

Agradecimientos al Sand and Dust Storm Warning Advisory and Assement System (SDSWAS), por la implicación en este trabajo.

Los autores de este documento quieren agradecer a ECMWF, NILU y a los desarrolladores del modelo FLEXTRA Andreas Stohl (NILU, Norwegian Institute for Air Research) en cooperación con Gerhard Wotawa y Petra Seibert (Institute of Meteorology and Geophysics, Vienna).

Agradecimientos al Gobierno de Canarias por el suministro de datos de PM10 de la Red de Vigilancia de la Calidad del Aire.

Los autores también quieren agradecer a NOAA-CIRES-DOE Twentieth Century Reanalysis Project version 3 por los recursos usados de National Energy Research Scientific Computing Center gestionado por Lawrence Berkeley National Laboratory que es apoyado por the Office of Science of the U.S. Department of Energy bajo el contrato número DE-AC02-05CH11231 y usa recursos de NOAA's Remotely Deployed High Performance Computing Systems.

Además los autores agradecen a AXA Research Fund que apoya la investigación de la línea de polvo mineral en el BSC, COST Association a través de la COST Action CA16202 (inDust), AERONET y todos los colaboradores del Centro Regional para el Norte de África, Oriente Medio y Europa del SDS-WAS.

Agradecimientos a los observadores que forman el Grupo de Predicción y Vigilancia de Las Palmas (GPV de Canarias) por su esencial involucración en la toma de datos de AOD, ya que estas medidas permiten obtener valiosas series de datos y complementan al resto de medidas incluidas en el programa Globe. 


\title{
REFERENCIAS BIBLIOGRÁFICAS
}

\author{
https://www3.gobiernodecanarias.org/medioambiente/calidaddelaire/documentos/Informe\%20Calidad \\ \%20del\%20Aire\%20Canarias 2017.pdf
}

http://glossary.ametsoc.org

Índice de Calidad del Aire: https://www.boe.es/eli/es/o/2019/03/18/tec351/con

Alonso-Pérez, S., Cuevas, E., Querol, X., Viana, M. and Guerra, J. C. (2007). Impact of the Saharan dust outbreaks on the ambient levels of total suspended particle (TSP) in the Marine Boundary Layer (MBL) of the Subtropical Eastern North Atlantic Ocean. Atmos. Environ. 41/40, 9468-9480, doi:10.1016/j.atmosenv.2007.08.049.

Barreto, A., E. Cuevas, P. Pallé, P. M. Romero, C. Guirado, C. J. Wehrli, and F. Almansa (2014). Recovering long-term aerosol optical depth series (1976-2012) froman astronomical potassium-based resonance scattering spectrometer. Atmospheric Measurement techniques, 7, p. 4103-4116.

Camino, C., E. Cuevas, S. Basart, S. Alonso-Pérez, J.M. Baldasano, E. Terradellas, B. Marticorena, S. Rodríguez, A. Berjón (2015). An empirical equation to estimate mineral dust concentrations from visibility observations in Northern Africa, Aeolian Research, Vol. 16, Pages 55-68.

Cuevas, E., Camino, C., Benedetti, A., Basart, S., Terradellas, E., Baldasano, J. M., Morcrette, J. J., Marticorena, B., Goloub, P., Mortier, A., Berjón, A., Hernández, Y., Gil-Ojeda, M., and Schulz, M (2015). The MACC-II 2007-2008 reanalysis: atmospheric dust evaluation and characterization over northern Africa and the Middle East, Atmos. Chem. Phys., 15, 3991-4024, https://doi.org/10.5194/acp-15-3991$\underline{2015}$.

Cuevas, E., A.J. Gómez-Peláez, S. Rodríguez, E. Terradellas, S. Basart, R.D. García, O.E. García, S. Alonso-Pérez (2017). The pulsating nature of large-scale Saharan dust transport as a result of interplays between mid-latitude Rossby waves and the North African Dipole Intensity. Atmospheric Environment, 167 , p. 586-602.

Cuevas, E., Romero-Campos, P. M., Kouremeti, N., Kazadzis, S., Räisänen, P., García, R. D., Barreto, A., Guirado-Fuentes, C., Ramos, R., Toledano, C., Almansa, F., and Gröbner, J. (2019). Aerosol optical depth comparison between GAW-PFR and AERONET-Cimel radiometers from long-term (2005-2015) 1 min synchronous measurements, Atmos. Meas. Tech., 12, 4309-4337, https://doi.org/10.5194/amt12-4309-2019.

Díaz, J., Tobías, A., and Linares, C. (2012). Saharan dust and association between particulate matter and case-specific mortality: a case crossover analysis in Madrid (Spain), Environ. Health, 11, 1-6, doi:10.1186/1476-069X-11-11, 2012.

Dominguez-Rodriguez,A., Abreu-Gonzalez,P., Rodríguez,S., Avanzas, P., \& Ruben A. Juarez-Prera (2017). Short-term effects of air pollution, markers of endothelial activation, and coagulation to predict major adverse cardiovascular events in patients with acute coronary syndrome: insights from AIRACOS study, Biomarkers, 22:5, 389-393, DOI: 10.3109/1354750X.2016.1160430 
Domínguez Rodríguez, A., Baez-Ferrer, N., Rodríguez, S., Abreu-González, P., González-Colaço Harmand, M., Amarnani-Amarnani, V., Cuevas, E., Consuegra-Sánchez, L., Alonso-Pérez, S., Avanzas, P., Burillo Putze, G. (2019). Impacto de la exposición a la calima del polvo del Sáhara en los pacientes con insuficiencia cardiaca aguda atendidos en un servicio de urgencias, Emergencias, 31, 161-166.

Dorta P. (2007). Catálogo de riesgos climáticos en Canarias: Amenazas y vulnerabilidad. Geographicalia, 51 p. 133-160.

Foltz, G.R., McPhaden, M.J. (2008). Impact of Saharan dust on tropical North Atlantic SST. J. Clim. 21, $5048 \mathrm{e} 5060$

García, R.D., O. E. García, E. Cuevas, V. E. Cachorro, A. Barreto, C. Guirado-Fuentes, N. Kouremeti, J. J. Bustos, P. M. Romero-Campos, and A. M. de Frutos (2016). Aerosol optical depth retrievals at the Izaña Atmospheric Observatory from 1941 to 2013 by using artificial neural networks. Atmospheric Measurement techniques, 9, p.53-62.

GAW Report, 162. Leonard A. Barrie, C. Wehrli. WMO/GAW Experts Workshop on a Global SurfaceBased Network for Long Term Observations of Column Aerosol Optical Properties (8-10 March 2004; Davos, Switzerland)

Ginoux, P., M. Chin, I. Tegen, J. M. Prospero, B. Holben, O. Dubovik, and S.-J. Lin (2001). Sources and distributions of dust aerosols simulated with the GOCART model, J. Geophys. Res., 106(D17), 2025520273.

Ginoux, P., J. M. Prospero, T. E. Gill, N. C. Hsu, and M. Zhao (2012). Global-scale attribution of anthropogenic and natural dust sources and their emission rates based on MODIS Deep Blue aerosol products, Rev. Geophys., 50, RG3005, doi: 10.1029/2012RG000388.

González López, B (2005). Meteorología Aeronáutica. Editorial AVA (Actividades Varias Aeronáuticas) $1^{\text {a }}$ edición: Año 2005. 385 pp.

Goudie, A.S.,Middleton, N.J. , (2001). Saharan dust storms: nature and consequences. Earth Sci. Rev. $56(1), 179 \mathrm{e} 204$.

Huneeus, N., Boucher, O., Chevallier, F. (2013). Atmospheric inversion of SO2 and primary aerosol emissions for the year 2010, Atmos. Chem. Phys., 13, 6555-6573.

Holben, B. N., Eck, T. F., Slutsker, I. A., Tanre, D., Buis, J. P., Setzer, A., Lavenu, F. (1998). AERONET_A federated instrument network and data archive for aerosol characterization. Remote sensing of environment, 66(1), 1-16.

Karanasiou, A., Moreno, N., Moreno, T., Viana, M., de Leeuw, F.,Querol, X., (2012). Health effects from Sahara dust episodes in Europe: Literature review and research gaps. Environ. Int. 47, 107e114.

Meteoalerta, (2018). Plan Nacional de Predicción y Vigilancia de Fenómenos Meteorológicos Adversos. METEOALERTA. Agencia Estatal de Meteorología (AEMET). http://www.aemet.es/documentos/es/eltiempo/prediccion/avisos/plan_meteoalerta/plan_meteoalerta.p df (accessed 26 July 2019).

Prospero, J.M., (1999). Long-range transport of mineral dust in the global atmosphere: impact of African dust on the environment of the southeastern United States.PNAS 96 (7), 3396e3403. http://dx.doi.org/10.1073/pnas.96.7.3396.

Prospero, J.M., Lamb, P.J (2003). African droughts and dust transport to the Caribbean:climate change implications. Science 302, 1024e1027. http://dx.doi.org/10.1126/science.1089915.

Prospero, J.M., Collard, F.-X., Molinié, J., Jeannot, A., (2014): Characterizing the annual cycle of African dust transport to the Caribbean Basin and South America and its impact on the environment and air quality. Glob. Biogeochem. Cycles 29. http://dx.doi.org/10.1002/2013GB004802. 
Rodríguez, S., E. Cuevas, J. M. Prospero, A. Alastuey, X. Querol, J. López-Solano, M. I. García and S. Alonso-Pérez (2015). Modulation of Saharan dust export by the North African dipole. Atmospheric Chemistry and Physics, 15, 7471-7486.

Stohl, A., G. Wotawa, P. Seibert, and H. Kromp-Kolb (1995). Interpolation errors in wind fields as a function of spatial and temporal resolution and their impact on different types of kinematic trajectories.J. Appl. Meteor. 34, 2149-2165.

Stohl, A. (1998). Computation, accuracy and applications of trajectories - a review and bibliography.Atmos. Environ. 32, 947-966.

Stohl, A., and P. Seibert (1998). Accuracy of trajectories as determined from the conservation of meteorological tracers.Q. J. Roy. Met. Soc. 124, 1465-1484.

Tegen, I., Torres, R., (2005). Global iron connections: desert dust, ocean biogeochemistry and climate. Science $308,67 \mathrm{e} 71$

Wehrli, C.: GAWPFR: A network of aerosol optical depth observations with precision filter radiometers, GLOBAL ATMOSPHERE WATCH, p. 36, 2005. 


\section{Anexo 1}

\section{Lanzarote:}

Tiene 4 estaciones con altitudes comprendidas entre 10 y 44 metros. Hay estaciones tipo Industrial-Urbana, Industrial-Suburbana, Fondo-Urbana y Tráfico-Urbana.

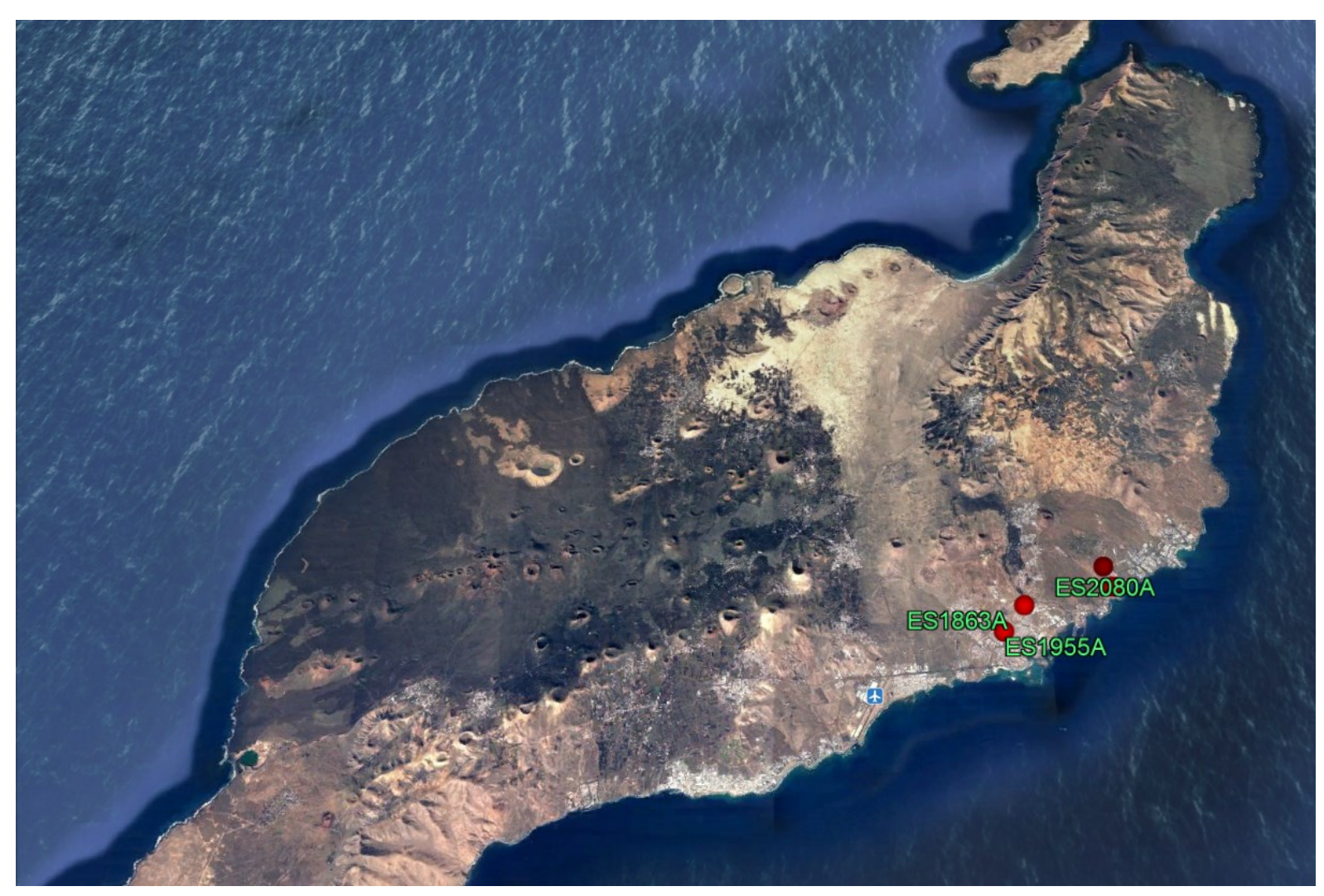

\begin{tabular}{|c|c|c|c|c||c||c|c|}
\hline Indlcatlvo & MUNICIPIO & NOMBRE & LATITUD & LONGITUD & ALIITUD & TIPO_ESTACION & TIPO_AREA \\
\hline \hline ES1863A & ARRECIFE & ARRECIFE & 28,977 & $-13,5476$ & 44 & INDUSTRIAL & URBANA \\
\hline ES1864A & TEGUISE & COSTA TEGUISE & 28,9903 & $-13,5166$ & 36 & INDUSTRIAL & SUBURBANA \\
\hline ES1955A & ARRECIFE & CIUDAD DEPORTIVA-ARRECIFE & 28,9679 & $-13,5559$ & 22 & FONDO & URBANA \\
\hline ES20804 & TEGUISE & LAS CALETAS-TEGUISE & 28,9829 & $-13,514$ & 10 & TRA FICO & SUBURBANA \\
\hline
\end{tabular}




\section{Fuerteventura:}

Tiene instaladas 5 estaciones de tipo Industrial-Urbana, Fondo-Urbana y Fondo-Rural, con altitudes comprendidas entre 15 y 160 metros.

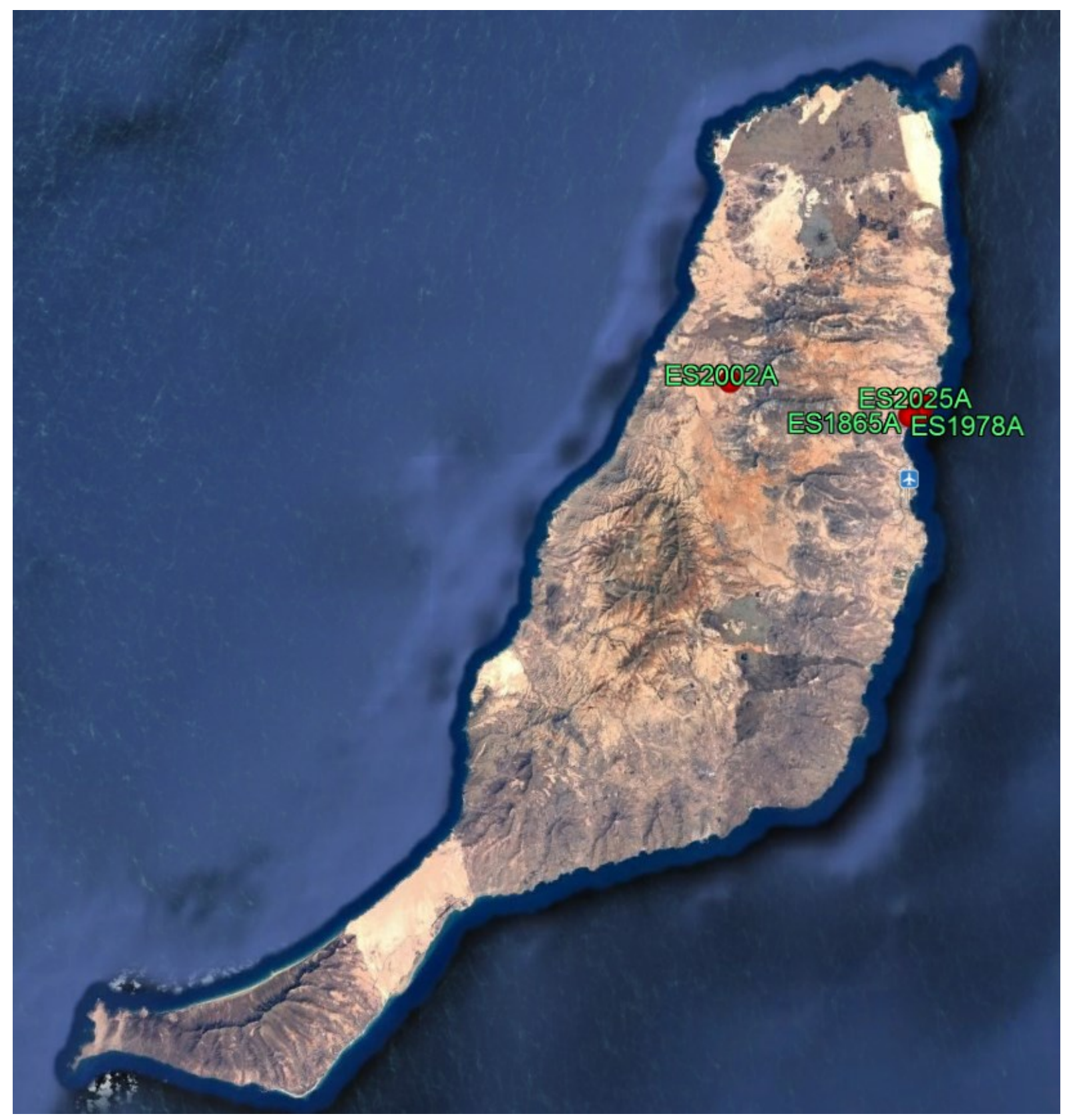




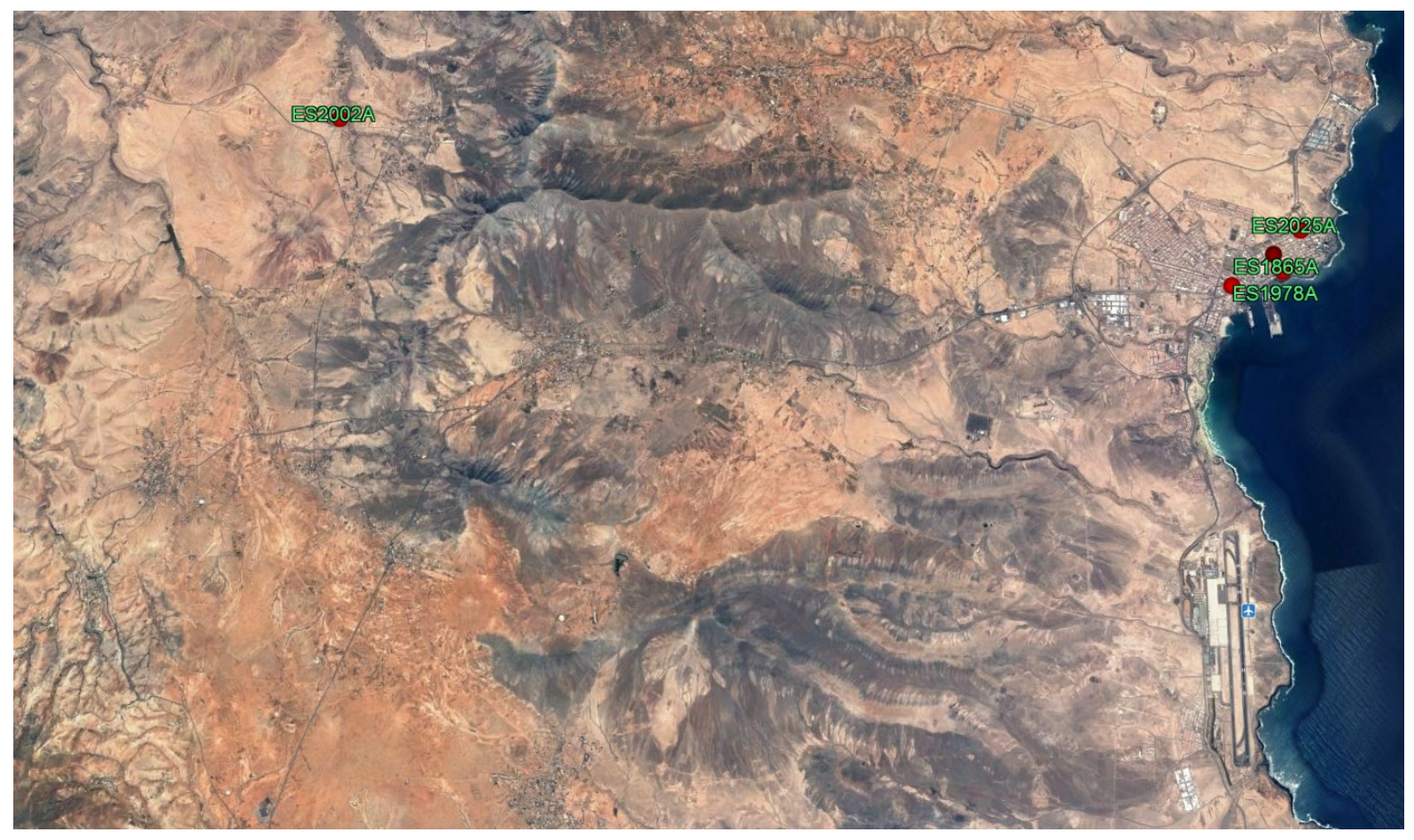

\begin{tabular}{|c|c|c|c|c|c|c|c|}
\hline indicativo & MUNICIPIO & NOMBRE & LATITUD & LONGIUD & ALTITUD & TIPO_ESTACION & TIPO AREA \\
\hline ES1865A & PUERTO DEL ROSARIO & CENTRO DE ARTE JUAN ISMAEL & 28,5003 & $-13,8524$ & 20 & INDUSTRIAL & URBANA \\
\hline ES1966A & PUERTO DEL ROSARIO & PARQUE DELA PIEDRA & 28,5028 & $-13,8537$ & 15 & INDUSTRIAL & URBANA \\
\hline ES1978A & PUERTO DEL ROSARIO & CASA PALACIO-PUERTO DELROSARIO & 28,4994 & $-13,8608$ & 23 & FON DO & URBANA \\
\hline ES2002A & PUERTO DEL ROSARIO & TEFIA-PUERTO DEL ROSARIO & 28,5272 & $-14,0044$ & 160 & FONDO & RURAL \\
\hline ES2025A & PUERTO DEL ROSARIO & EL CHARCO.PTO DEL ROSARIO & 23,5062 & $-13,849$ & 15 & INDUSTRIAL & URBANA \\
\hline
\end{tabular}




\section{Gran Canaria:}

Hay 13 estaciones de tipo Industrial-Urbana, Tráfico-Urbana, Industrial-Rural, IndustrialUrbana, Fondo-Urbana, Fondo-Suburbana y Urbana-Urbana, con altitudes entre 11 y 460 metros.

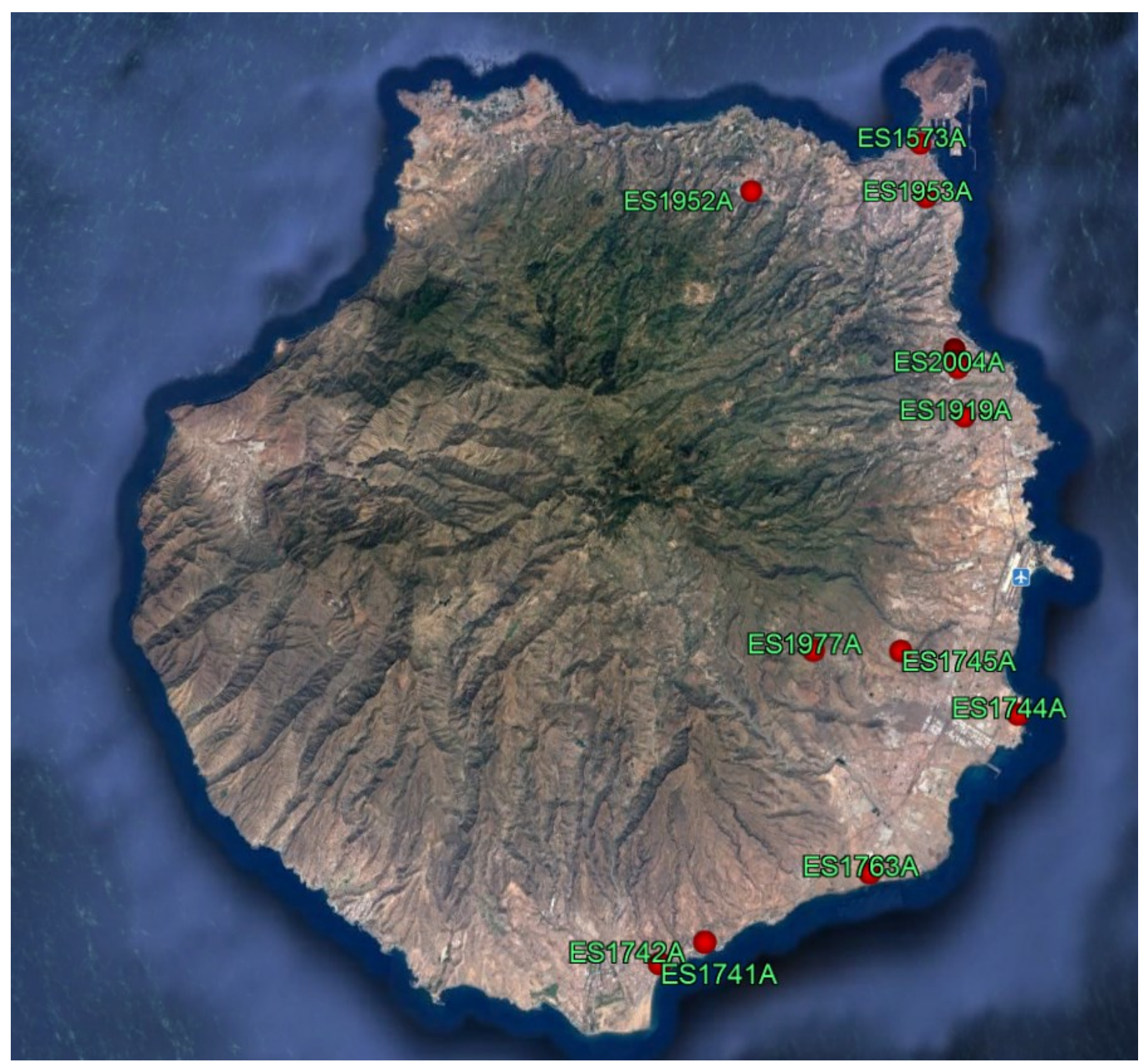

\begin{tabular}{|c|c|c|c|c|c|c|c|}
\hline indicstivo & MUNICIPIO & NOMBRE & LATIUD & LONGIUDD & ALTIIUD & TIPO_ESTACION & TIPO AREA \\
\hline ES0973A & PALMAS DE GRAN CANA RIA (LAS) & JINAMAR IIII FASE & 28,0351 & $-15,4163$ & 53 & INDUSTRIAL & URBANA \\
\hline ES0896A & TELDE & PEDROLEZCANO & 28,0299 & $-15,4161$ & 90 & INDUSTRIAL & URBANA \\
\hline ES1573A & PALMAS DE GRAN CANA RI A (LAS) & MERCADO CENTRAL & 28,1337 & $-15,4328$ & 11 & TRAFICO & URBANA \\
\hline ES1741A & SAN BA RT OLOME DE TIRAIANA & PLAYA DEL INGLES & 27,7637 & $-15,5639$ & 17 & TRAFICO & URBANA \\
\hline ES1742A & SAN BA RT OLOME DE TIRAIANA & SAN AGUSTIN & 27,7726 & $-15,5419$ & 15 & TRAFICO & URBANA \\
\hline ES1744A & AGUIMES & ARINAGA & 27,8691 & $-15,3971$ & 23 & INDUSTRIAL & RURAL \\
\hline ES1745A & AGUIMES & AGUIMES & 27,8976 & $-15,445$ & 265 & INDUSTRIAL & URBANA \\
\hline ES1763A & SAN BA RT QLOME DE TIRAIANA & CASTILO DEL ROMERAL & 27,9013 & $-15,4612$ & 13 & INDUSTRIAL & URBANA \\
\hline ES1919A & TELDE & PARQUE DE SAN JUAN-TELDE & 28,0037 & $-15,4118$ & 113 & FONDO & URBANA \\
\hline ES1952A & ARUCAS & POLIDEPORTIVO AFONSO-ARUCAS & 28,1113 & $-15,5209$ & 226 & FONDO & SUBURBANA \\
\hline ES1953A & LAS PALMAS DE GRAN CANARIA & PARQUE LASREHOYAS & 28,1075 & $-15,43$ & 85 & URBANA & URBANA \\
\hline ES1977A & SANTA UUA DE TIRAJANA & CAMPINGTEMISAS-STA UUAA DET. & 27,8993 & $-15,-4993$ & 460 & FONDO & SUBURBANA \\
\hline ES2004A & TELDE & LA LOMA-TELDE & 28,0263 & $-15,4147$ & 115 & INDUSTRIAL & URBANA \\
\hline
\end{tabular}




\section{Tenerife:}

Con 22 estaciones, es la que más cobertura tiene. Son de tipo Industrial-Urbana, IndustrialSuburbana, Fondo-Urbana, Fondo-Suburbana y Fondo-Rural. Se encuentran comprendidas entre los 2 y los 580 metros.

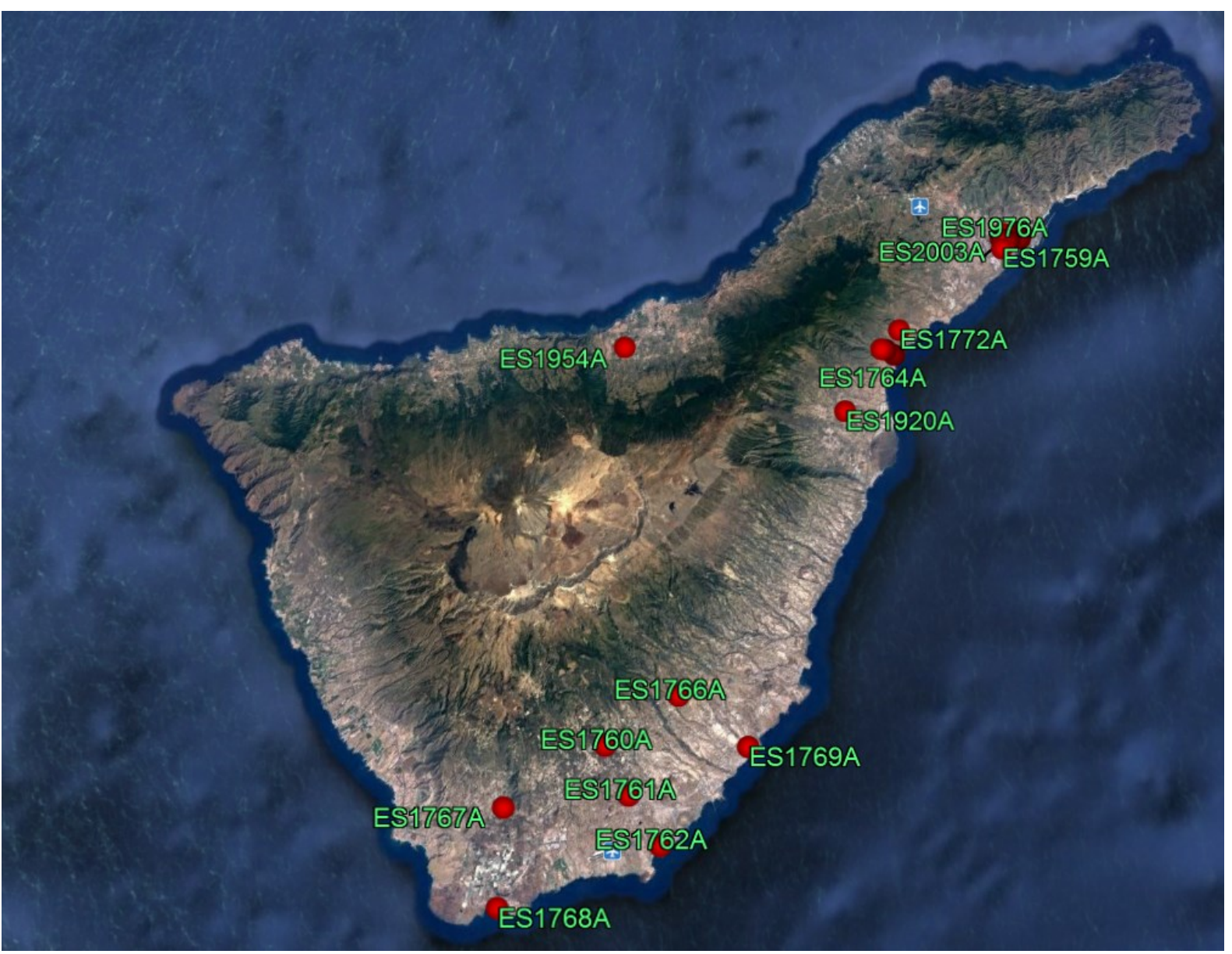

\begin{tabular}{|c|c|c|c|c|c|c|c|}
\hline indicetivo & MURAPIO & NOMBFE & LATIIUD & IONGIUD & ALTIIUD & TIPO ESTAOON & TIPO $A R E A$ \\
\hline ES1131A & SANTA CRLZ DE TENERFE & TOMECANO & 28,4622 & $-16,2619$ & 67 & INDUSTRAL & URBANA \\
\hline ES17564 & CANDELARIA & CALETILA & 28,3767 & -163619 & 24 & INDUSTRAL & URBANA \\
\hline ES17594 & SANTA CRLZ DE TENERFE & CASA CUNA & 28,451 & $-16,2777$ & $1 \mathrm{BB}$ & INDUSTRAL & URBANA \\
\hline ES17604 & GRANADLA DEABONA & GRANADLLA & 28,1125 & $-16,5776$ & 530 & INDUSTRAL & SUBURBANA \\
\hline ES17614 & GRANA DLA DEABONA & SANISI DAO & 28,08 & $-16,5599$ & 235 & INDUSTRAL & URBANA \\
\hline ES17624 & GRANADLA DEABONA & MEDANO & 28,0473 & -165361 & 12 & INDUSTRAL & URBANA \\
\hline ES1764A & CANDELARIA & IGUESTE & 28,3605 & $-16,372$ & 215 & INDUSTRAL & SUBURBANA \\
\hline ES17664 & ARONA & ELRIO & 28,1451 & $-16,5237$ & 500 & INDUSTRAL & SUBURBANA \\
\hline ES1767A & ARONA & BLZANADA & 28,0725 & $-16,653$ & 308 & FONDO & SUBURBANA \\
\hline ES17634 & ARONA & GALIETAS & 28,0077 & $-16,6559$ & 3 & FONDO & URBANA \\
\hline ES1769A & ARCO & SAN M GUEL DETAIAO & 28,1114 & $-16,4716$ & 30 & INDUSTRAL & SUBURBANA \\
\hline ES1772A & CANDELARIA & BARRANCO HONDO & 28,3934 & $-16,3581$ & 396 & INDUSTRAL & SUBURBANA \\
\hline E519204 & ARAFO & LA HDALGA-ARAFO & 283372 & $-16,3997$ & 275 & FONDO & SUBURBANA \\
\hline ES1954A & REALEOS (LOS) & BALSA DEZAMORA-LOS REAIEIOS & 28,3831 & $-16,5707$ & 371 & FONDO & RURAL \\
\hline ES19754 & SANTA CRLZ DE TENERFE & DEPOSITO TRSTANSTAA CRLZ DE TF & 28,4582 & $-16,2788$ & 200 & FONDO & URBANA \\
\hline ES19764 & SANTA CRLZ DE TENERFE & VUELTA LOS PAJAROS-STA CRLZ DETF & 28,4618 & $-16,2766$ & 158 & INDUSTRAL & URBANA \\
\hline ESOOOOA & SANTA CRLZ DE TENERFE & PISONA MUNIC PALLSTA CRUZDETF & 28,458 & $-16,2633$ & 60 & INDUSTRAL & URBANA \\
\hline ES20034 & SANTA CRLZ DE TENER FE & TENA ART GAS-STA CRUZ DE TENERFE & 28,4554 & $-16,2768$ & 169 & FONDO & URBANA \\
\hline ES20204 & SANTA CRLZ DE TENERFE & GARCIA ESCAMEZ-STA CRLZ DE TF & 28,4567 & $-16,2718$ & 119 & INDUSTRAL & URBANA \\
\hline ES2O21A & SANTA CRLZ DE TENERFE & PARQUE LA GRANUA-STA CRLZ DE TF & 28,463 & $-16,2649$ & 78 & INDUSTRAL & URBANA \\
\hline ES2022A & CANDELARIA & DEPOSITO LA GUANOHA-CANDELARIA & 28,3802 & $-16,36023$ & 128 & INDUSTRAL & SUBURBANA \\
\hline ES20384 & SANTA CRLZ DE TENERFE & TIO PNO-STA CRUZDE TENERFE & 28,4593 & $-16,2702$ & 104 & INDUSTRAL & URBANA \\
\hline
\end{tabular}




\section{La Gomera}

Tiene 2 estaciones de tipo Fondo-Urbana e Industrial-Urbana con altitudes entre 2 y 49 metros.

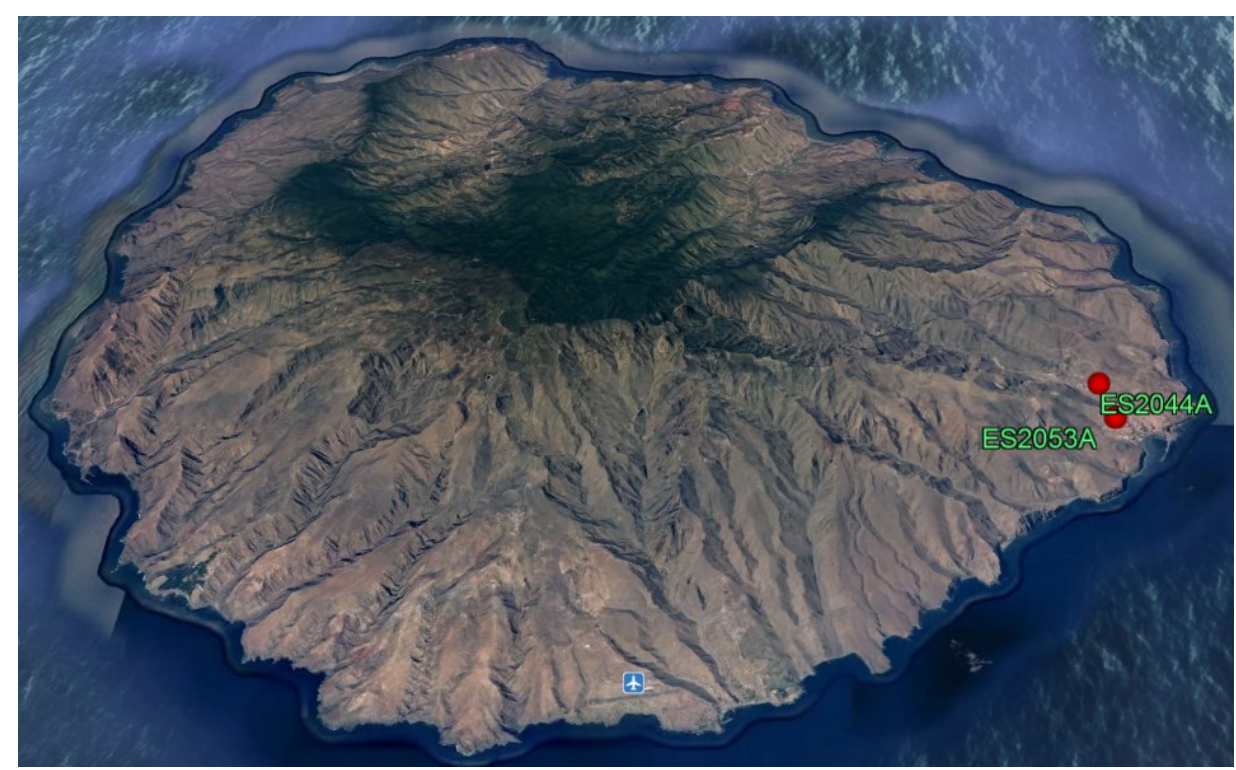

\begin{tabular}{|c|c|c|c|c|c|c|c|}
\hline ndicstivo & MUNICIPIO & NOMBRE & LATIUD & LONGIUDD & ALTIUD D & TIPO ESTACION & TIPO_AREA \\
\hline 520444 & SAN SEBASTIAN DE LA GOMERA & RESIDENCIA ESCOLAR-SS GOMERA & 28,0991 & $-17,1205$ & 20 & FONDO & \\
\hline ES20534 & SAN SEBASTIAN DE LA GOMERA & LAS GALANAS -SS GOMERA & 28,0901 & $-17,1181$ & $\Delta 9$ & INDUSTRIAL & URBA \\
\hline
\end{tabular}




\section{La Palma}

Tiene 4 de tipo Fondo-Suburbana, Industrial-Suburbana, Industrial-urbana y Fondo-Rural, entre 52 y 364 metros.

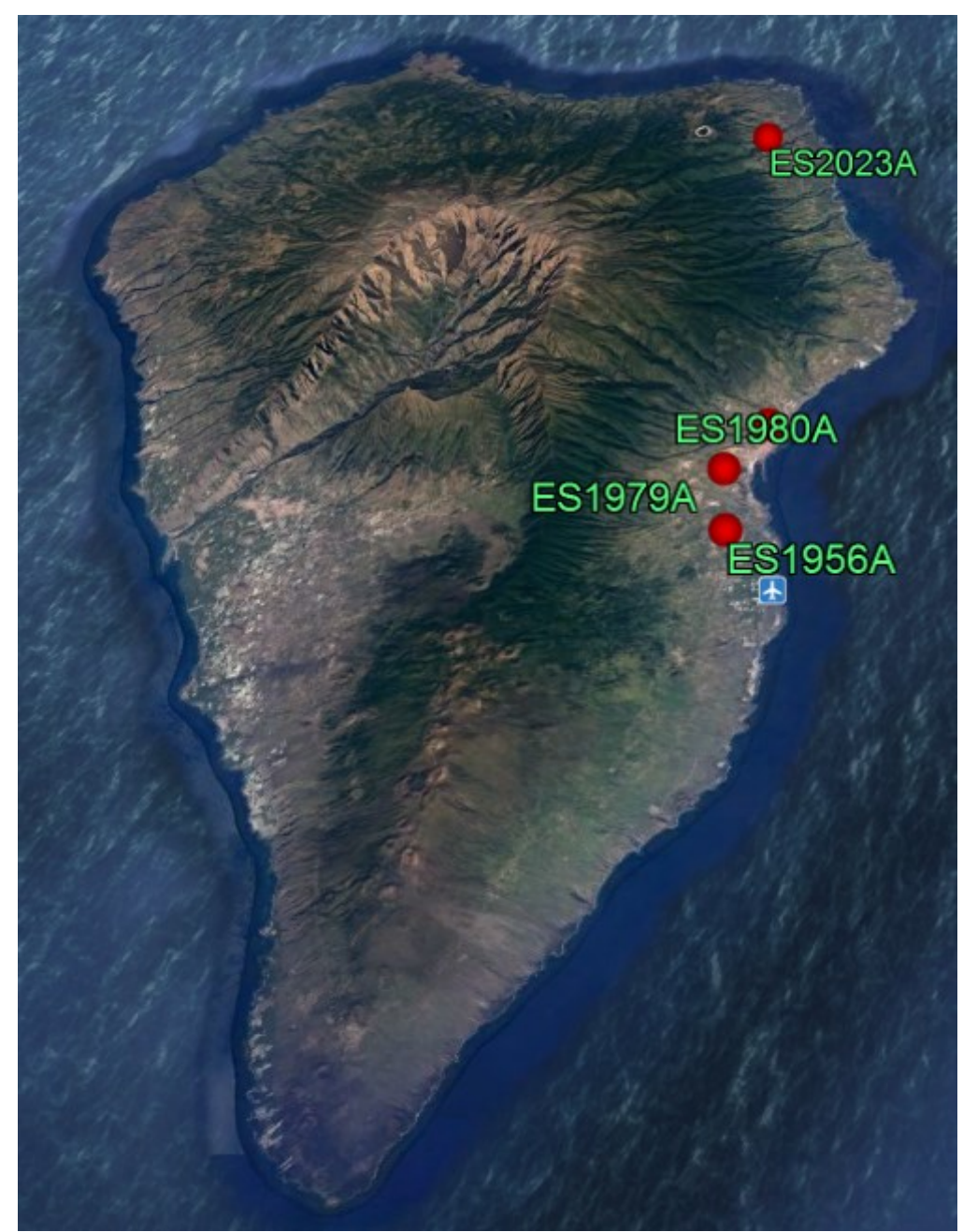

\begin{tabular}{|c|c|c|c|c|c|c|c|}
\hline indicstivo & MUNICIPIO & NOMBRE & LATIIUD & LONGIUD & ALTIIUD & TIPO_ESTACION & TIPO AREA \\
\hline ES1956A & BRET̃A BAJA & SAN ANTONIO-BRERAA BAJA & 28,6454 & $-17,7715$ & 208 & FONDO & SUBURBANA \\
\hline ES1979A & BRET̃A ALTA & LA GRAMA-BREন̃A ALTA & 28,6677 & $-17,7756$ & 245 & INDUSTRIAL & SUBURBANA \\
\hline ES19904 & SANTA CRUZ DE LA PAUMA & EL PILAR-STA CRLZ DE LA PALMA & 28,686 & $-17,7646$ & 52 & INDUSTRIAL & URBANA \\
\hline ES2023A & SAN ANDRES Y SAUCES & LAS BALSAS-S.ANDRES Y SAUCES & 28,8051 & $-17,7826$ & 364 & FONDO & RURAL \\
\hline
\end{tabular}




\section{El Hierro}

Tiene una única estación tipo Fondo-Suburbana a 375 metros de altitud.

\begin{tabular}{|c|c|c|c|c||c||c||c|}
\hline indicativo & MUNICIPIO & NOMBRE & LATITUD & LONGITUD & ALTITUD & TIPO_ESTACION & TIPO_AREA \\
\hline ES2024A & VALVERDE & ECHEDO-VALVERDE & 27,8318 & $-17,9217$ & 375 & FONDO & SUBURBANA \\
\hline
\end{tabular}

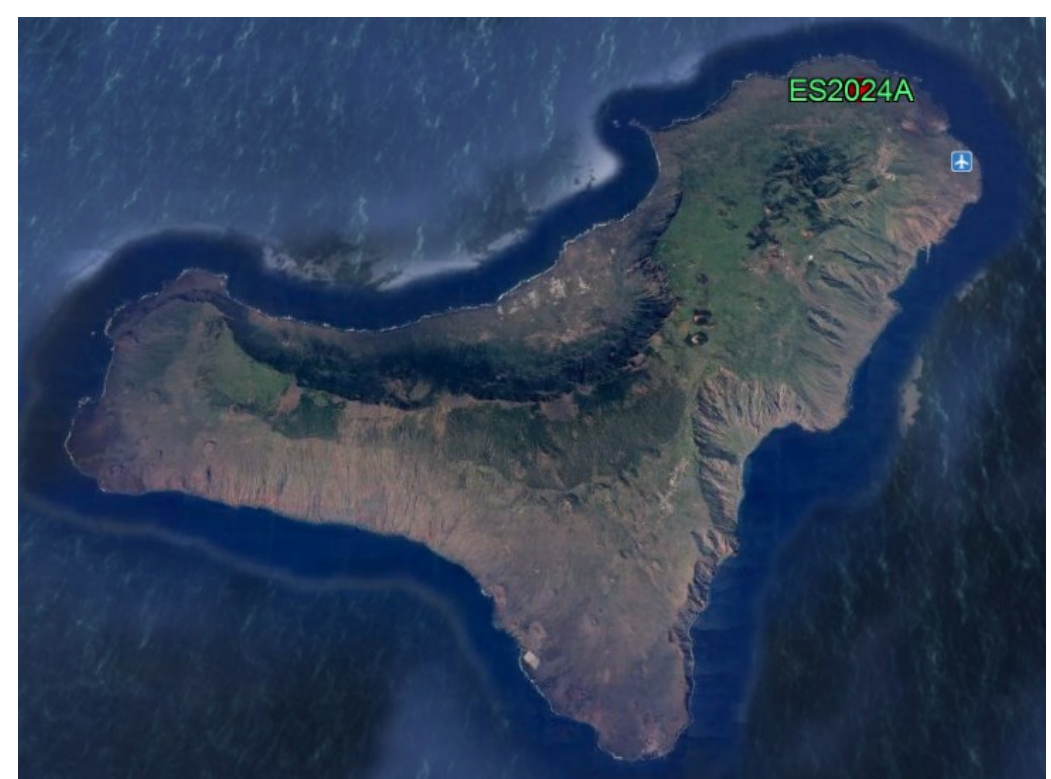




\section{Anexo 2}

Fechas de los episodios detectados para los cálculos realizados en el apartado 2.

\begin{tabular}{|c|c|c|}
\hline Fecha Inicio Episodio & Fecha Fin Episodio & Intensidad \\
\hline $17 / 01 / 2010$ & $20 / 01 / 2010$ & Moderada \\
\hline $06 / 02 / 2010$ & $08 / 02 / 2010$ & Moderada \\
\hline $17 / 03 / 2010$ & $20 / 03 / 2010$ & Fuerte \\
\hline $26 / 04 / 2010$ & $01 / 05 / 2010$ & Débil \\
\hline $31 / 05 / 2010$ & $05 / 06 / 2010$ & Débil \\
\hline $06 / 07 / 2010$ & $13 / 07 / 2010$ & Moderada \\
\hline $17 / 07 / 2010$ & $19 / 07 / 2010$ & Débil \\
\hline 09/08/2010 & $13 / 08 / 2010$ & Moderada \\
\hline $25 / 08 / 2010$ & $31 / 08 / 2010$ & Débil \\
\hline $13 / 09 / 2010$ & $16 / 09 / 2010$ & Débil \\
\hline $21 / 09 / 2010$ & $26 / 09 / 2010$ & Moderada \\
\hline $28 / 10 / 2010$ & $30 / 10 / 2010$ & Débil \\
\hline $02 / 11 / 2010$ & $06 / 11 / 2010$ & Fuerte \\
\hline $14 / 12 / 2010$ & $16 / 12 / 2010$ & Débil \\
\hline $28 / 12 / 2010$ & $30 / 12 / 2010$ & Fuerte en Lan y Fue \\
\hline $04 / 01 / 2011$ & 08/01/2011 & Débil \\
\hline $15 / 01 / 2011$ & $20 / 01 / 2011$ & Fuerte \\
\hline $20 / 03 / 2011$ & $24 / 03 / 2011$ & Débil \\
\hline $10 / 05 / 2011$ & $17 / 05 / 2011$ & Débil \\
\hline $12 / 06 / 2011$ & $17 / 06 / 2011$ & Débil \\
\hline $19 / 06 / 2011$ & $25 / 06 / 2011$ & Débil \\
\hline $27 / 06 / 2011$ & $05 / 07 / 2011$ & Débil \\
\hline $29 / 07 / 2011$ & 03/08/2011 & Débil \\
\hline $14 / 08 / 2011$ & $17 / 08 / 2011$ & Débil \\
\hline 05/09/2011 & $10 / 09 / 2011$ & Débil \\
\hline 03/10/2011 & 07/10/2011 & Débil \\
\hline $10 / 10 / 2011$ & $12 / 10 / 2011$ & Débil \\
\hline $17 / 10 / 2011$ & $18 / 10 / 2011$ & Débil \\
\hline $11 / 11 / 2011$ & $13 / 11 / 2011$ & Débil \\
\hline $01 / 12 / 2011$ & $02 / 12 / 2011$ & Débil \\
\hline $04 / 12 / 2011$ & $05 / 12 / 2011$ & Moderada \\
\hline $07 / 12 / 2011$ & $11 / 12 / 2011$ & Moderada \\
\hline $20 / 12 / 2011$ & $21 / 12 / 2011$ & Débil \\
\hline 09/01/2012 & $15 / 01 / 2012$ & Moderada \\
\hline $18 / 01 / 2012$ & $20 / 01 / 2012$ & Débil \\
\hline $08 / 03 / 2012$ & $10 / 03 / 2012$ & Fuerte \\
\hline $15 / 03 / 2012$ & $20 / 03 / 2012$ & Débil \\
\hline $21 / 03 / 2012$ & $24 / 03 / 2012$ & Débil \\
\hline
\end{tabular}




\begin{tabular}{|c|c|c|}
\hline $26 / 03 / 2012$ & 29/03/2012 & Débil \\
\hline $16 / 04 / 2012$ & $18 / 04 / 2012$ & Débil \\
\hline $11 / 05 / 2012$ & $18 / 05 / 2012$ & Débil \\
\hline $23 / 06 / 2012$ & $30 / 06 / 2012$ & Fuerte \\
\hline $11 / 07 / 2012$ & $23 / 07 / 2012$ & Débil \\
\hline $30 / 07 / 2012$ & $05 / 08 / 2012$ & Moderada \\
\hline $19 / 08 / 2012$ & $24 / 08 / 2012$ & Moderada \\
\hline $08 / 12 / 2012$ & $12 / 12 / 2012$ & Débil \\
\hline $27 / 12 / 2012$ & $29 / 12 / 2012$ & Débil \\
\hline 04/01/2013 & 06/01/2013 & Moderada \\
\hline $30 / 01 / 2013$ & $01 / 02 / 2013$ & Débil \\
\hline $04 / 02 / 2013$ & $06 / 02 / 2013$ & Fuerte \\
\hline $10 / 02 / 2013$ & $11 / 02 / 2013$ & Débil \\
\hline $14 / 02 / 2013$ & $18 / 02 / 2013$ & Débil \\
\hline $18 / 04 / 2013$ & $23 / 04 / 2013$ & Moderada \\
\hline 29/07/2013 & $17 / 08 / 2013$ & Moderada \\
\hline $19 / 08 / 2013$ & $24 / 08 / 2013$ & Débil-Moderada \\
\hline $26 / 11 / 2013$ & $28 / 11 / 2013$ & Moderada \\
\hline $02 / 12 / 2013$ & $04 / 12 / 2013$ & Débil \\
\hline $09 / 12 / 2013$ & $17 / 12 / 2013$ & Moderada \\
\hline $21 / 12 / 2013$ & $22 / 12 / 2013$ & Débil \\
\hline $29 / 12 / 2013$ & $01 / 01 / 2014$ & Débil \\
\hline 08/01/2014 & $13 / 01 / 2014$ & Débil \\
\hline $15 / 03 / 2014$ & $19 / 03 / 2014$ & Débil \\
\hline 29/06/2014 & $02 / 07 / 2014$ & Débil \\
\hline $14 / 08 / 2014$ & $17 / 08 / 2014$ & Débil \\
\hline $18 / 08 / 2014$ & $21 / 08 / 2014$ & Débil \\
\hline $26 / 08 / 2014$ & $30 / 08 / 2014$ & Débil \\
\hline $21 / 10 / 2014$ & $24 / 10 / 2014$ & Débil \\
\hline $01 / 11 / 2014$ & $04 / 11 / 2014$ & Débil \\
\hline $11 / 12 / 2014$ & $13 / 12 / 2014$ & Fuerte \\
\hline $22 / 12 / 2014$ & $26 / 12 / 2014$ & Fuerte \\
\hline $31 / 12 / 2014$ & $02 / 01 / 2015$ & Fuerte \\
\hline $03 / 01 / 2015$ & $05 / 01 / 2015$ & Fuerte \\
\hline $10 / 01 / 2015$ & $14 / 01 / 2015$ & Fuerte \\
\hline 06/03/2015 & $08 / 03 / 2015$ & Fuerte \\
\hline $11 / 05 / 2015$ & $17 / 05 / 2015$ & Débil-Moderada \\
\hline $20 / 05 / 2015$ & $23 / 05 / 2015$ & Débil \\
\hline 06/07/2015 & $11 / 07 / 2015$ & Débil \\
\hline $13 / 07 / 2015$ & $17 / 07 / 2015$ & Débil \\
\hline $20 / 07 / 2015$ & $24 / 07 / 2015$ & Débil \\
\hline 06/08/2015 & 09/08/2015 & Débil-Moderada \\
\hline $12 / 08 / 2015$ & $13 / 08 / 2015$ & Débil-Moderada \\
\hline $21 / 09 / 2015$ & $26 / 09 / 2015$ & Débil \\
\hline $02 / 10 / 2015$ & 06/10/2015 & Débil \\
\hline
\end{tabular}




\begin{tabular}{|c|c|c|}
\hline $08 / 11 / 2015$ & $10 / 11 / 2015$ & Moderada \\
\hline $11 / 11 / 2015$ & $14 / 11 / 2015$ & Débil \\
\hline $15 / 11 / 2015$ & $16 / 11 / 2015$ & Débil \\
\hline $30 / 11 / 2015$ & $01 / 12 / 2015$ & Débil \\
\hline $03 / 12 / 2015$ & $04 / 12 / 2015$ & Moderada \\
\hline $13 / 12 / 2015$ & $17 / 12 / 2015$ & Débil \\
\hline $25 / 12 / 2015$ & $28 / 12 / 2015$ & Fuerte \\
\hline $18 / 01 / 2016$ & $18 / 01 / 2016$ & \\
\hline $24 / 01 / 2016$ & $27 / 01 / 2016$ & Débil \\
\hline $02 / 03 / 2016$ & $03 / 03 / 2016$ & Fuerte \\
\hline $15 / 03 / 2016$ & $18 / 03 / 2016$ & Débil \\
\hline $22 / 06 / 2016$ & $26 / 06 / 2016$ & Débil \\
\hline $12 / 07 / 2016$ & $15 / 07 / 2016$ & Débil \\
\hline $18 / 07 / 2016$ & $22 / 07 / 2016$ & Débil-Moderada \\
\hline $25 / 07 / 2016$ & $28 / 07 / 2016$ & Débil \\
\hline $04 / 08 / 2016$ & $07 / 08 / 2016$ & Débil \\
\hline $26 / 08 / 2016$ & $31 / 08 / 2016$ & Débil \\
\hline $28 / 09 / 2016$ & $30 / 09 / 2016$ & Débil-Moderada \\
\hline $25 / 12 / 2016$ & $29 / 12 / 2016$ & Fuerte \\
\hline 01/01/2017 & $04 / 01 / 2017$ & Débil \\
\hline 07/01/2017 & 09/01/2017 & Débil \\
\hline $12 / 01 / 2017$ & $14 / 01 / 2017$ & Fuerte \\
\hline $16 / 01 / 2017$ & $17 / 01 / 2017$ & Débil \\
\hline $17 / 02 / 2017$ & $17 / 02 / 2017$ & Débil \\
\hline $22 / 02 / 2017$ & $25 / 02 / 2017$ & Débil \\
\hline 09/03/2017 & $13 / 03 / 2017$ & Débil-Moderada \\
\hline $31 / 03 / 2017$ & 03/04/2017 & Débil \\
\hline $22 / 06 / 2017$ & $27 / 06 / 2017$ & Débil \\
\hline $14 / 07 / 2017$ & $19 / 07 / 2017$ & Débil \\
\hline 06/08/2017 & $10 / 08 / 2017$ & Débil-Moderada \\
\hline $17 / 08 / 2017$ & $26 / 08 / 2017$ & Débil \\
\hline 03/09/2017 & 09/09/2017 & Débil \\
\hline $13 / 09 / 2017$ & $20 / 09 / 2017$ & Débil \\
\hline $23 / 09 / 2017$ & $26 / 09 / 2017$ & Débil \\
\hline $12 / 10 / 2017$ & $17 / 10 / 2017$ & Moderada \\
\hline $26 / 10 / 2017$ & $28 / 10 / 2017$ & Débil \\
\hline $11 / 11 / 2017$ & $13 / 11 / 2017$ & Débil \\
\hline $21 / 11 / 2017$ & $28 / 11 / 2017$ & Débil \\
\hline $05 / 12 / 2017$ & $08 / 12 / 2017$ & Débil-Moderada \\
\hline $25 / 12 / 2017$ & $26 / 12 / 2017$ & Débil \\
\hline
\end{tabular}

